NASA

Technical

Paper

3487

December 1994
Influence of Turbulence Parameters, Reynolds Number, and Body Shape on StagnationRegion Heat Transfer

G. James Van Fossen,

Robert J. Simoneau, and Chan Y. Ching

(NASA-TP-3487) INFLUENCE OF

TURBULENCE PARAMETERS, REYNOLDS

NUMBER, AND BODY SHAPE ON

STAGNATION-REGION HEAT TRANSFER

(NASA. Lewis Research Center)
N95-28719

Unclas 


\section{NASA \\ Technical \\ Paper \\ 3487}

1994

Influence of Turbulence Parameters, Reynolds

Number, and Body Shape on StagnationRegion Heat Transfer

G. James Van Fossen and Robert J. Simoneau Lewis Research Center

Cleveland, Ohio

Chan Y. Ching

Syracuse University

Syracuse, New York 
Trade names or manufacturers' names are used in this report for identification only. This usage does not constitute an official endorsement, either expressed or implied, by the National Aeronautics and Space Administration. 


\title{
Influence of Turbulence Parameters, Reynolds Number, and Body Shape on Stagnation-Region Heat Transfer
}

\author{
G. James Van Fossen and Robert J. Simoneau \\ National Aeronautics and Space Administration \\ Lewis Research Center \\ Cleveland, Ohio 44135
}

ańd

Chan Y. Ching

Syracuse University

Syracuse, New York

\section{Summary}

The purpose of the present work was threefold: (1) to determine if a free-stream turbulence length scale existed that would cause the greatest augmentation in stagnation-region heat transfer over laminar levels; (2) to investigate the effect of velocity gradient on stagnation-region heat transfer augmentation by free-stream turbulence; and (3) to develop a prediction tool for stagnation heat transfer in the presence of free-stream turbulence. Heat transfer was measured in the stagnation region of four models with elliptical leading edges that had ratios of major to minor axes of 1:1, 1.5:1, 2.25:1, and $3: 1$. Five turbulence-generating grids were fabricated; four were square mesh, biplane grids made from square bars. The fifth grid was an array of fine parallel wires that were perpendicular to the model spanwise direction.

Heat transfer data were taken at Reynolds numbers ranging from 37000 to 228000 . Turbulence intensities were in the range of 1.1 to 15.9 percent while the ratio of integral length scale to leading-edge diameter ranged from 0.05 to 0.30 . Stagnation-point velocity gradient was varied by nearly 50 percent.

Stagnation-region heat transfer augmentation was found to increase with decreasing length scale but no optimum length scale was found. Heat transfer augmentation due to turbulence was found to be unaffected by the velocity gradient near the leading edge. A correlation was developed that fit heat transfer data for the square-bar grids to within \pm 4 percent.

\section{Introduction}

Heat transfer to a stagnation region is important in many engineering applications; none, however, is more critical than in the gas turbine where combustor exit temperatures often exceed the melting point of superalloy turbine airfoil materials. In most cases the highest heat transfer rate on a turbine airfoil occurs at the stagnation point, which makes it critical for the design of cooling schemes to obtain an accurate prediction of heat transfer in this region.

For a laminar free stream, the stagnation region can be modeled as a circular or elliptical cylinder in crossflow and the heat transfer can be found if the pressure distribution is known (ref. 1). Free-stream turbulence can augment stagnation-region heat transfer; enhancement of 190 percent over laminar values has been measured (ref. 2). In a gas turbine the stream of combustion products that approaches an airfoil is not laminar; turbulence intensities of 11 and 15 percent were measured at the exit of combustors by Zimmerman (ref. 3) and Goebel et al., (ref. 4) respectively.

Stagnation-region heat transfer augmentation in the presence of free-stream turbulence is believed to be caused by vorticity amplification (see ref. 5 for a review). Freestream turbulence can be viewed as a continuum of tangled, vortical filaments. As illustrated in figure 1, those filaments with components normal to the stagnation line and normal to the free-stream flow are convected into the stagnation region where they are stretched and tilted by the divergence of streamlines and acceleration around the bluff body. This stretching causes the vorticity to be intensified through conservation of angular momentum. Prior experimental and numerical results (refs. 6 to 8 ) show that vorticity in the stagnation region causes heat transfer to be increased while the boundary layer remains laminar.

Turbulent eddies that are very large relative to the size of the bluff body are not stretched and, thus, act only as mean flow variations, but eddies that are very small (approaching Kolmogorov scales) are destroyed by viscous dissipation before they can interact with the boundary layer. This leads to the hypothesis that somewhere between these two extremes there must be an optimum eddy size that causes the highest heat transfer augmentation.

By considering vorticity amplification theory, it seems reasonable that leading-edge velocity gradient would have an effect on stagnation heat transfer. Higher velocity gradients 


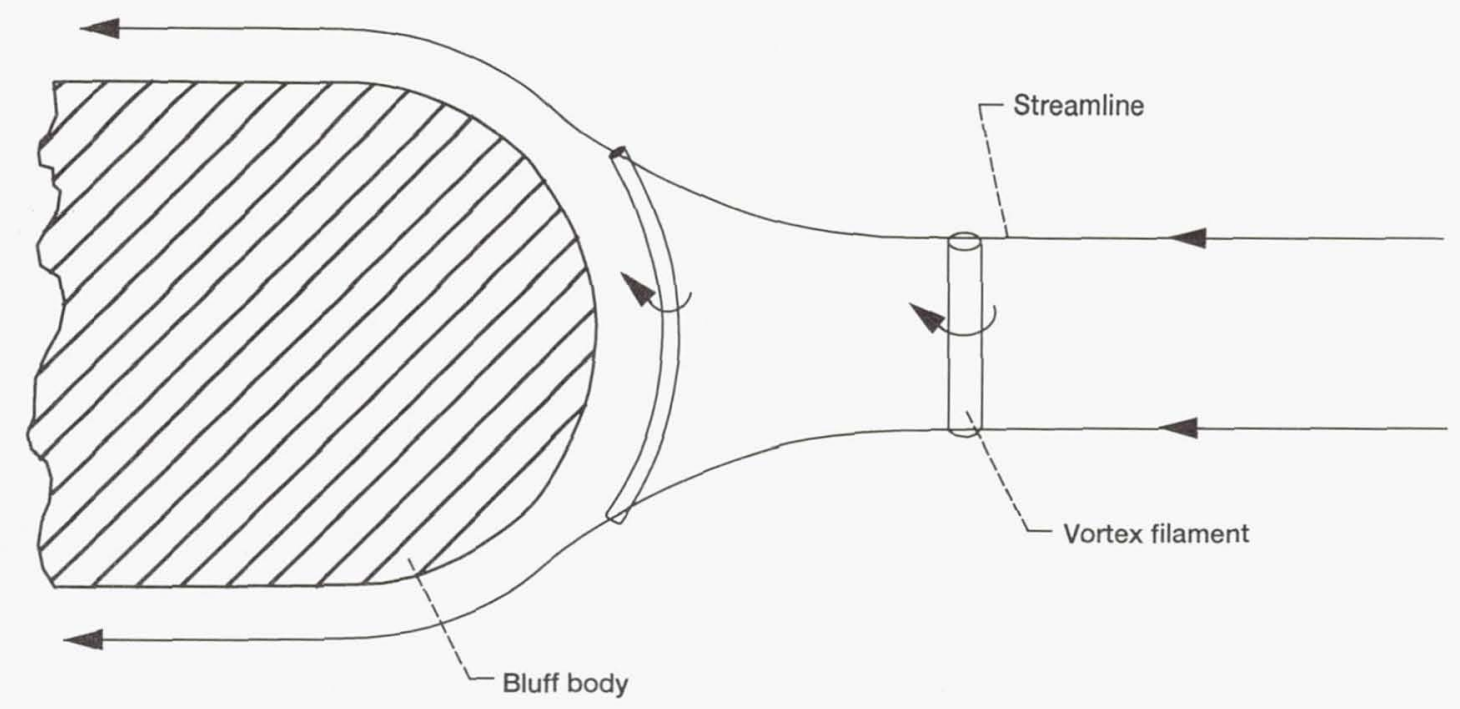

Figure 1.-Vortex filaments stretched and tilted by divergence of streamlines and acceleration around leading edge.

would cause more rapid stretching of the vortical filaments as they are convected past the leading edge thus causing higher heat transfer augmentation.

Three goals of this research were: (1) to determine if an optimum eddy size exists, (2) to study the effect of leadingedge velocity gradient on stagnation-region heat transfer augmentation, and (3) to develop a more accurate prediction tool that could be used by designers to evaluate stagnation-region heat transfer.

It has been known for many years that free-stream turbulence can augment stagnation-region heat transfer (refs. 9 and 10); however, results of experiments are inconsistent and attempts to correlate heat transfer augmentation as a function of turbulence intensity and Reynolds number, while ignoring the length scale (refs. 11 to 15 ), have not been entirely successful. Any resulting correlations usually predict the experimenter's data but not data from other researchers.

Although Lowery and Vachon (ref. 16) measured lateral length scale in their study of the effect of grid-generated turbulence on stagnation-region heat transfer, they did not have a sufficient variety of grids to deduce an effect of scale. Their resulting correlation, based on intensity and Reynolds number only, has been used as a standard against which subsequent data sets have been compared, sometimes with large discrepancies (see, for example, ref. 17).

There have been several attempts to isolate the effect of turbulence length scale; Yardi and Sukhatme (ref. 18) used four different grids to generate a range of length scales. The four grids were all of different geometry; specifically, two were screens and two were biplane grids, all had different rod-spacing-to-rod-diameter ratios. They showed a trend of increasing heat transfer with decreasing length scale; however, there is so much scatter in the data that their claim of ten boundary layer thicknesses for an optimum length scale is questionable.

Dyban et al., (ref. 19) used perforated plates as well as a fully developed, turbulent pipe flow to investigate the effect of intensity and scale on stagnation-region heat transfer. Their results showed increasing augmentation with decreasing scale but they did not attempt to correlate the data based on this finding.

More recently, Ames (ref. 20) used simulated combustor segments to generate turbulence and measure its effect on heat transfer to a flat plate and to a stagnation region. Ames concentrated on relatively large scale turbulence where the ratio of the length scale to the leading-edge diameter was greater than 1.0. He used the rapid distortion theory of Hunt (ref. 21) and the measurements of Hunt and Graham (ref. 22) near a plane surface to develop a model for the spectrum of turbulence near stagnation. He integrated his model spectrum to estimate the eddy viscosity in the stagnation region. The viscosity was then used in a phenomenological model, similar to the procedure used by Smith and Kuethe (ref. 13), to develop a new correlating parameter involving Reynolds number, turbulence intensity, and what Ames calls an energy scale (the average size of the energy-containing eddies). Ames used cylinders with three different diameters to investigate stagnation-region heat transfer; his data were correlated well using his new parameter. The data of several other researchers (refs. 16 and 19) were also correlated by his parameter but with more scatter.

For the present work, four models with elliptical leading edges were fabricated with heat transfer gages in the stagnation region. The models had major-to-minor axis ratios of 1:1 (circular), 1.5:1, 2.25:1 and 3:1; all models had the same radius of curvature at the stagnation point. The models were 
qualified in a low-turbulence wind tunnel by comparing measurements with a numerical solution for stagnation-region heat transfer as well as with Frössling's solution (ref. 1). Five turbulence-generating grids were fabricated. Four were square-mesh, biplane grids made from square bars with different bar widths; each of the four had identical mesh-to-bar width ratio. The fifth grid was an array of fine, parallel wires that were perpendicular to the model spanwise direction.

Turbulence intensity and integral length scale were measured as a function of distance from the grids with the model removed. Stagnation-region heat transfer was measured with each grid at various distances upstream of the model. Data were taken at Reynolds numbers based on leading-edge diameter ranging from 37000 to 228000 . Turbulence intensities were in the range of 1.1 to 15.9 percent while the ratio of integral length scale to cylinder diameter ranged from 0.05 to 0.30 . Stagnation-point velocity gradient was varied by nearly 50 percent.

Measurements of length scale and intensity are presented herein as well as the stagnation-region heat transfer results from all four models. A correlation involving the turbulence parameters and Reynolds numbers that fit the heat transfer data for the square-bar grids to within \pm 4 percent is also presented. The data of other researchers is compared with the correlation. A method for determining the heat transfer distribution downstream of the stagnation point will be presented. It will also be shown that leading-edge heat transfer augmentation by free-stream turbulence is unaffected by stagnationpoint velocity gradient.

\section{Symbols}

A surface area of gauge, $\mathrm{m}^{2}$

$a_{e} \quad$ major axis of ellipse

$B$ tunnel blockage, ratio of model thickness to tunnel height

$b$ bar width of turbulence-generating grid, $\mathrm{cm}$

$b_{e}$

$d$

minor axis of ellipse

diameter of model leading edge $(=2 R), \mathrm{cm}$

E

$$
\text { mean hot wire voltage, } \mathrm{V}
$$

\section{$\operatorname{Fr}(s / R) \quad$ Frössling number}

G1 to G5 grid label $q$

$R$

Re

$R(\tau) \quad$ autocorrelation of velocity signal

$r(s) \quad$ local recovery factor

s

$T$

$T u$

$U$

$U_{e}$

$U_{0}$

$u^{\prime}$

$v^{\prime}$

W

$x$

$y$

$\alpha$

$\delta$

$\kappa$

$\lambda$

$\Lambda$

$\rho$

$\sigma$

$\tau$

$\Phi$

Prandtl number

heat flow, W

leading edge radius, $\mathrm{cm}$

Reynolds number

temperature, $\mathrm{K}$

turbulence intensity

mean velocity, $\mathrm{m} / \mathrm{sec}$

effective cooling velocity, $\mathrm{m} / \mathrm{sec}$

magnitude of velocity, $\mathrm{m} / \mathrm{sec}$ streamwise direction spanwise direction

tunnel width, $\mathrm{cm}$

streamwise distance, $\mathrm{cm}$

measurement uncertainty microscale, $\mathrm{cm}$ air density, $\mathrm{Kgm} / \mathrm{m}^{3}$

standard deviation

time shift, sec mesh spacing of bars in turbulence grid, $\mathrm{cm}$

surface distance from stagnation, $\mathrm{cm}$.

fluctuating velocity component in

fluctuating velocity component in

spanwise distance from centerline of tunnel, $\mathrm{cm}$ angle between $U_{0}$ and hotwire constant in Champagne's law, equation (1) integral length scale of turbulence, $\mathrm{cm}$

heat transfer augmentation factor, equation (13) 


\begin{tabular}{|c|c|}
\hline \multicolumn{2}{|c|}{ Subscripts } \\
\hline avg & average \\
\hline$b$ & bar width \\
\hline caljet & hot wire calibration jet \\
\hline$d$ & leading edge diameter \\
\hline$E I$ & electrical heating \\
\hline gap & epoxy filled gap between gauges \\
\hline lam & laminar \\
\hline$r$ & recovery \\
\hline $\mathrm{rad}$ & radiation \\
\hline st & static \\
\hline$t$ & total \\
\hline$t u$ & turbulence intensity \\
\hline$w$ & wall \\
\hline
\end{tabular}
y spanwise (parallel to model leading edge)
$\infty \quad$ free stream

\section{Test Facility, Instrumentation, and Data Acquisition}

\section{Wind Tunnel}

The experiments were carried out in the wind tunnel shown in figure 2, which is described in detail in an earlier report by Van Fossen and Simoneau (ref. 7). Air drawn from the test cell passed through a flow-conditioning section that consisted of identical damping screens up- and downstream of soda-straw flow straighteners. The screens were 18-mesh with $0.24-\mathrm{mm}$ diameter wires and had 68.7 percent open area. The soda straws were $0.64-\mathrm{cm}$ in diameter and $19.7 \mathrm{~cm}$ long. Air then passed through a 4.85:1 contraction before entering the $15.2-\mathrm{cm}$ wide by $68.6-\mathrm{cm}$ high test section. The maximum velocity attainable was about $46 \mathrm{~m} / \mathrm{sec}$. Clear tunnel turbulence levels were less than 0.5 percent for all flow rates. After leaving the test section, the flow passed through a transition section into a 10-in. pipe in which a sharp-edged, flow-measuring orifice plate with flange taps was located. Air

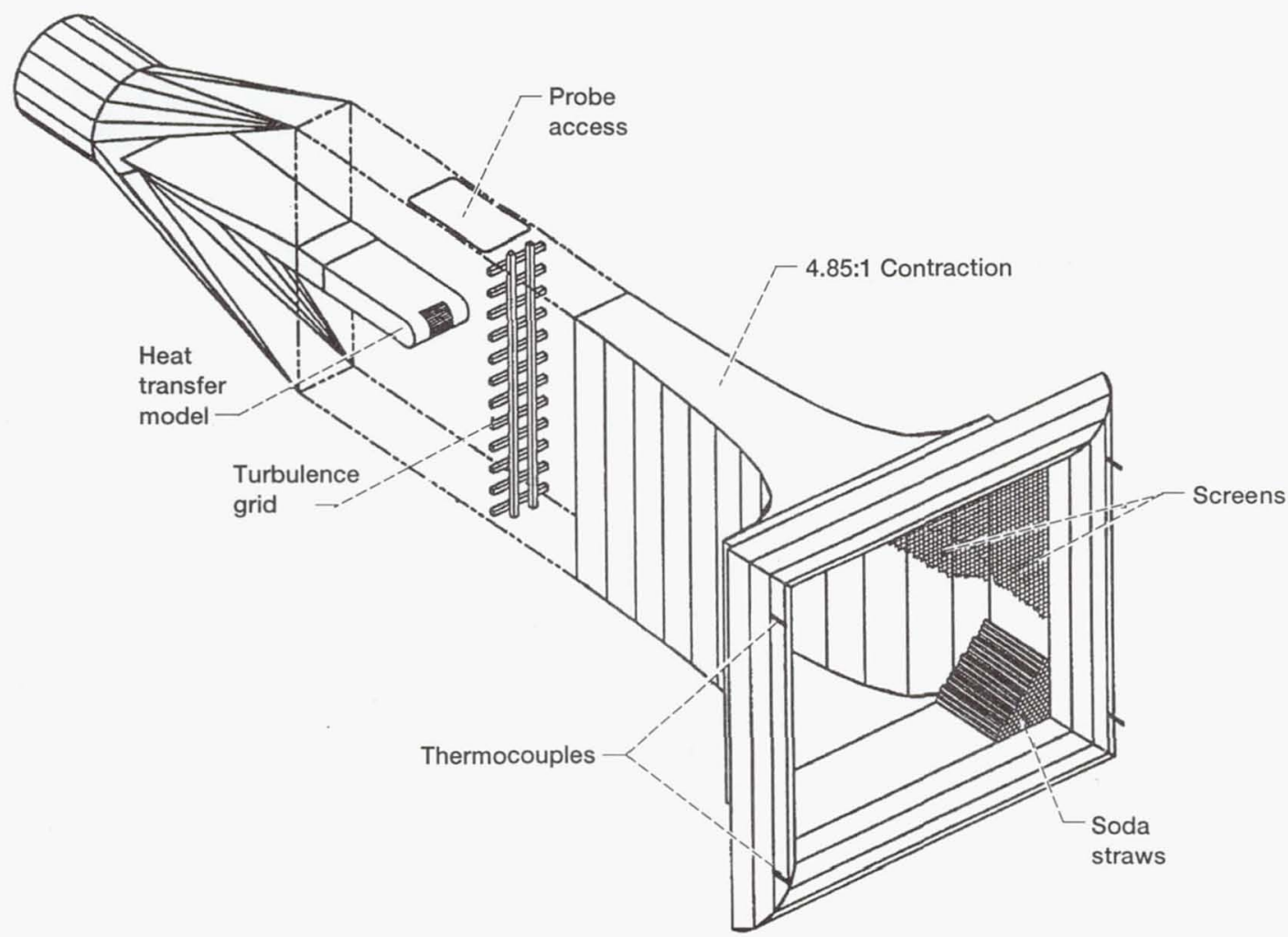

Figure 2.-Wind tunnel. 
next passed through a butterfly valve which was used to control the tunnel flow rate, and then to the laboratory exhaust system. The readings from four type $\mathrm{E}$ thermocouples located around the perimeter of the inlet were averaged to obtain the stagnation temperature. An actuator system with four degrees of freedom was used to position a hot-wire probe at any desired $x-y$ location within the rectangle shown in figure 2.

\section{Turbulence Grids}

Five turbulence-generating grids were used in this study. Four were square bar, square mesh, biplane grids. The fifth grid consisted of an array of parallel wires oriented perpendicular to the streamwise and spanwise directions. Grid parameters are defined in figure 3 and dimensions of the grids are given in table I. Henceforth grids will be referred to by the labels given
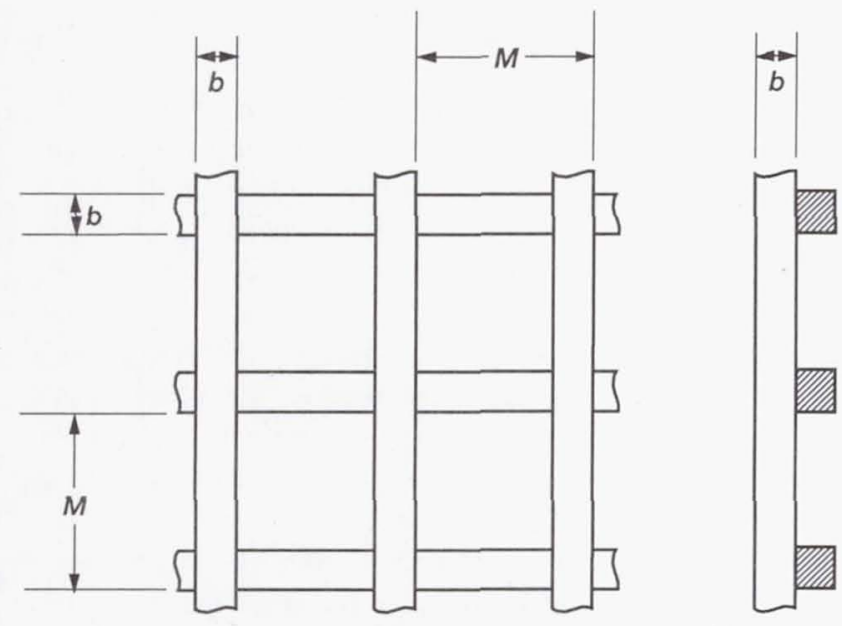

Figure 3.-Biplane grid configuration. in this table. Grids $\mathrm{G} 1$ to $\mathrm{G} 4$ were fabricated keeping the ratio of mesh spacing to bar width constant at 4.5 yielding an open area of 60.5 percent. Grid G5 consisted of $0.51 \mathrm{~mm}$ wires spaced $6.35 \mathrm{~mm}$ apart. Turbulence-generating grids could be installed at axial locations ranging from 2.41 to $52.3 \mathrm{~cm}$ upstream of the model stagnation point.

\section{Heat Transfer Models}

The four heat transfer models used in this study had elliptical leading edges. The ratio of major to minor axes, $a_{e}{ }^{\prime b} e_{e}$, were 1:1, 1.5:1, 2.25:1 and 3:1. All models had the same radius of curvature $R$ of $3.30 \mathrm{~cm}$ at the stagnation point. A comparison of the model profiles and the tunnel walls is shown in figure 4(a), along with an enlarged cross-sectional view (fig. 4(b)). All models had wedge-shaped afterbodies that extended about $61 \mathrm{~cm}$ downstream to eliminate vortex shedding. Figure 5 is a photograph of the heat transfer models and afterbodies. The purpose of the 4 models was to provide different velocity gradients in the stagnation region to determine if this would have an effect on stagnation heat transfer augmentation. Leading-edge velocity gradients calculated with an inviscid two-dimensional panel code (ref. 23) are shown in figure 6; the calculation included the tunnel sidewalls.

The circular leading-edge model had 19 heat flux gauges and the elliptical models all had 29 heat flux gauges embedded symmetrically about the stagnation line. The dimensionless surface distance to the center of each gauge from the stagnation line is given in table II. A typical model cross section showing the heat flux gauge arrangement is shown in figure 4(b). Each heat flux gauge consisted of an aluminum strip, which was $6.60 \mathrm{~cm}$ long (43 percent of the model span) by $0.476 \mathrm{~cm}$ wide and $0.32 \mathrm{~cm}$ deep. A Kapton ${ }^{\circledR}$-encapsulated, foil, electric
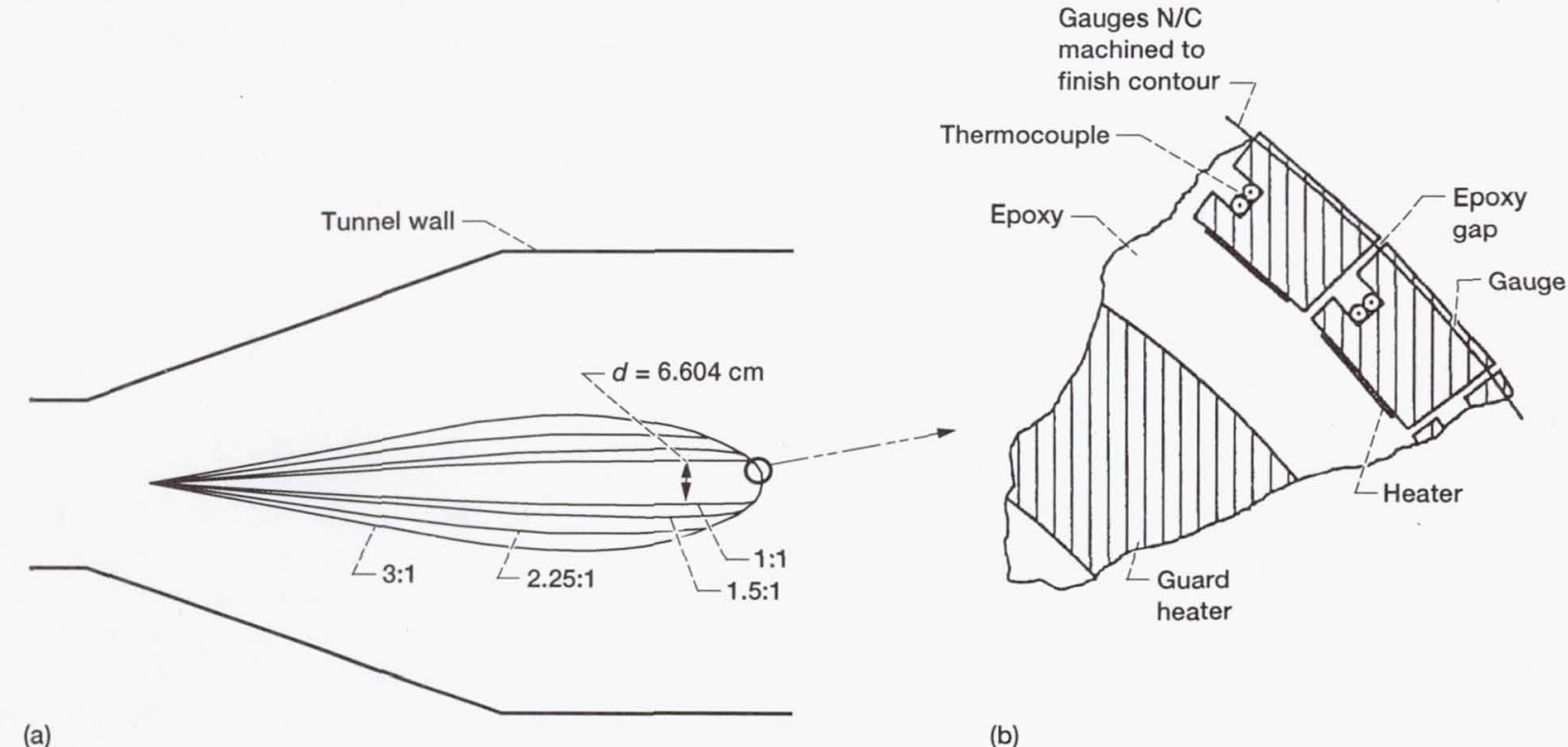

(a)

Figure 4.-Comparison of model profiles. 


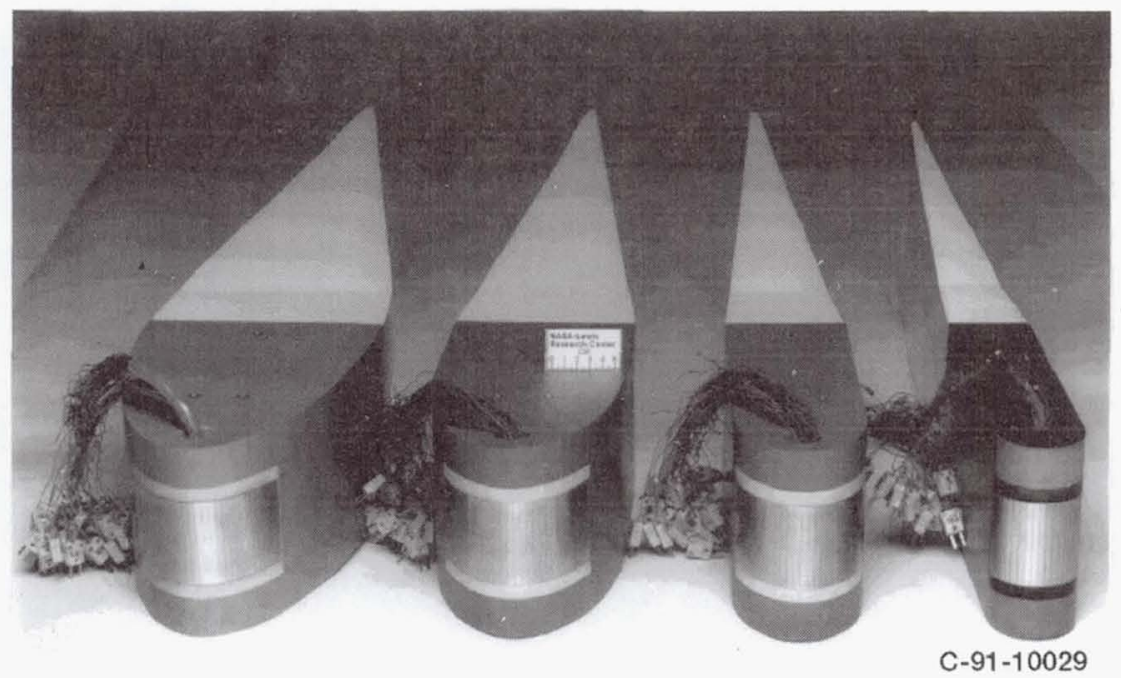

Figure 5.-Stagnation heat transfer models.

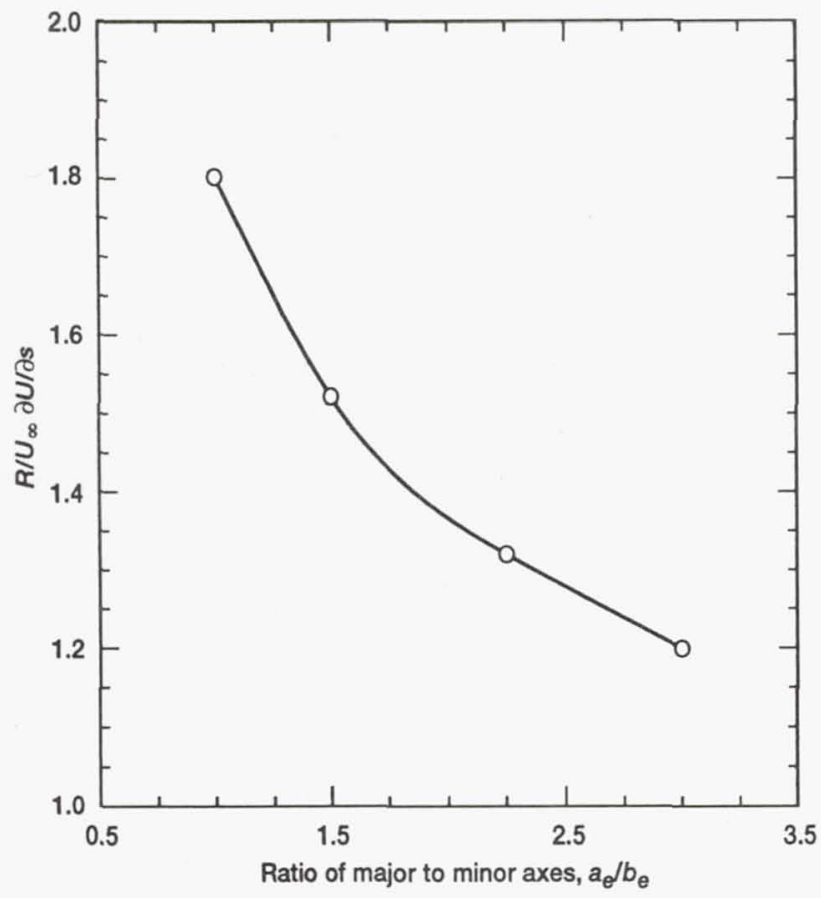

Figure 6.-Leading edge velocity gradients (calculated from panel code (ref. 23)).

heater was fastened to the back of each aluminum strip with pressure-sensitive adhesive. The temperature of each gauge was measured by a type $\mathrm{K}$ thermocouple embedded in a groove. The furthest downstream gauges on either side of the stagnation point were used as guard heaters to minimize heat conduction losses in the streamwise direction. A guard heater behind the heat flux gauges prevented heat conduction to the interior of the model. The average gap between the aluminum strips was 0.25 $\mathrm{mm}$ and was filled with epoxy. The aluminum strips were maintained at a constant temperature by a specially designed control circuit, (ref. 24). Steady state, spanwise-averaged, heat transfer coefficients were calculated for each aluminum strip based on the electric power supplied to the strip and the wallto-fluid temperature difference.

\section{Hot Wire}

Turbulence measurements were obtained using a twochannel, constant-temperature, linearized, hot-wire anemometer system. Turbulence intensities and autocorrelations were measured using a standard, $5 \mu \mathrm{m}$, single, hot wire oriented perpendicular to the flow direction. A cross-flow type $\mathrm{X}$-wire probe was used for two component measurements. The hot-wire signals were linearized with analog linearizers. A signal conditioner was used for addition and subtraction of the linearized signals from the $\mathrm{X}$-wire. For the single-wire data, a programmable digital multimeter was used to calculate the root mean square (rms) of the fluctuating component of the linearized bridge voltage from 100 samples. For the Xwire data, the mean square voltage was read from an integrating, analog, true rms meter with an adjustable time constant. Mean voltages were read on an integrating digital voltmeter with an adjustable time constant.

\section{Data Acquisition}

A dual-channel, Fast Fourier Transform, spectrum analyzer was used to obtain the autocorrelation data. The analyzer featured a 12-bit analog-to-digital conversion rate of 2.56 times the selected frequency and an anti-aliasing filter with a rolloff of $120 \mathrm{~dB} /$ octave. The selectable frequency range was from $10 \mathrm{~Hz}$ to $100 \mathrm{kHz}$. The analyzer could collect and digitize analog, time domain data, convert to the autocorrelation function, and average a programmable number of autocorrelations together in real time. A personal computer was interfaced to the spectrum analyzer for data storage and processing. 
Steady-state operating conditions (temperatures, pressures, and gauge voltages and currents, etc.) were recorded on the laboratory data acquisition system called ESCORT (ref. 25). For every heat transfer data point, 20 readings of each data channel were recorded. These 20 readings were averaged to give a single value for each channel. To eliminate any offset between data channels caused by the solid-state multiplexers, before each day's run all the inputs to ESCORT were shorted and a zero reading was obtained. This zero reading was subtracted from each subsequent data reading.

\section{Experimental Procedure}

\section{Hot-Wire Calibration}

The hot wires used for the turbulence measurements were calibrated in an air jet at nearly the same temperature as the wind tunnel flow. Velocity calibrations were made with a two-point, iteration method in conjunction with the signal linearizers (ref. 26). The frequency response of the hot-wire anemometer system was estimated to be around $30 \mathrm{kHz}$ with the standard square wave test.

A cross-flow type $\mathrm{X}$-wire for the two-component turbulence measurements was calibrated, assuming that Champagne's cooling law (ref. 27) applied

$$
U_{e}^{2}(\alpha)=U_{0}^{2}\left(\cos ^{2} \alpha+\kappa^{2} \sin ^{2} \alpha\right)
$$

This relates the effective cooling velocity $U_{e}$ to the actual velocity $U_{0}$ where $\alpha$ is the angle between $U_{0}$ and the wire, and $\kappa$ is a correction factor to account for the cooling due to the tangential velocity component along the wire. The value of $\kappa$ was determined experimentally by varying the angle $\alpha$ between 35 and $55^{\circ}$ at jet velocities of 23 and $46 \mathrm{~m} / \mathrm{sec}$. A least-squares curve fit of equation (1) was then used to find $\kappa$. As a further check on the value of $\kappa$ at the orientation used in the tests, the wire was held fixed at $45^{\circ}$ to the flow and the effective cooling velocity recorded at velocities from 9 to $46 \mathrm{~m} / \mathrm{sec}$ in steps of $4.6 \mathrm{~m} / \mathrm{sec}$. Once again, a least-squares fit was used to evaluate $\kappa$. The difference between the $\kappa$ values from the two methods was around 7 percent. The actual value of $\kappa$ used in the data reduction was the average from the two methods.

Prior to each use of the $\mathrm{X}$-wire, the probe was installed in the calibration jet with the bisector of the angle between the wires aligned with the flow direction. Each of the wires was then linearized using the method described above for the single wire. In the wind tunnel, the $\mathrm{X}$-wire was rotated until the mean voltages from both wires showed the same value, which indicated the probe was aligned with the mean flow direction.

\section{Thermal Conductivity of Epoxy}

The thermal conductivity of the epoxy used in the gaps between the aluminum heat flux gauges, which was required for data reduction, was determined experimentally. A uniform layer of epoxy $0.318 \mathrm{~cm}$ thick was deposited between two 6.4-cm square copper plates. An electric heater was adhesively bonded to one plate while a water cooling line was brazed to the opposite plate. Thermocouples were attached to both copper plates and the whole unit was enclosed in a vacuum chamber, which eliminated convective heat loss.

The power level to the electric heater was fixed and the unit was allowed to come to equilibrium; the voltage, current, and copper plate temperatures were then recorded. Several such runs were made at different power levels. An energy balance equated the electric power input to the sum of the heat conducted through the epoxy layer and the heat radiated from the heated plate. Gray body radiation to black surroundings was assumed. Two unknowns, the thermal conductivity of the epoxy layer and the emissivity of the copper, were simultaneously solved for by using a least-squares technique. Values obtained for emissivity and thermal conductivity were 0.83 and $0.16 \mathrm{~W} / \mathrm{m}-\mathrm{K}$ respectively.

\section{Heat Flux Measurements}

The nominal operating temperatures of the gauges were between 319 and $327 \mathrm{~K}$; the average recovery temperature of the air was $300 \mathrm{~K}$ giving wall-to-air temperature ratios of approximately 1.06 to 1.1 . All of the heat flux gauges were maintained at the same temperature within $\pm 0.2^{\circ} \mathrm{C}$. This was accomplished by fine-tuning the gain on the thermocouple voltage amplifier in the control circuit, which in turn changed the power supplied to the gauge.

Heat flux measurements were carried out with each grid at several streamwise distances from the stagnation line of the leading edge. For each grid position, heat transfer data was acquired for at least three Reynolds numbers ranging from 37000 to 228000 .

\section{Data Reduction and Uncertainty Analysis}

\section{Turbulence}

Intensity.-Turbulence intensities were calculated from the single hot wire and the $\mathrm{X}$-wire. The local turbulence intensity for the single wire was calculated as the ratio of the rms to mean linearized voltage.

Two component turbulence intensities were calculated from the linearized signals of the X-wire. By neglecting terms to the second order in turbulence and to the third order in $\kappa$, for linearized, constant temperature operation, 
Champagne (ref. 27) obtained:

$$
\begin{aligned}
& \overline{\frac{u^{\prime 2}}{U^{2}}}=\frac{1}{4} \overline{\left[\frac{e_{1}}{E_{1}}+\frac{e_{2}}{E_{2}}\right]^{2}} \\
& \overline{\frac{v^{\prime 2}}{U^{2}}}=\frac{1}{4}\left[\frac{1+\kappa^{2}}{1-3 \kappa^{2}+4 \kappa^{4}}\right] \overline{\left[\frac{e_{1}}{E_{1}}-\frac{e_{2}}{E_{2}}\right]^{2}}
\end{aligned}
$$

If the bisector of the angle between the wires is aligned with the flow, the mean voltages of the two wires $E_{1}$ and $E_{2}$ are equal and the hot-wire response equations for the above quantities reduce to very simple forms requiring only the addition and subtraction of the fluctuating voltages from wires 1 and $2\left(e_{1}\right.$ and $\left.e_{2}\right)$ to compute $u^{\prime}$ and $v^{\prime}$.

Integral Length Scale.-The integral length scale describes the average eddy size associated with the turbulence. There are at least three practical ways to obtain the integral length scale:

1. Two single-wire probes are oriented parallel to each other with the wires normal to the flow direction so that one can be traversed in a direction lateral to the flow. The two signals are multiplied together and averaged over time at each lateral separation distance; the resulting crosscorrelation function is integrated over separation distances from 0 to $\infty$ resulting in a lateral length scale $\Lambda_{y}$ which for isotropic turbulence is half of the longitudinal scale $\Lambda_{x}$.

2. The power spectrum is obtained from a single-wire probe. The value of the power spectrum at zero frequency is proportional to the longitudinal length scale $\Lambda_{x}$.

3. The autocorrelation is obtained for a single-wire probe. Taylor's hypothesis that time and streamwise distance are related by the mean velocity is invoked; thus, the autocorrelation is equivalent to a longitudinal crosscorrelation in space. The integral of the autocorrelation function then gives a time scale which, when multiplied by the mean velocity, is equivalent to the longitudinal length scale $\Lambda_{x}$.

Each of the above methods has its pitfalls. Method 1 is very tedious and time-consuming and also involves calibrating two hot wires and traversing across many points in space. Theoretically, the cross-correlation function should approach zero as the probe separation distance becomes large. However, low frequency noise in the flow causes the crosscorrelation function to fluctuate when the two probes are separated by large distances. This makes it difficult to know where to stop integrating and thus introduces error into the lateral length scale (ref. 28).

As pointed out by Comte-Bellot and Corrsin (ref. 29), it is impossible to measure the value of the spectrum at zero frequency even if the instrument is DC-coupled. Typically, the spectrum is extrapolated back to zero frequency by using frequencies above those corresponding to scales that are physi- cally possible in the rig. This requires judgement and can also lead to error for method 2.

In theory, methods 2 and 3 are equivalent since the autocorrelation is the transform of the power spectrum. The autocorrelation method also suffers from the low-frequency noise problem, that is low-frequency noise keeps the autocorrelation from approaching zero in a consistent manner. Many investigators have used the first zero crossing as the upper limit of integration (refs. 20, 30, and 31). Figure 7 shows a typical pair of autocorrelations taken behind our grid G1; the autocorrelations shown are the result of 400 sequential autocorrelations averaged together to form a single curve. Examination of this figure makes it clear that integrating until the first zero crossing will give very different length scales for these two cases.

The availability of a spectrum analyzer that could compute the autocorrelation and average any number of them together made method 3 the natural choice; however, low-frequency noise was still a problem. Several windowing functions that, when multiplied by the autocorrelation, caused the product to approach zero for large time delays were tried but proved unsatisfactory. It was finally decided to use a least-squares fit of the autocorrelation data by the exponential function

$$
R(\tau)=e^{-C_{\tau} \tau}
$$

Data between $0.33 \leq R(\tau) \leq 1.0$ were used for the curve fit; the resulting fit is seen in figure 7 . The autocorrelation approaches $\tau=0$ with a zero slope; therefore, the exponential function does not reproduce the autocorrelation for very small values of $\tau$ but the fit is satisfactory over the main

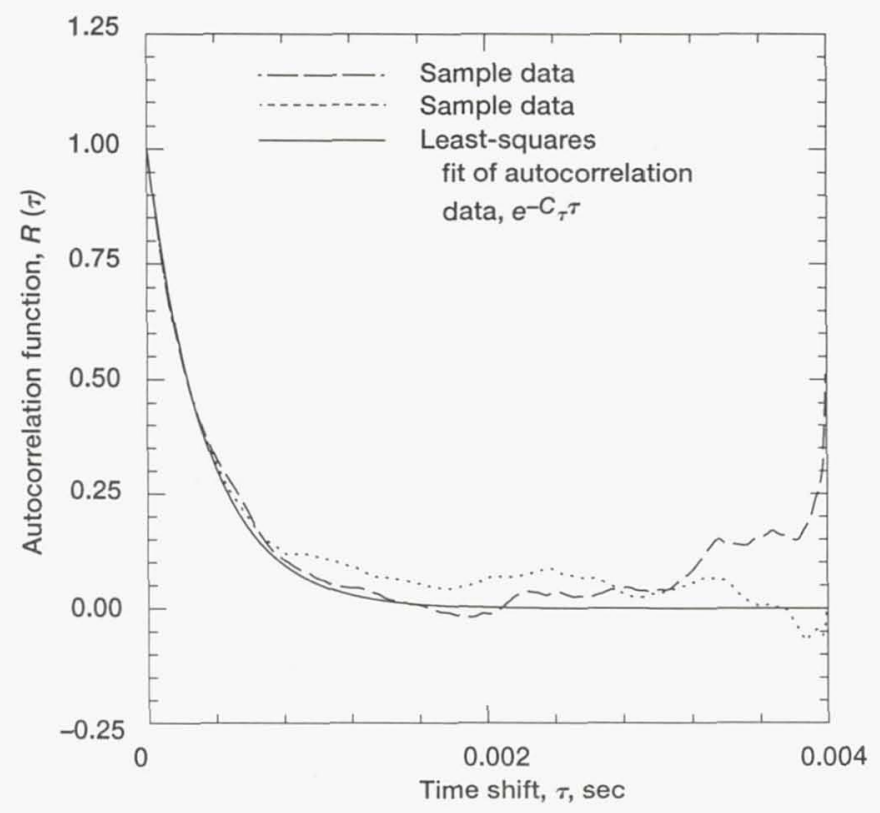

Figure 7.-Typical autocorrelation functions (grid G1, velocity, $43.9 \mathrm{~m} / \mathrm{sec}$ ). 
range of interest and the problem of determining the upper limit of integration is solved. By integrating equation (4) between 0 and $\infty$, and multiplying by the mean velocity $U$, the longitudinal length scale then becomes,

$$
\Lambda_{x}=U \int_{0}^{\infty} R(\tau) d \tau=\frac{U}{C_{\tau}}
$$

If the hot wire is long compared to the length scale of the flow, errors in intensity and scale, caused by averaging of flow variations over the wire length, can result. Correction for the hot-wire length was not made for the present tests; the smallest integral scale measured was 2.6 times the active length of the hot wire.

\section{Heat Transfer}

Power from the electric heaters is removed from the aluminum strips by convection to the air, radiation to the surroundings, and conduction to the epoxy gap between the gauges where it is convected to the air. An energy balance was solved for the Frössling number for each gauge as follows:

$$
\operatorname{Fr}(s / R)=\frac{\left(q_{E I}-q_{\mathrm{rad}}-q_{\mathrm{gap}}\right) d}{A\left(T_{w}-T_{r}\right) k \sqrt{R e_{d}}}
$$

where

$q_{E I} \quad$ heat added by the heater (voltage $\times$ current)

$q_{\text {rad }}$ heat lost by radiation

$q_{\text {gap }}$ heat conducted away to the epoxy gap and to the unguarded ends of the heaters

$d \quad$ leading-edge diameter $(=2 R)$

$A \quad$ exposed gauge surface area

$T_{w} \quad$ gauge temperature

$T_{r} \quad$ recovery temperature at the gauge location

$k \quad$ thermal conductivity of air

$R e_{d}$ Reynolds number

An estimate of the gap loss $q_{\text {gap }}$ between the heaters can be obtained from an exact solution for two-dimensional heat conduction in a rectangle that is half of the epoxy-gap-width wide and the aluminum-gauge-depth deep. Two adjacent sides are assumed to be insulated, one side is held at the constant temperature of the aluminum strip and the final side is convecting to the air at a known temperature. The loss from the unguarded ends of the strips can be estimated from the same solution by assuming a large gap. See Van Fossen et. al. (ref. 24) for details of this analysis.

Corrections for radiation heat loss $q_{\mathrm{rad}}$ were also made by assuming gray body radiation to black surroundings and emissivity of 0.05 for the aluminum gage. Heat lost through the sides and ends of the strips was on the order of 10 percent of the total heat flow, while the radiation heat loss was on the order of 0.2 percent.

The recovery temperature was calculated from

$$
T_{r}=T_{s t, \infty}+r(s)\left(T_{t}-T_{s t, \infty}\right)
$$

where $T_{s t, \infty}$ is the static temperature upstream of the model. The local recovery factor $r(s)$ was calculated as

$$
r(s)=1-\left(\frac{\rho U(s)}{(\rho U)_{\infty}}\right)^{2}(1-\sqrt{P r})
$$

The local mass flow ratio $r U(s) /(r U)_{\infty}$ was found from a numerical solution of flow over the model (ref. 32). The analysis included the effect of the tunnel walls. Figure 8 is a comparison of recovery factors obtained by this method with those reported by Eckert and Drake (ref. 33) for a circular cylinder; agreement is quite good.

The thermal conductivity and viscosity of air were evaluated at the free-stream, total temperature from equations given by Hillsenrath et al. (ref. 34). Total temperature was used to evaluate these properties because Rigby and Van Fossen showed in a numerical study (ref. 32) that if they were based on a reference temperature that involved the wall temperature, then reversing the direction of heat flux (cooling the wall) caused an undesirable change in the Frössling number.

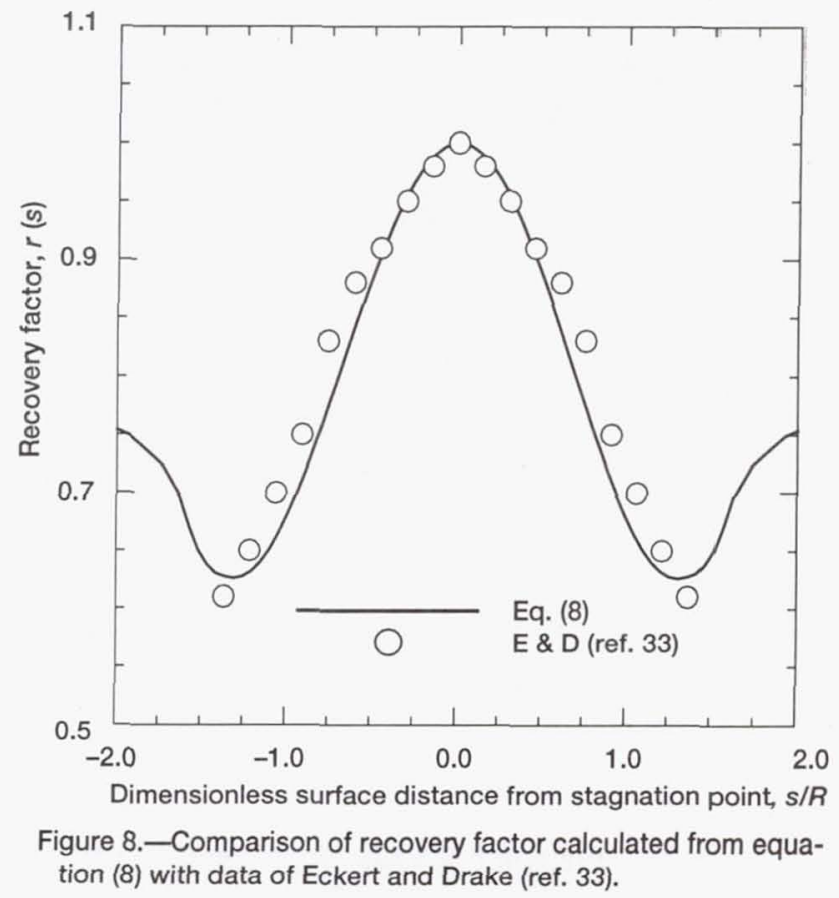


The Reynolds number $R e_{d}$ was based on the diameter of the leading edge $d$, and the mass-velocity was averaged between the flow area with maximum model blockage and the unblocked, upstream flow area, that is,

$$
(\rho U)_{\mathrm{avg}}=(\rho U)_{\infty} \frac{(2-B)}{2(1-B)}
$$

where the blockage $B$ is the ratio of maximum model thickness to tunnel height. Blockage ranged from 0.096 for the circular leading edge to 0.293 for the $3: 1$ ellipse.

\section{Uncertainty Analysis}

The method of Kline and McClintock (ref. 35) was used to combine estimates of the bias error of each measuring instrument. Estimates of the precision of each measurement were calculated from 20 samples of each steady-state measurement and combined by the same method. Results of the uncertainty analysis for the Frössling number are presented in table III.

The uncertainty in turbulence intensity and length scale was estimated with the method suggested by Yavuzkurt (ref. 36) and is presented in table IV.

\section{Results and Discussion}

\section{Turbulence}

Intensity.-Variation of turbulence intensity without the model in the test section is shown versus dimensionless distance downstream of the grid in figure 9. For all five grids, the decay of the intensity was in qualitative agreement with the correlation of Baines and Peterson (ref. 37), which is also shown in figure 9 for reference. Each grid and velocity had slightly different characteristics so intensity data for each case were fit with a power law of the form

$$
T u=a\left(\frac{x}{b}\right)^{m}
$$

Coefficients for each of the fits appear in table V and the curve fit for each case is shown in figure 9. Representative plots of the variation in turbulence intensity in the spanwise direction are shown in figure 10 ; typically, the variation was around 5 percent.

Isotropy.-Figure 11 shows the ratio $\sqrt{u^{\prime 2}} / \sqrt{v^{\prime 2}}$ which is a measure of isotropy for the turbulence; a value of 1.0 would indicate isotropic flow in the $x-y$ plane (the plane of the stagnation stream sheet). Turbulence for the square-bar, squaremesh grids (G3 and G4) seems to be nearly isotropic while that for grid G5 shows highly nonisotropic behavior with $\sqrt{u^{\prime 2}} / \sqrt{v^{\prime 2}}$ values ranging from a high of 1.42 down to
0.95 depending on Reynolds number and distance from the grid. In general, the turbulence from grid G5 is more anisotropic at lower flow rates and moves toward isotropy as distance from the grid increases.

The X-wire results for the streamwise turbulence component were in close agreement with those obtained using the single hot wire. For example, values of the turbulence intensity with grid G3 calculated from the single hot wire and the $\mathrm{X}$-wire are within 8 percent at all Reynolds numbers.

Length Scale.-Figure 12 shows the variation of the integral length scale in the streamwise direction behind grids G1 to G5. Increase in the integral length scale with distance from the grid is apparent in all cases. This is expected, since the smaller eddies dissipate faster than the larger ones. Also shown in the figure is a correlation developed by Roach (ref. 38 ), who relates the growth rate of microscale with distance from the grid. His theory shows microscale variation to be dependent on Reynolds number. Roach states that it is not possible to develop a theory for the variation of integral scale with distance. He therefore assumed that the integral scale should follow the growth of microscale in the downstream direction but, based on empirical evidence, removed the Reynolds number dependence. His correlation has the form

$$
\frac{\Lambda_{x}}{b}=I\left(\frac{x}{b}\right)^{0.5}
$$

He determined from his data that $I=0.2$. The present data tend to follow the square root of distance dependence of Roach's correlation but the constant is an average 35 percent larger and varies from grid to grid. Individual curve fits of the integral scale versus distance from the grid were made for each grid; the results are shown in figure 12 and in table V. These curve fits were used to determine the value of length scale when evaluating the heat transfer dependence on length scale. Note that the integral scales for grids G1 to G4 show no Reynolds number dependence but those of grid G5 are very dependent on Reynolds number.

Naudascher and Farell (ref. 39) also developed a correlation for both the microscales and integral scales of grid turbulence. Their correlation showed a Reynolds number dependence for the integral scale. The correlation involved the ratio of microscales to integral scale at infinity which was unknown but is bracketed by values of 1.25 and 3.0; with these limiting values, their correlation bracketed the integral scale data of several other authors. The integral scale data for grids G1 to G4 are shown in figure 13 versus the Naudascher and Farell correlation parameter. Also shown in figure 13 is their correlation with the two bracketing values discussed above. The present length scale data are correlated better by the relation of Roach.

All turbulence measurements were made without the model present. When the model is present downstream of the grid, turbulence is distorted as the stagnation point is 

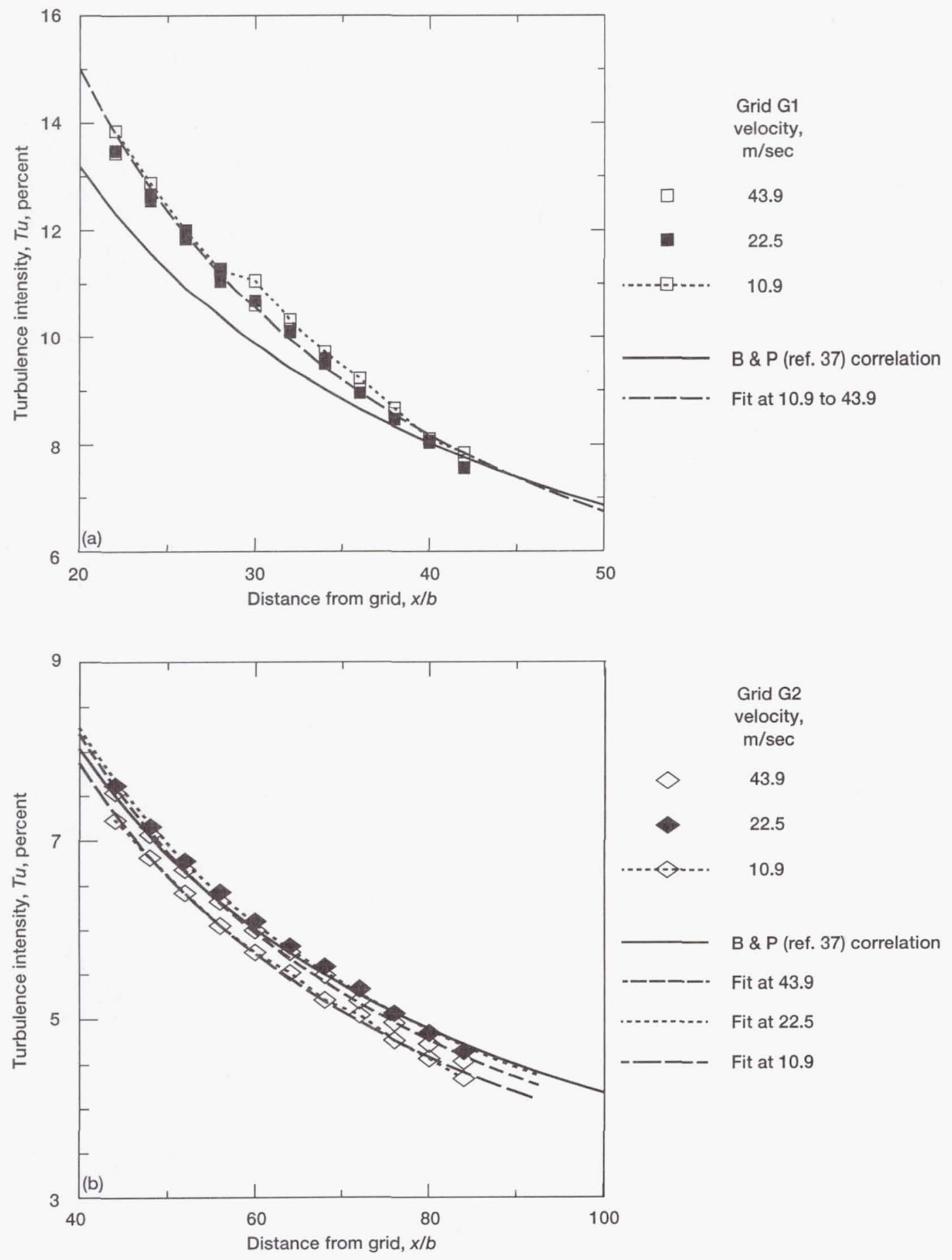

Figure 9.-Turbulence intensity versus dimensionless distance from grid for (a) Grid G1, (b) Grid G2, (c) Grid G3, (d) Grid G4, and (e) Grid G5. 

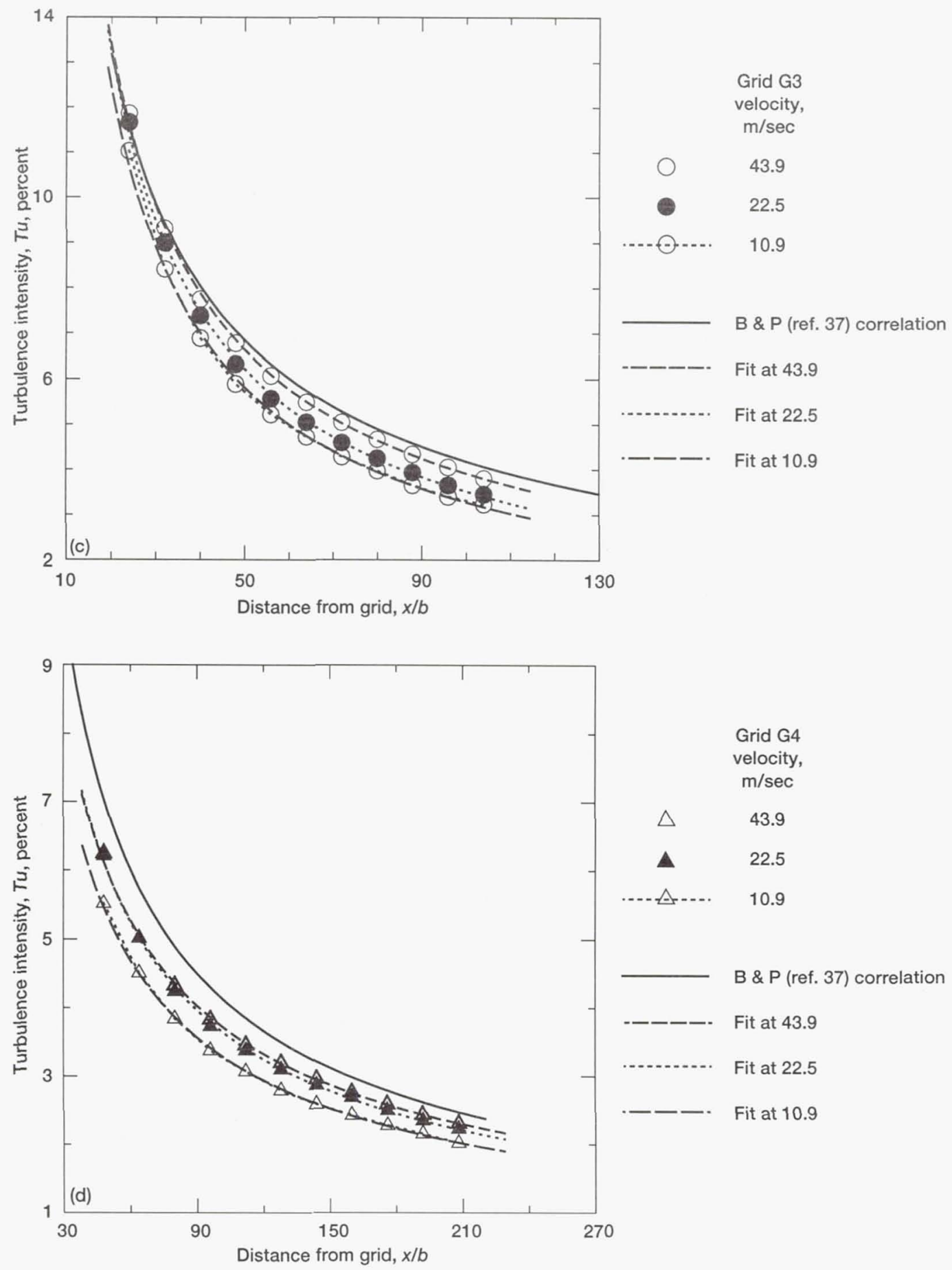

Figure 9.-Continued. (c) Grid G3. (d) Grid G4. 


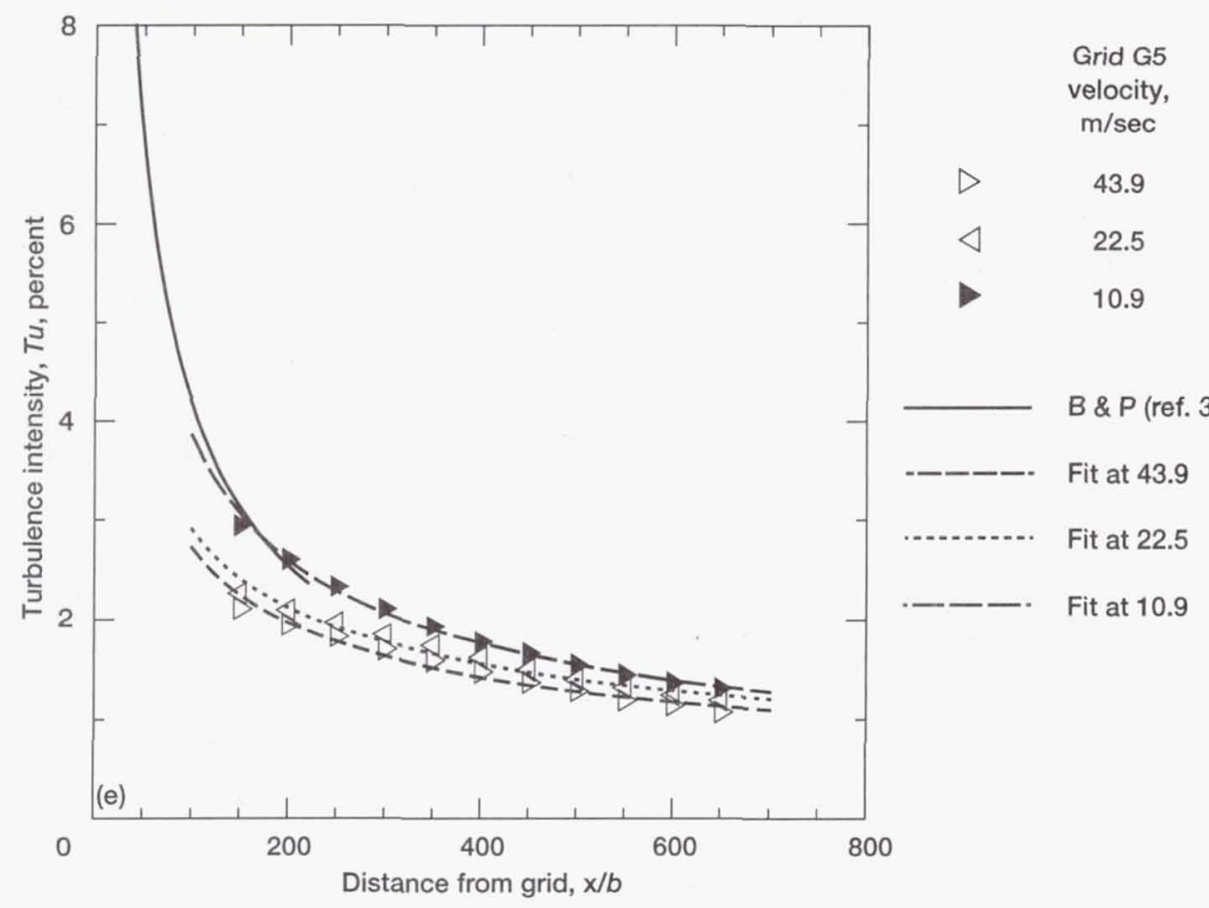

Figure 9.-Concluded. (e) Grid G5.

approached. The fluctuating component of velocity increases and the mean velocity approaches zero (ref. 40) sending intensity levels very high. This brings up the problem of where to evaluate the turbulence intensity and length scale for use in a heat transfer correlation. We felt that tests of most turbulence-producing components, (e.g., combustor) would be conducted without the model present; therefore, turbulence intensity and length scale used in the following correlations were evaluated from the curve fits in table $\mathrm{V}$ by using the distance from the grid to the stagnation point of the model. Turbulence intensity varied from 1.1 to 15.9 percent. The ratio of length scale to leading-edge diameter ranged from 0.05 to 0.30 .

\section{Heat Transfer}

Verification of Experimental Method.-Frössling number data for each of the models is given in tables VI through IX. Data for the circular leading edge model are presented for gauges 2 to 18 and for the elliptical leading edge models for gauges 2 to 28 . Gauges 1 and 19 for the circular leading edge model and 1 and 29 for the elliptical models are considered guard heaters. Gauges 10 and 15 are centered on the stagnation line for the circular and elliptical models respectively. Grid designation G0 represents the low turbulence data.

Heat transfer results in the leading-edge region with no turbulence grid in the tunnel are shown in figure 14 for the four different models. Measured free-stream turbulence intensity in this case was less than 0.5 percent. Frössling number data are presented as a function of surface distance from stagnation that is made dimensionless by the leading edge radius $R$. In all cases the data agree to within the estimated experimental error with the two-dimensional numerical solution from the PARC code (ref. 32) and with the Frössling solution, which was obtained by using the velocities calculated from the panel code (ref. 23), thus confirming the accuracy of the experimental technique. The worst agreement between the experimental and numerical results is for the $2.25: 1$ model; experimental results are from 1.4 to 9.2 percent above the numerical results at the stagnation point. The upper limit of discrepancy is above the estimated experimental error. This model seemed to have a mind of its own; on some days the model gave results that agreed quite well with the numerical results and on other days large errors were observed. Possible causes of this error were investigated including model profile, surface irregularities, thermocouple calibration, and clear-tunnel turbulence level. The model was $\mathrm{x}$-rayed to see if the internal guard heater was touching the surface heat flux gauges. No obvious cause could be found; therefore, the data for this model are presented as is.

It is interesting to note past design practice used to estimate leading-edge heat transfer to a turbine airfoil. A circle was inscribed inside the airfoil tangent to the stagnation point with the same radius as the airfoil leading edge. Heat transfer at the stagnation point for laminar flow was 


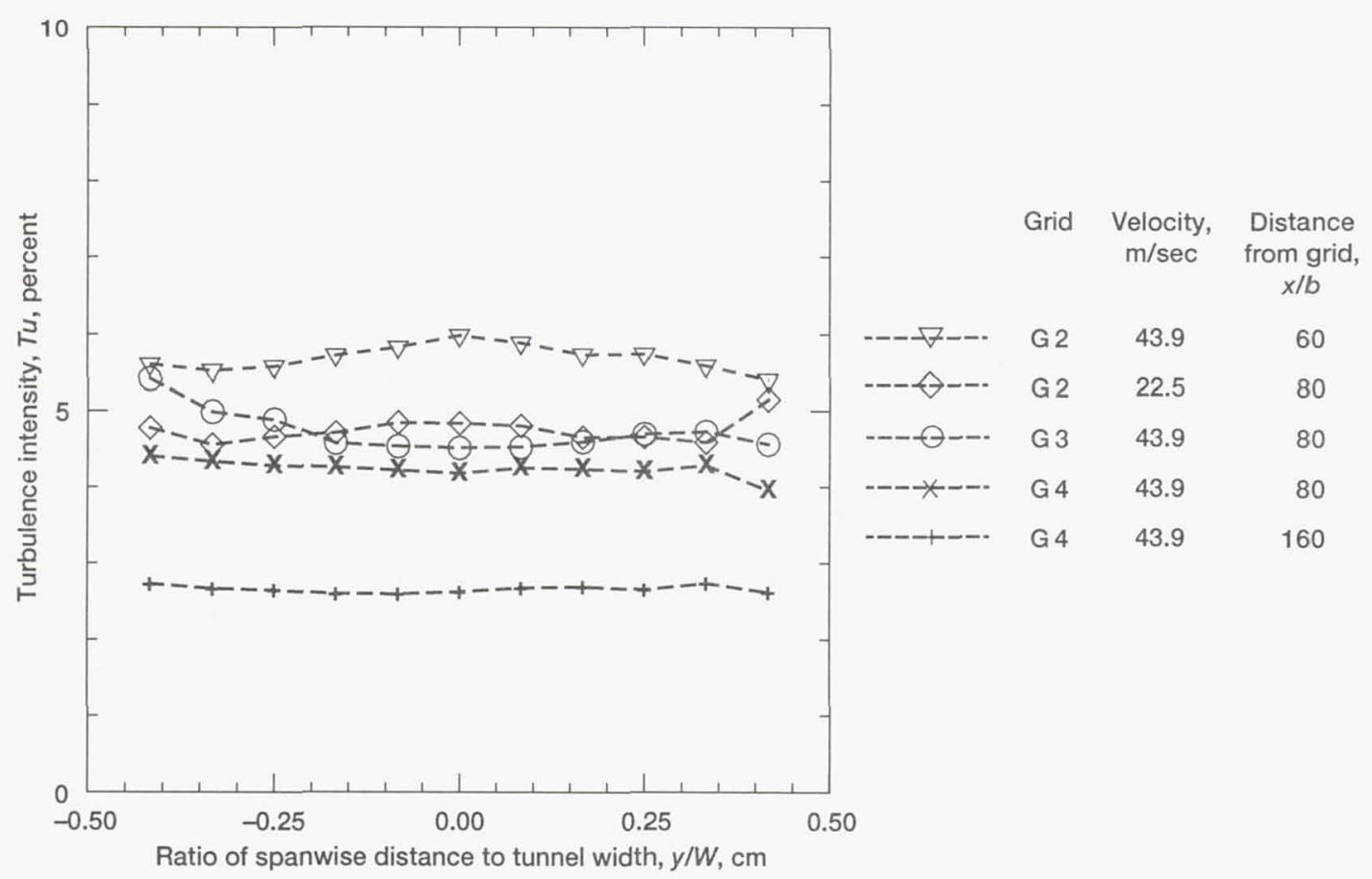

Figure 10.-Variation of turbulence intensity in the spanwise direction.

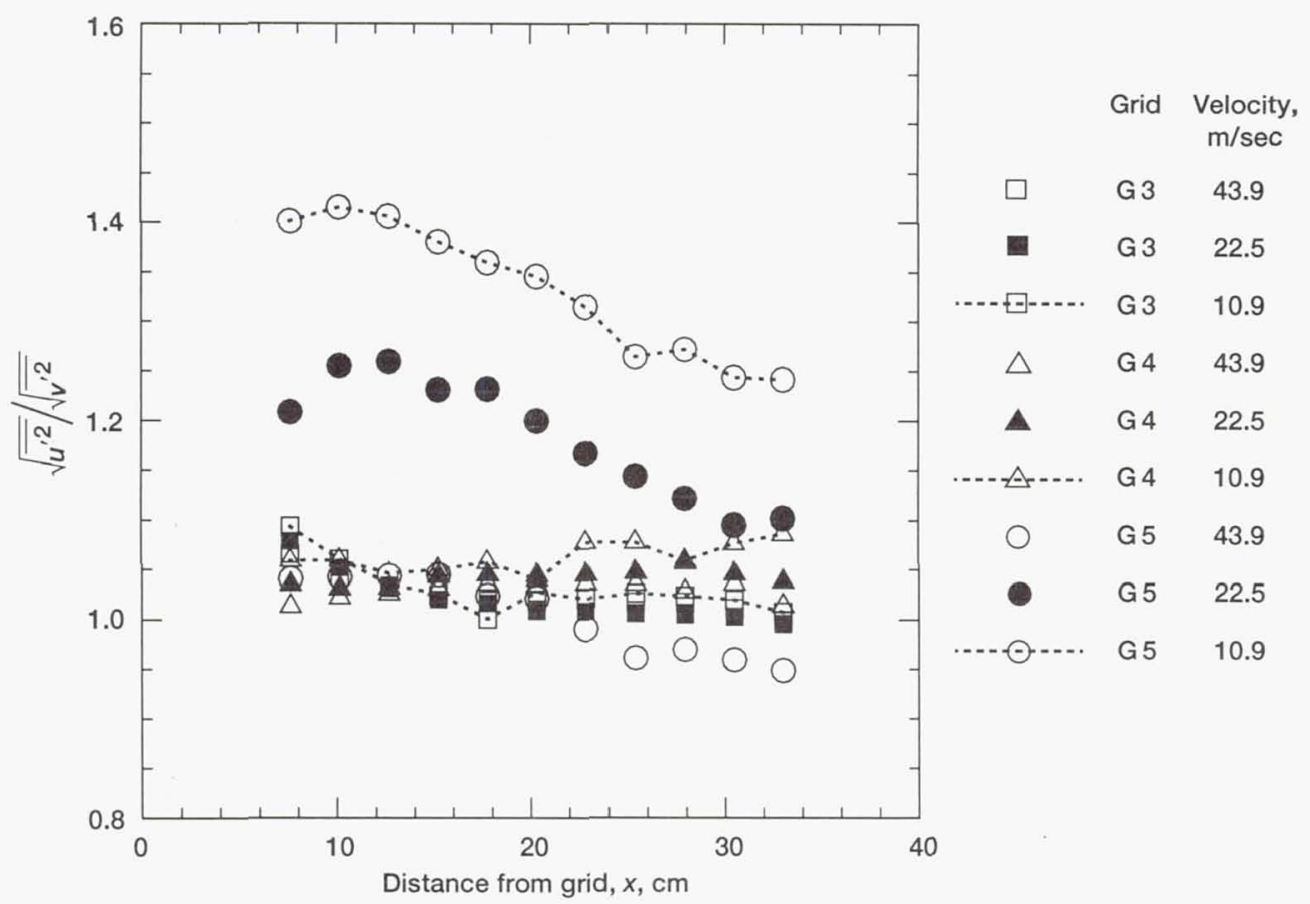

Figure 11.-Isotropy of turbulence from grids G3, G4, and G5. 

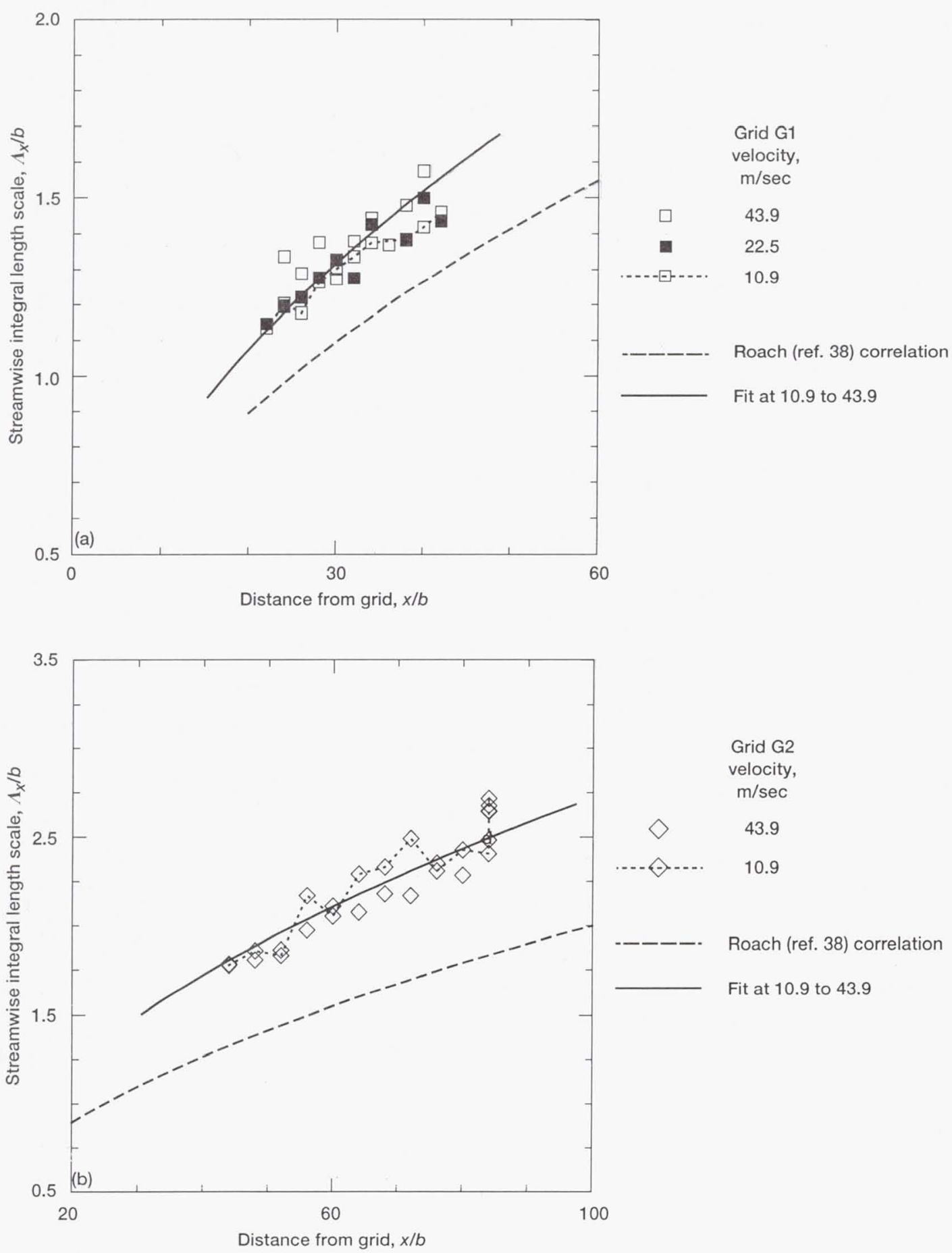

Figure 12.-Longitudinal integral scale versus dimensionless distance from the grid for (a) Grid G1, (b) Grid G2, (c) Grid G3, (d) Grid G4, and (e) Grid G5. 

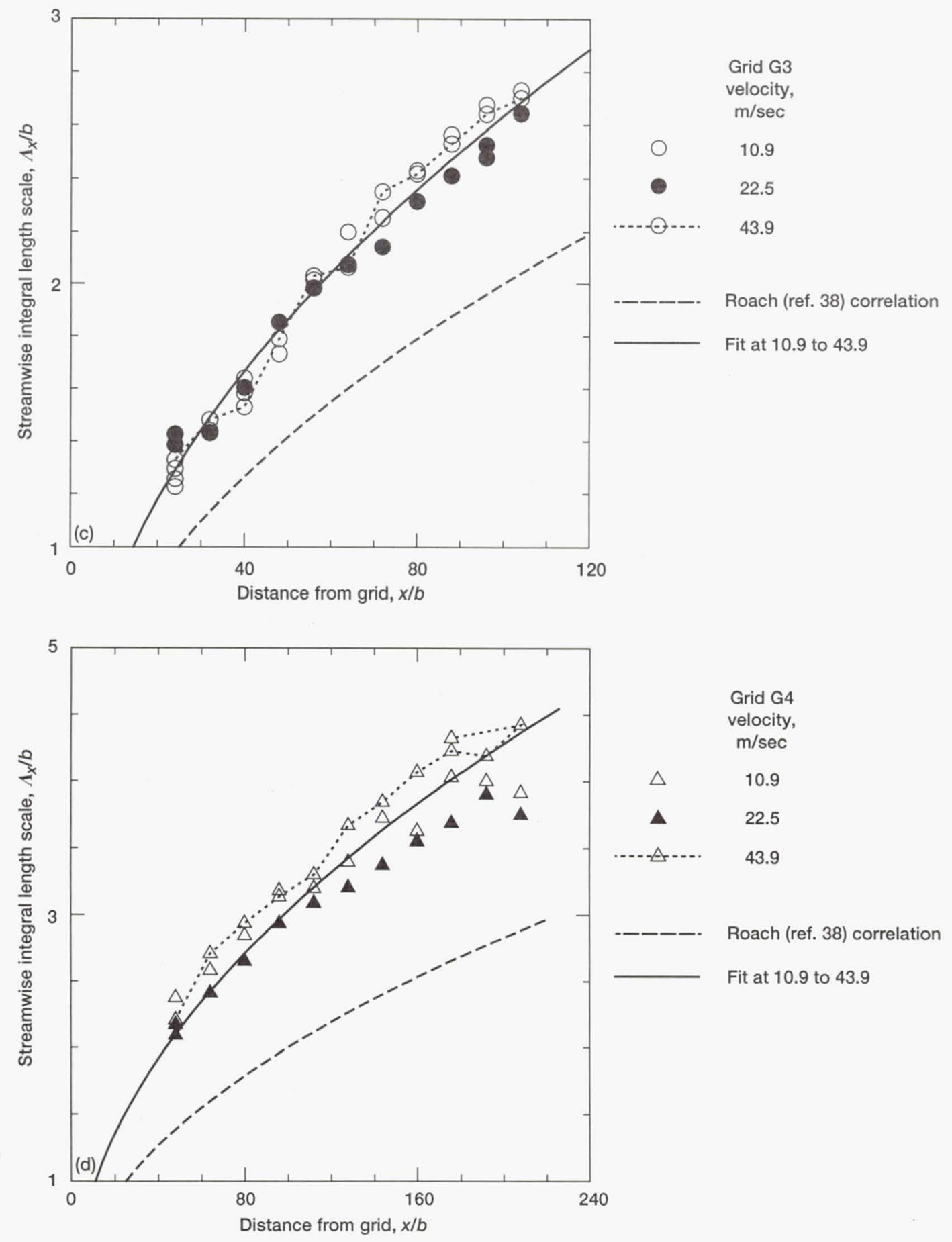

Figure 12.-Continued. (c) Grid G3. (d) Grid G4. 


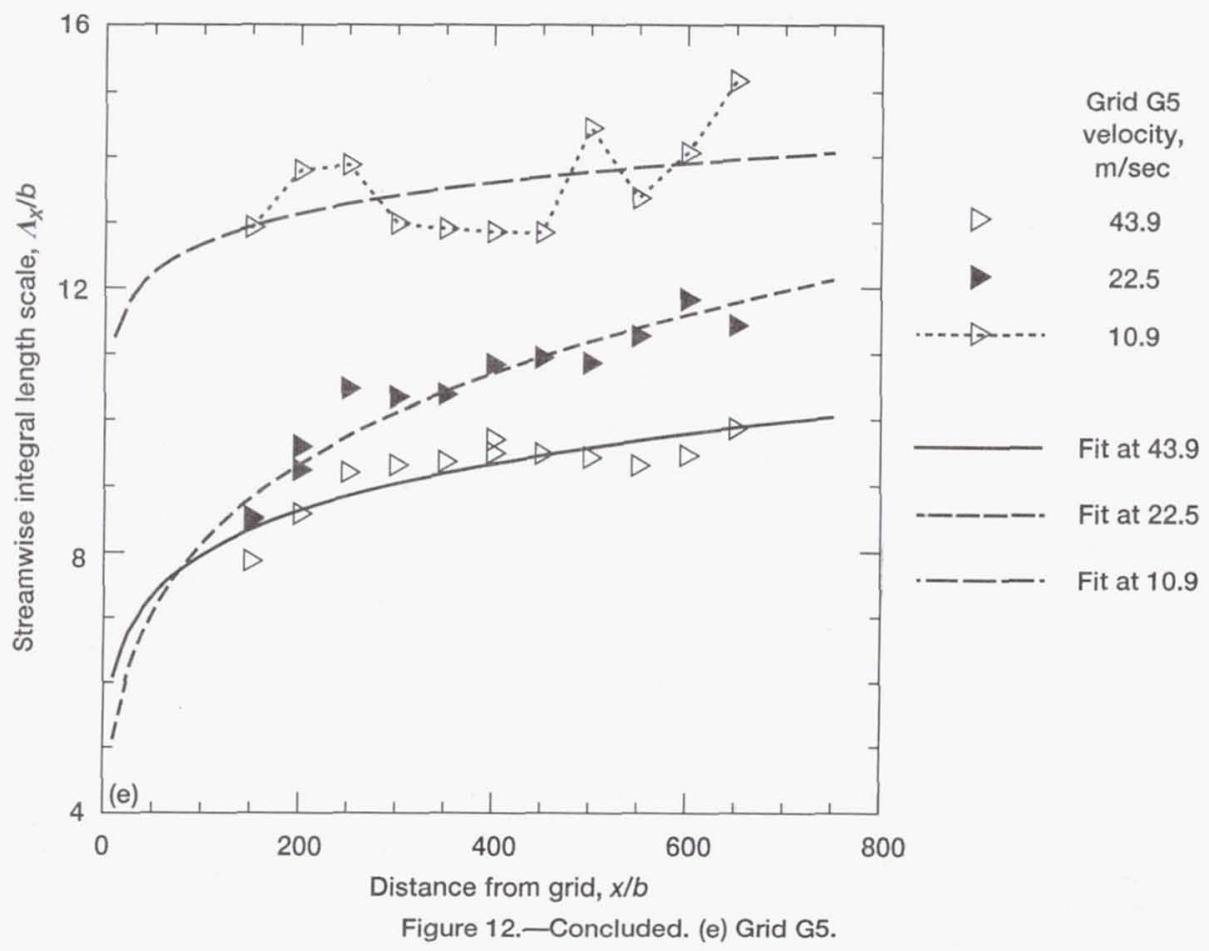

then calculated from a circular cylinder in cross flow correlation using the diameter of the inscribed circle. Various multipliers were then applied to this result to account for turbulence. All four models have the same radius of curvature at the leading edge but, as seen in figure 14, the stagnationpoint heat transfer is different for each model. The conclusion must be that this method only works for a circular cylinder in cross flow; however, an accurate prediction of the laminar leading-edge heat transfer can be obtained from the Frössling solution given the surface velocity distribution or from a numerical solution for laminar flow over the airfoil.

Stagnation Region Augmentation-Circular Leading Edge.-Figure 15 shows the Frössling number at stagnation plotted against the correlating parameter $T u R e_{d}{ }^{1 / 2}$ developed by Smith and Kuethe (ref. 13). The range of length scale to leading-edge diameter ratio for each grid is indicated on the legend in the figure. Immediately evident is the fact that the data from the five different grids are not correlated by the parameter $T u R e_{d}{ }^{1 / 2}$. The heat-transfer augmentation continues to increase as scale decreases, therefore, for the present data, no optimum length scale was found. Also shown in the figure is the correlation developed by Lowery and Vachon (ref. 16). The Lowery and Vachon correlation predicts the heat transfer data only in a narrow range of scales, and as the parameter $T u R e_{d}^{1 / 2}$ increases beyond about 40, the correlation turns downward instead of continuing up as the data indicate.
The stagnation heat transfer data from the model with the circular leading edge behind the square bar grids was fit with the function

$$
\operatorname{Fr}(0)=0.008 \sqrt{\operatorname{Tu} \operatorname{Re}_{d}^{0.8}\left(\frac{\Lambda_{x}}{d}\right)^{-0.574}}+C
$$

The constant $C$ was set to the zero turbulence Frössling number of 0.939 , which was calculated from the PARC-2D code. The other constants were determined from a least-square fit of the data. The curve fit and the data are compared in figure 16 ; the function correlates the data to within \pm 4 percent as shown by the bands drawn on either side of the correlation.

Turbulence for grids G1 to G4 was shown to be isotropic; that for grid G5 (the array of parallel wires) was not. The stagnation heat-transfer data for grid G5 are compared to the stagnation-region heat transfer correlation developed for grids G1 to G4 in figure 17. Although the data are correlated by the parameter on the abscissa, it is obvious from this figure that anisotropic turbulence with the majority of its vorticity oriented normal to the free stream, and normal to the axis of the leading edge, causes increased augmentation over isotropic turbulence. The data at high values of the abscissa in figure 17, where agreement with the correlation is the poorest, were taken closest to the wires. As distance from 


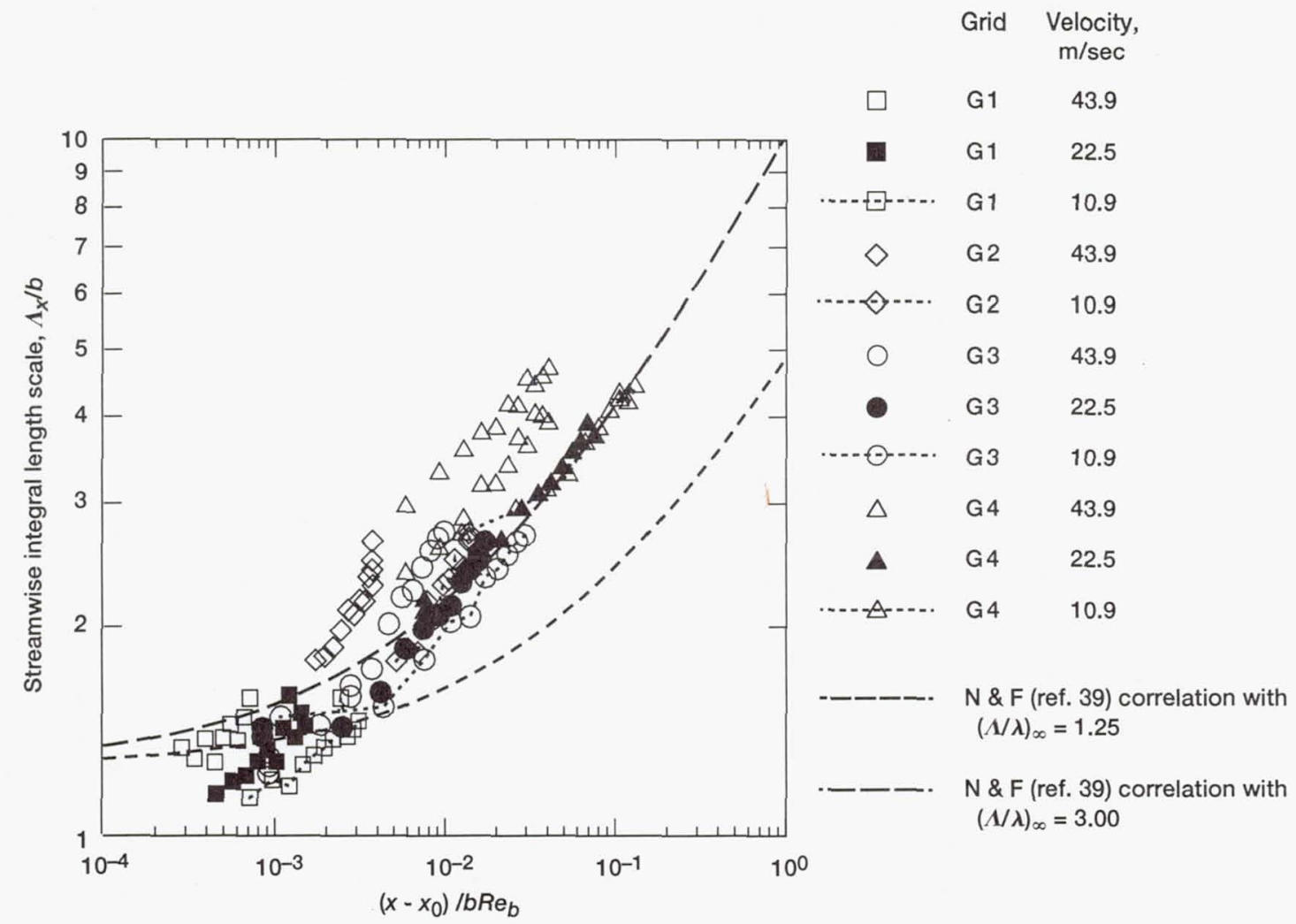

Figure 13.-Length scale data compared to the correlation of Naudascher and Farell (ref. 39).

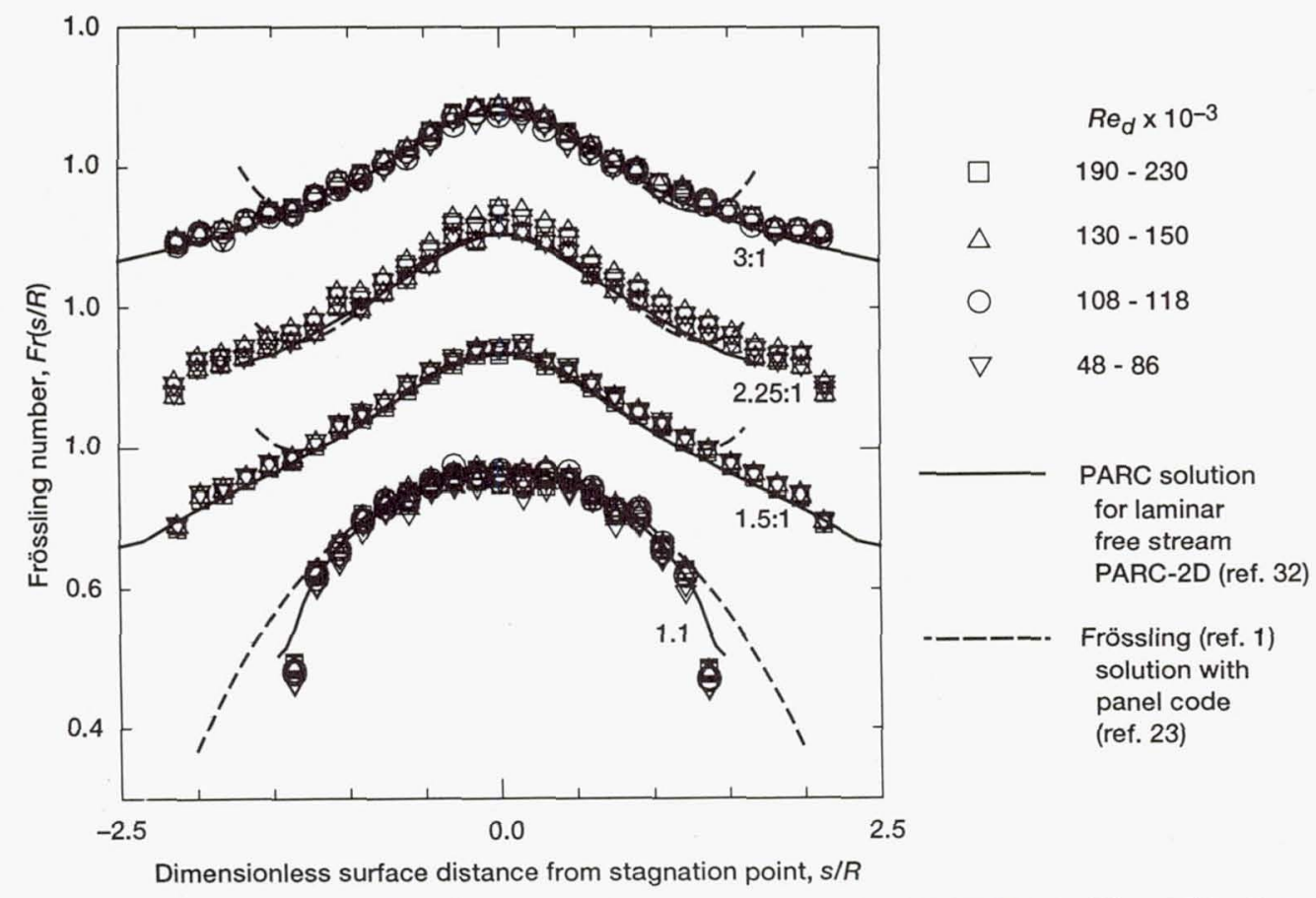

Figure 14.-Low turbulence Frössling number distribution compared to PARC-2D (ref. 32) and Frössling (ref. 1) solutions using velocity from panel code (ref. 23). 


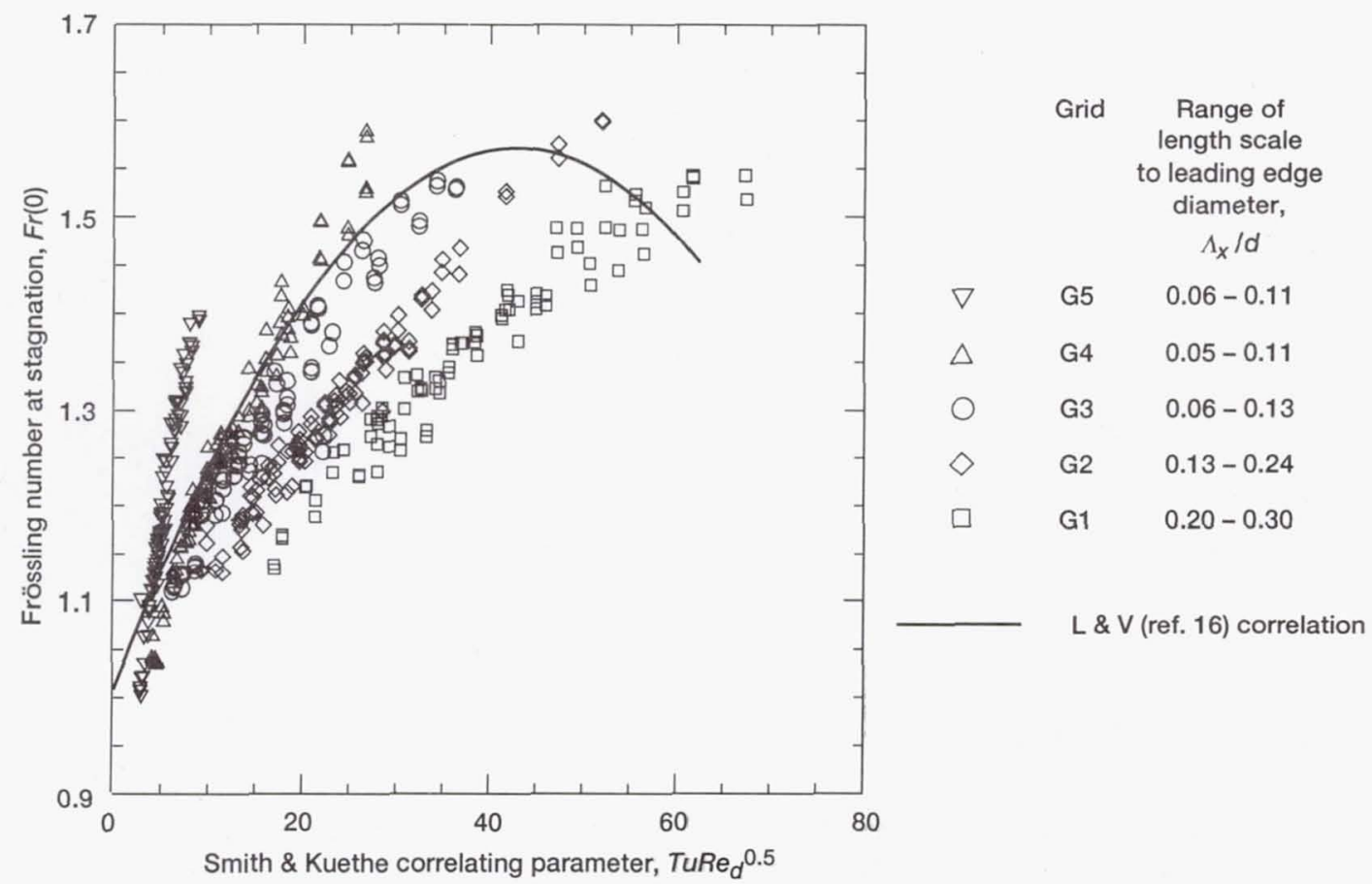

Figure 15.-Stagnation point Frössling number versus Smith \& Kuethe (ref. 13) parameter showing effect of length scale.

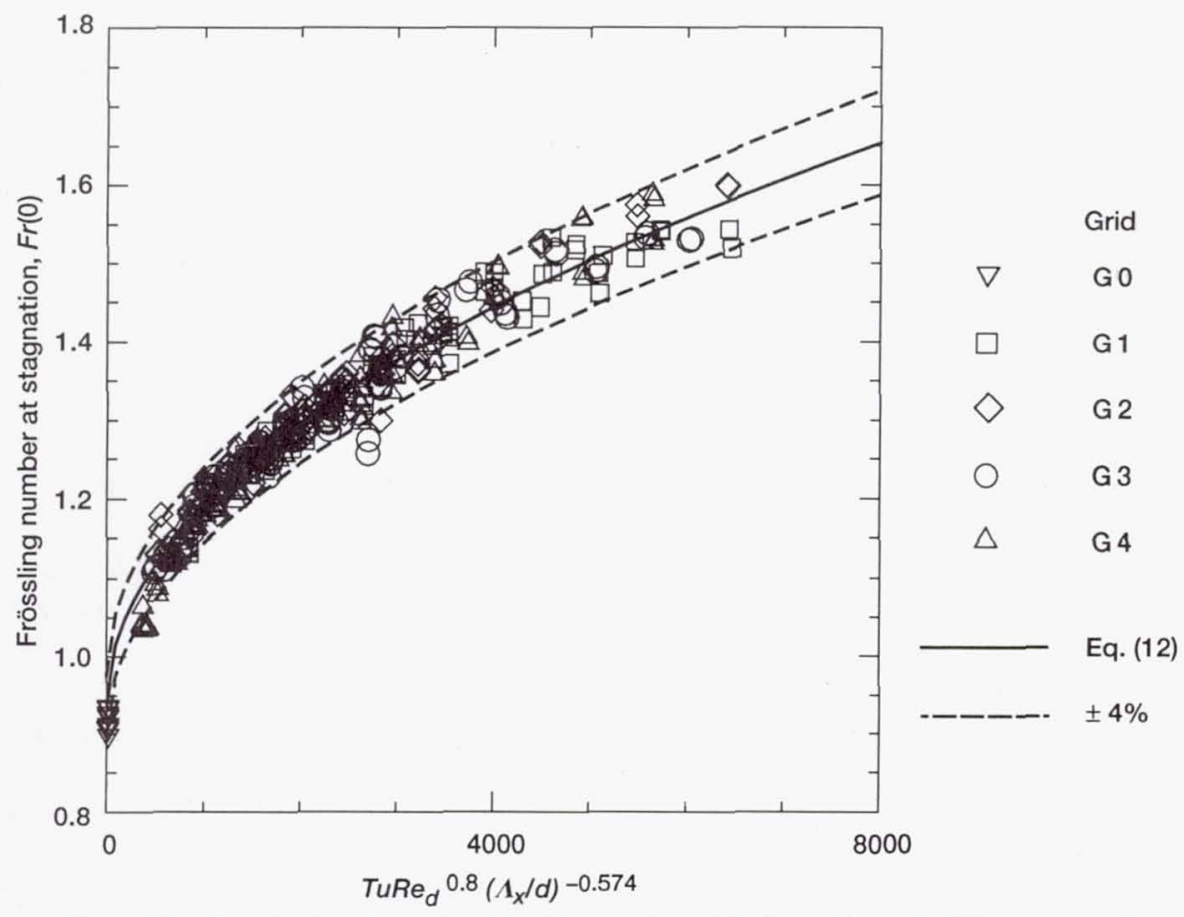

Figure 16.-Circular leading edge Frössling number data for grids $\mathrm{G} 1$ to $\mathrm{G} 4$ compared to equation (12). $F r(0)=0.008\left[T_{\text {TuRe }}{ }^{0.8}\left(\Lambda_{\mathrm{x}} / d\right)-0.574\right] 0.5+C ; C=0.939$. 


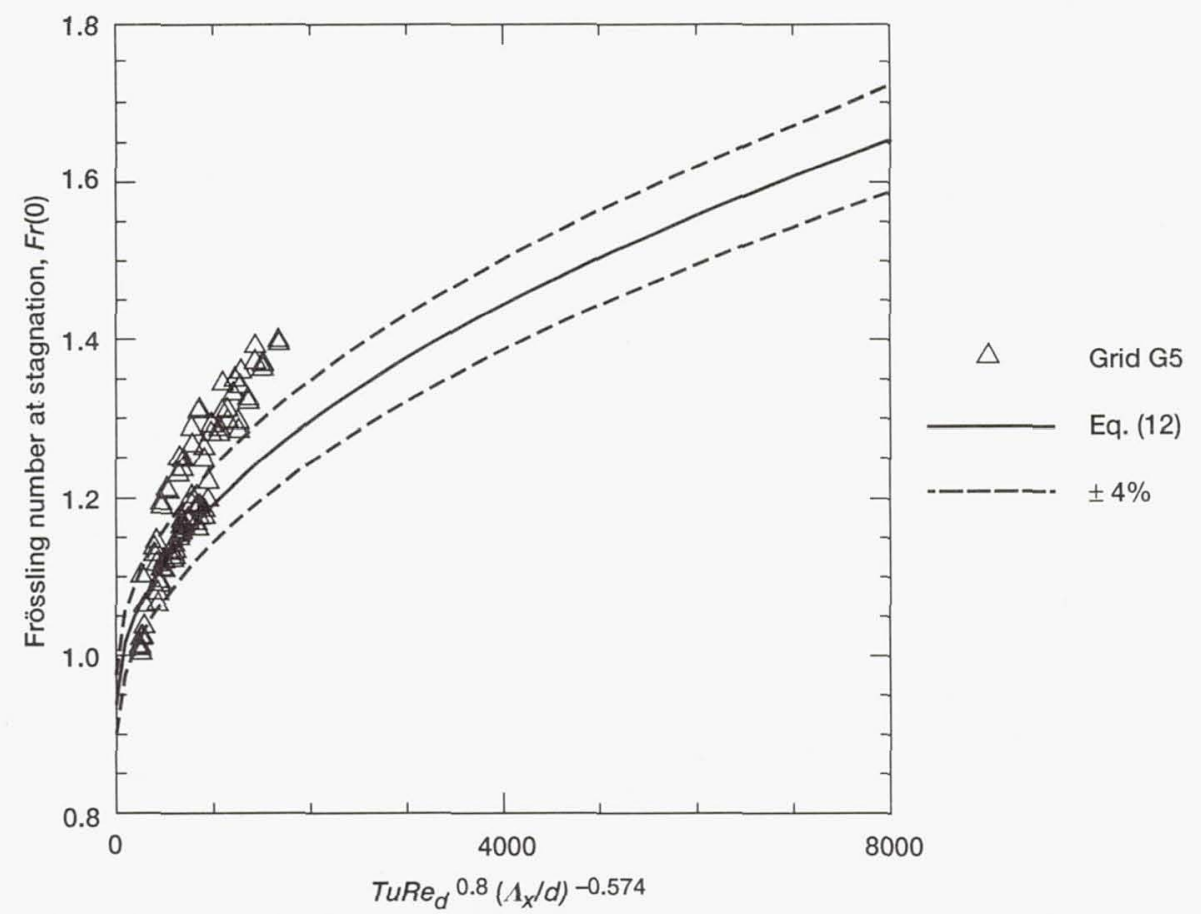

Figure 17.-Stagnation Frössling number data for grid G5 (parallel wires) compared to equation (12). $\operatorname{Fr}(0)=0.008\left[\mathrm{TuRe}_{d}{ }^{0.8}\left(\Lambda_{X} / d\right)-0.574\right]^{0.5}+C ; C=0.939$.

the wires increases, the degree of anisotropy decreases as seen in figure 11 and heat transfer data agree more with the correlation.

As stated in the Introduction of this paper, Ames (ref. 20) developed a correlation for stagnation heat transfer data that involved Reynolds number, turbulence intensity, and length scale. Figure 18 shows the present circular leading edge Frössling number data for grids G1 to G5 plotted against the parameter of Ames. Also shown in this figure is a leastsquare fit of Ames' data based on integral length scale $\Lambda_{x}$ instead of Ames' "energy scale." The Ames correlating parameter results in more scatter than the least-square curve fit used in equation (12). The data of Ames falls between the grids G1 to G4 (isotropic turbulence) and the grid G5 (anisotropic data). The turbulence generators used by Ames produced anisotropic turbulence with ratios of $v^{\prime} / u^{\prime}$ around 1.3. Our grid G5 produced a range of $v^{\prime} / u^{\prime}$ ratios from 0.95 to 1.42 .

Figure 19 is a comparison of the stagnation heat transfer data of other authors (refs. 2, 13, 15, and 16) who used similar turbulence generators with equation (12). For cases where the authors did not measure length scale, it was estimated using the correlations given in table V. This was accomplished by using equation (10) with coefficients for the closest matching geometry available from table $\mathrm{V}$ to estimate a value of $x / b$ from the intensity. Equation (11) was then used to calculate the length scale. Lateral length scale was measured by Lowery and Vachon (ref. 16); this was multiplied by 2 to convert it to longitudinal length scale. The data of the other authors is in good agreement with the present correlation falling mostly within the \pm 10 percent bands drawn about the correlation of equation (12).

Stagnation Region Augmentation-Elliptical Leading Edges.-Rigby and Van Fossen showed by numerical calculation that the stagnation-point Frössling number with simulated turbulence (sinusoidal velocity variation upstream of the leading edge) divided by the laminar Frössling number was independent of body shape. Following this line, the correlation for the circular leading edge was modified by dividing by the laminar stagnation Frössling number. The modified correlation then gives the stagnation-point heat transfer augmentation factor $\Phi$ caused by free-stream turbulence

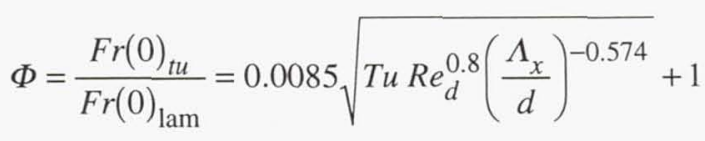

Values of the term $\operatorname{Fr}(0)_{\text {lam }}$ for the four models are dependent on the velocity gradient; the values are $0.939,0.870$, $0.811,0.775$ in order from the circular leading edge (1:1 ellipse) to the $3: 1$ ellipse. These values were also taken from the PARC-2D numerical solution with inlet mass flow defined by equation (9).

Comparison of the correlation for stagnation heat transfer augmentation by free-stream turbulence and the experimental data is shown in figure 20. The correlation was developed using only the circular leading-edge data, thus, the fit for that data is the best. In general, the fit is excellent and falls mostly 


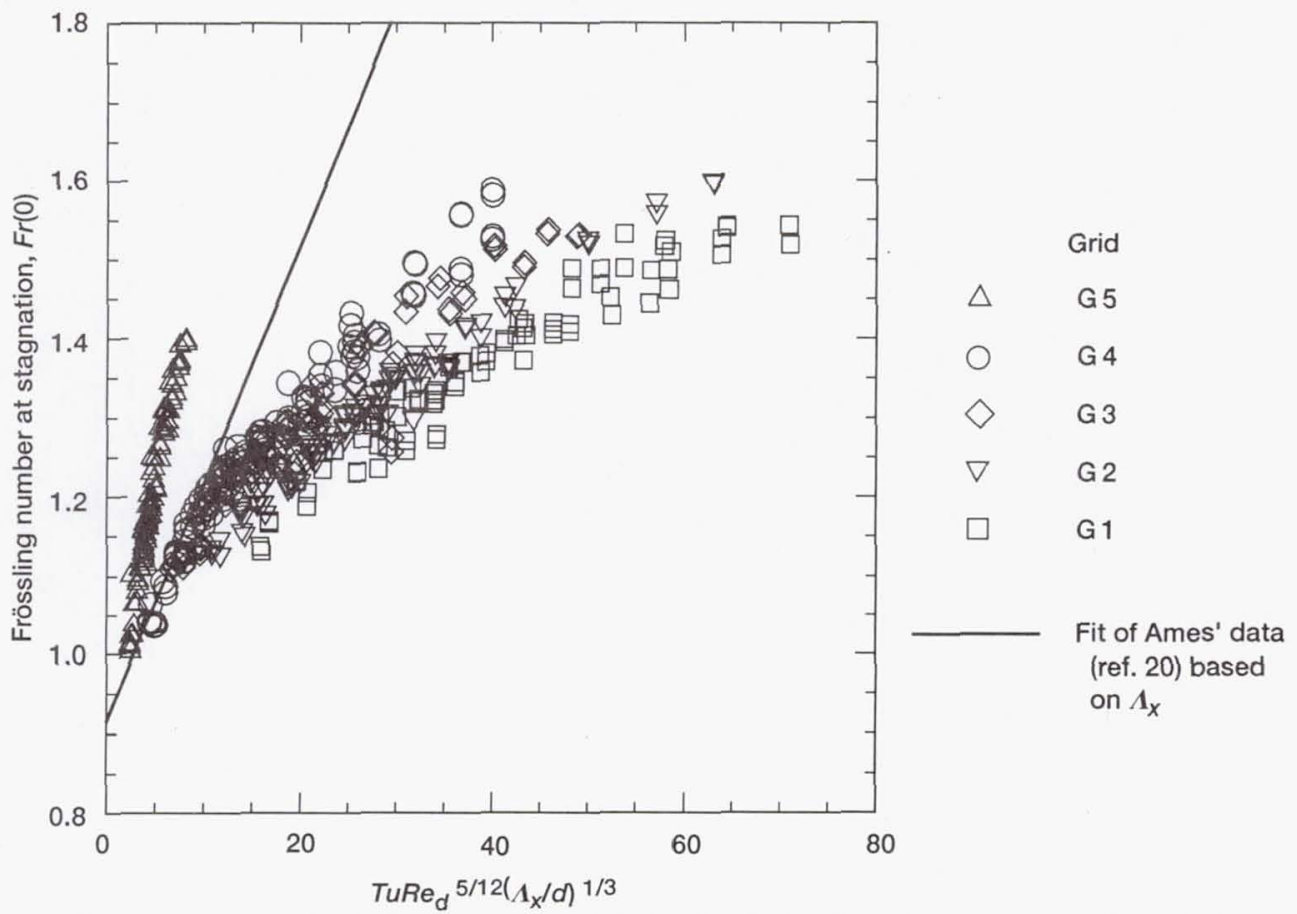

Figure 18.-Stagnation Frössling number data for circular leading edge versus Ames' correlating parameter (ref. 20).

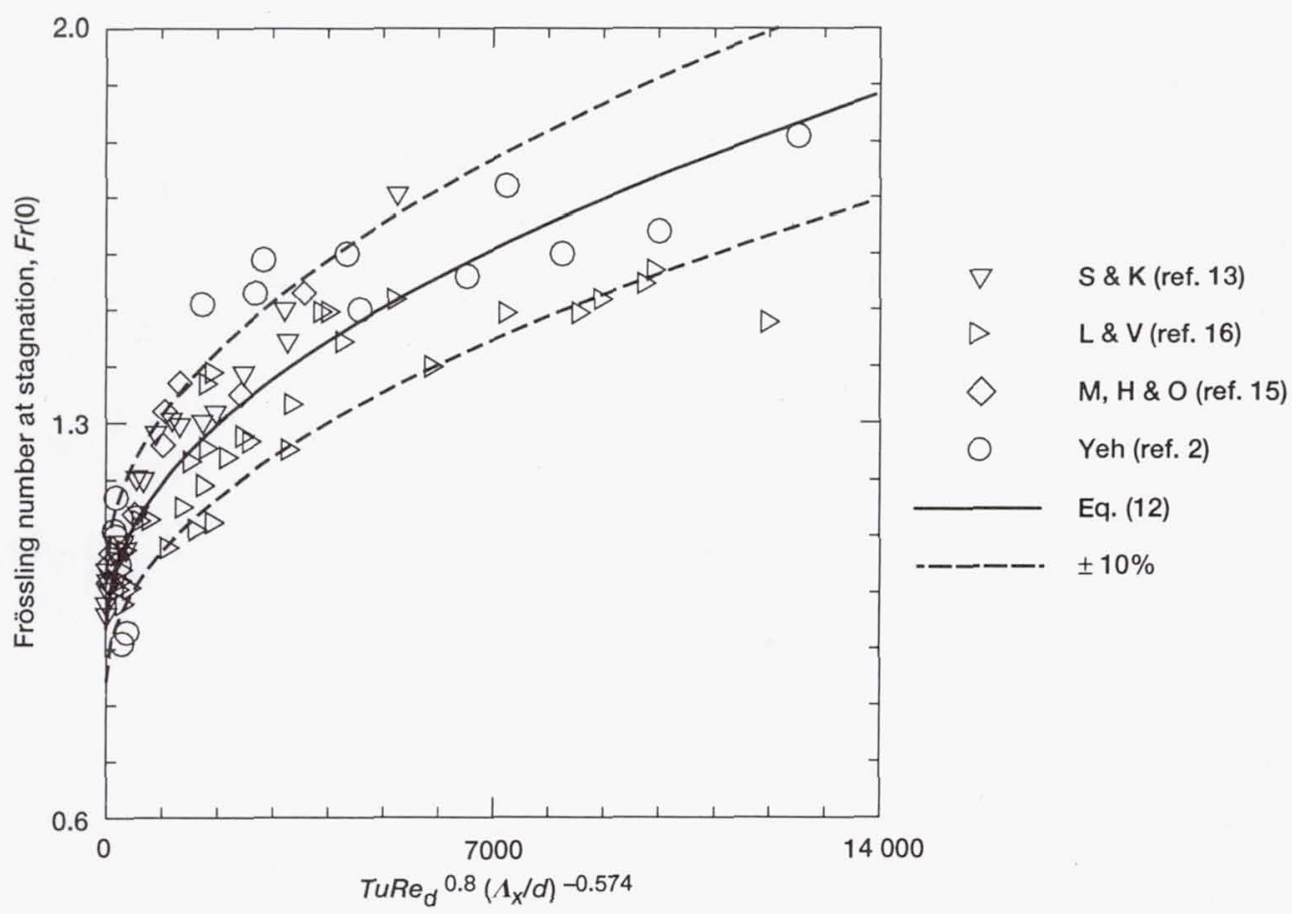

Figure 19.-Comparison of equation (12) with stagnation heat transfer data of other authors. 


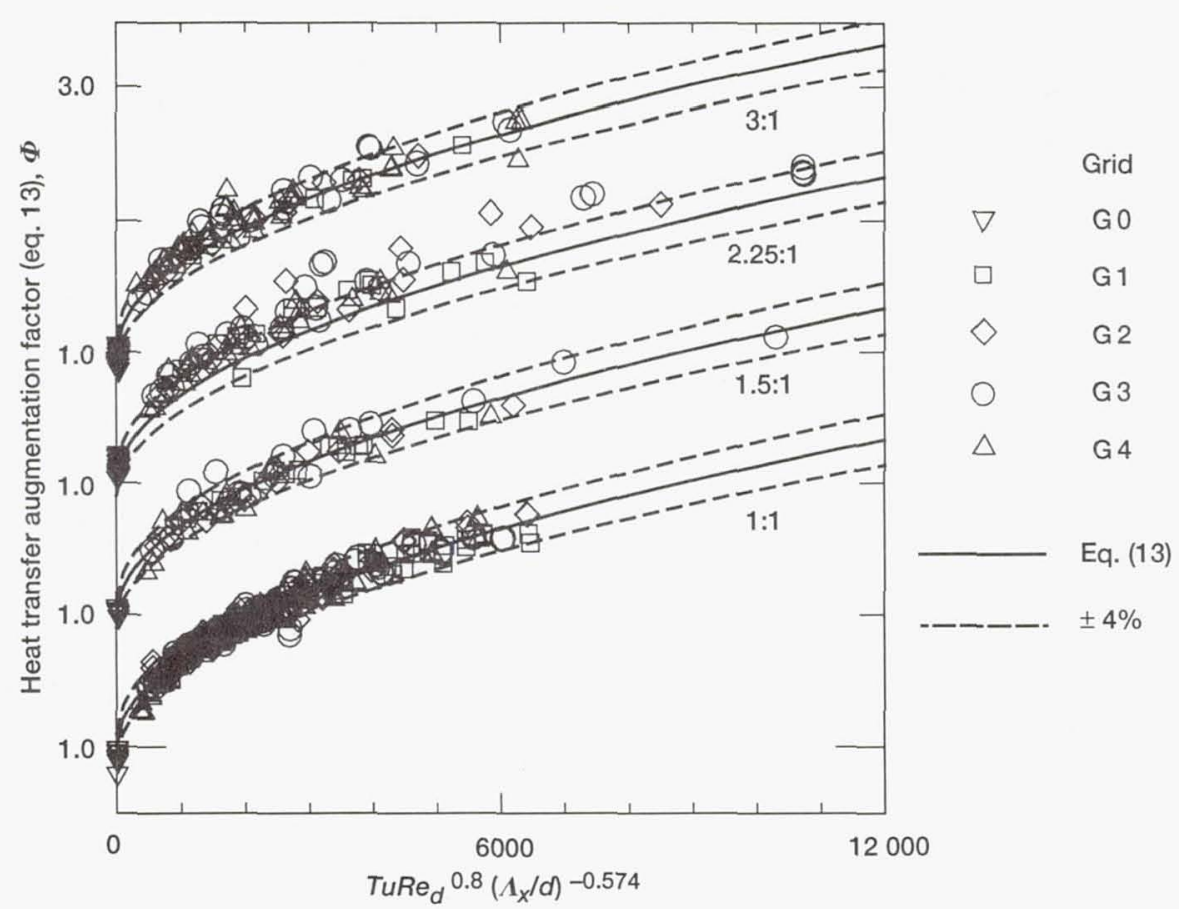

Figure 20.-Comparison of stagnation point heat transfer augmentation factor and correlation for elliptical leading edges.

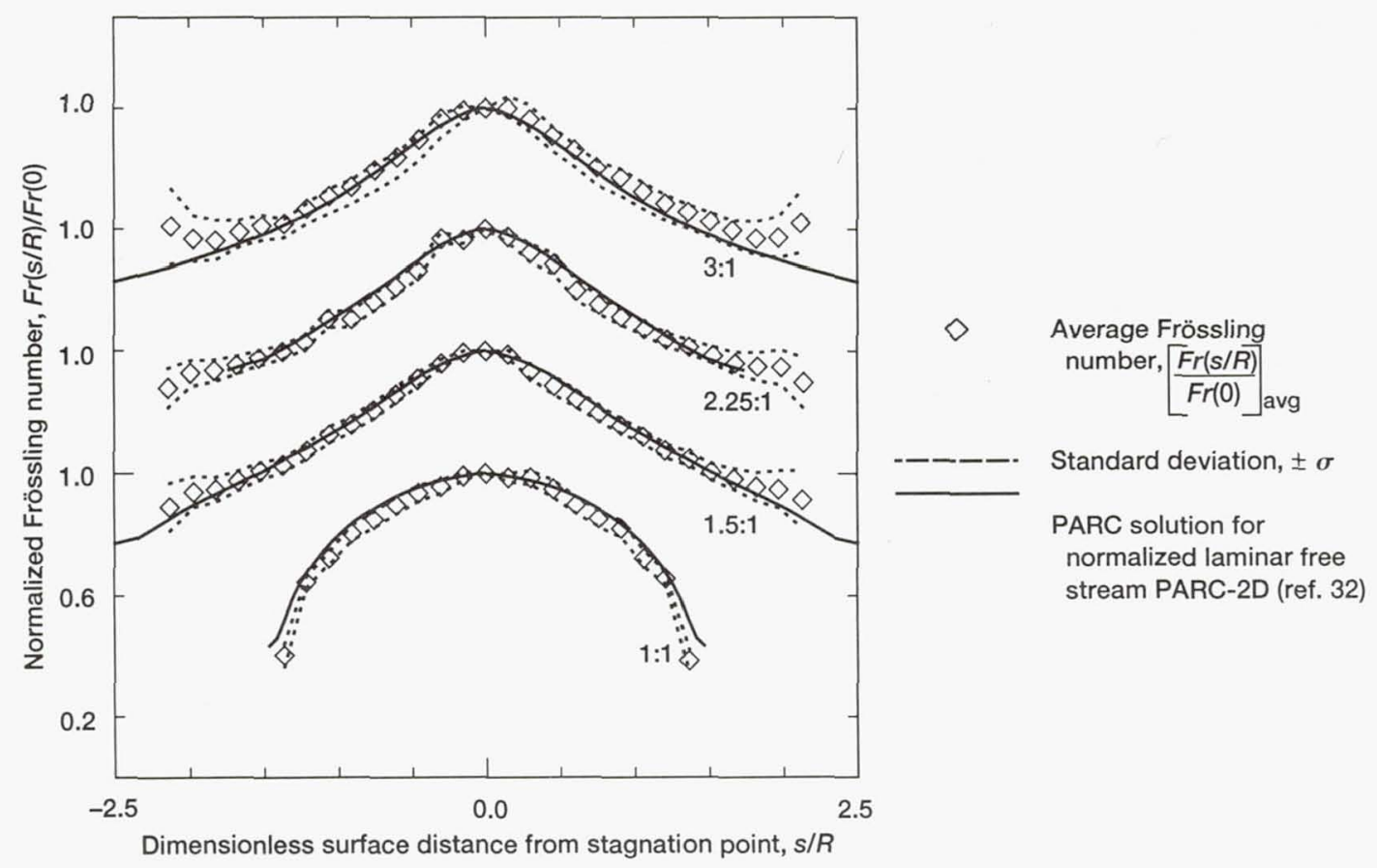

Figure 21.-Comparison of averaged, normalized, turbulent, Frössling number distribution with PARC-2D solution. 
within the \pm 4 percent bands drawn about the correlation. The 2.25:1 model has the most scatter; as mentioned earlier, this model had problems. If the Frössling number for the 2.25:1 model had been normalized using the average of the experimental data instead of the numerical solution, agreement with equation (13) would have been much better. The excellent agreement for the other three models confirms the validity of this correlation method.

As shown by Frössling's solution and the data in figure 14, the level of heat transfer at the stagnation point for zero turbulence flow depends on the velocity gradient. Equation (13) predicts the heat transfer augmentation above laminar levels and yet contains no term that involves the velocity gradient at the stagnation point. Thus, the hypothesis that heat transfer augmentation above laminar levels should increase in the presence of higher velocity gradients seems to be disproven by the present data.

Distribution of Heat Transfer Around Leading Edge.Figure 21 is a plot of the Frössling number normalized by the stagnation value versus dimensionless surface distance from the stagnation point for each of the models. The square symbols represent the average of the Frössling number data for the turbulent free stream for all grids, Reynolds numbers, and grid positions. The dotted lines represent the standard deviation of the normalized data and the solid line is the PARC solution for a laminar free stream which has been similarly normalized. Agreement between the normalized turbulent heat transfer distribution and the normalized laminar distribution is good. Thus, a good prediction of the heat transfer at a given distance from the stagnation point can be obtained by using equation (13) with reference 1 to predict the stagnation heat transfer, and then multiplying by the ratio of local to stagnation heat transfer from a solution for the laminar free stream, that is,

$$
F r(s / R)_{t u}=\left(\frac{F r(s / R)}{F r(0)}\right)_{\mathrm{lam}} F r(0)_{t u}
$$

\section{Conclusions}

Spanwise average stagnation-region heat transfer measurements were made on four models with elliptical leading edges, downstream of five turbulence generators. The ratio of major to minor axes for the elliptical leading edges ranged from 1:1 to $3: 1$; all the models had the same leading-edge radius of curvature. Velocity gradients at the stagnation point, made dimensionless by the leading-edge radius and free-stream velocity, ranged from 1.20 to 1.80 . Four of the turbulence generators were square mesh, square bar, biplane grids with identical mesh-spacing to bar-width ratios and bar widths that ranged from 0.16 to $1.27 \mathrm{~cm}$. The fifth turbulence generator was an array of parallel wires oriented normal to the model spanwise direction. Reynolds numbers based on leading-edge diameter ranged from 37000 to 228000 , turbulence intensities ranged from 1.1 to 15.9 percent, and the ratio of integral length scale to leading-edge diameter ranged from 0.05 to 0.30 . Conclusions are summarized as follows:

1. Low turbulence heat transfer results agree with both the Frössling solution and a numerical solution to within estimated experimental accuracy, which validates the experimental method.

2. The calculation of laminar leading-edge heat transfer by cylinder in cross-flow correlations can lead to large errors for noncircular profiles.

3. Augmentation of stagnation-region heat transfer by turbulence increases as integral length scale decreases.

4. No optimum length scale was found for the turbulencegenerating grids used in the present study $\left(\Lambda_{x} / d \geq 0.05\right)$.

5. A correlation for stagnation heat transfer augmentation above laminar levels for the four square bar grids was developed, which reduced data scatter to \pm 4 percent.

6. Dimensionless heat transfer augmentation is independent of body shape and, therefore, of velocity gradient at the stagnation point.

7. The heat transfer data for the array of parallel wires was correlated by the parameter that was developed, however, it was not predicted by equation (12), which indicated that augmentation must also be a function of the isotropy of the turbulent flow field.

8. The stagnation heat transfer data of other authors with similar turbulence generators was predicted to within \pm 10 percent by the correlation developed in this study.

9. Frössling number downstream of stagnation, normalized by the stagnation value, can be represented by a universal curve for both laminar and turbulent flow.

National Aeronautics and Space Administration

Lewis Research Center

Celveland, Ohio 44135, December 31, 1994

\section{References}

1. Frössling, N.: Evaporation, Heat Transfer, and Velocity Distribution in Two-Dimensional and Rotationally Symmetrical Laminar BoundaryLayer Flow. NACA TM-1432, 1958.

2. Yeh, F.C., et al.: High Reynolds Number and Turbulence Effects on Aerodynamics and Heat Transfer in a Turbine Cascade. AIAA Paper 932252, 1993.

3. Zimmerman, D.R.: Laser Anemometer Measurements at the Exit of a T63-C20 Combustor. (DDA-RN-79-4, Detroit Diesel Allison, NASA Contract NAS3-21267),NASA CR-159623, 1979.

4. Goebel, S.G., et al.: Measurements of Combustor Velocity and Turbulence Profiles. ASME Paper 93-GT-228, 1993.

5. Morkovin, M.V.: On the Question of Instabilities Upstream of Cylindrical Bodies. NASA CR-3231, 1979.

6. Hanarp, L.R.; and Suden, B.A.: Structure of the Boundary Layers on a Circular Cylinder in the Presence of Free Stream Turbulence. Lett Heat Mass Transfer, vol. 9, May-June 1982, pp. 169-177. 
7. Van Fossen, G.J.; and Simoneau, R.J.: A Study of the Relationship Between Free-Stream Turbulence and Stagnation Region Heat Transfer. J. Heat Transfer, vol. 109, no. 1, 1987, pp. 10-15.

8. Rigby, D.L.; and Van Fossen, G.J: Increased Heat Transfer to a Cylindrical Leading Edge Due to Spanwise Variations in the Free-Stream Velocity. AIAA Paper 91-1739, 1991.

9. Giedt, W.H.: Effect of Turbulence Level of Incident Air Stream on Local Heat Transfer From Cylinders. J. Aeronaut. Sci., vol. 18, no. 11, 1951, pp. $725-730$.

10. Seban, R.A.: The Influence of Free Stream Turbulence on the Local Heat Transfer From Cylinders. J. Heat Transfer, vol. 82c, May 1960, pp. 101-107.

11. Zapp, G.M.: The Effect of Turbulence on Local Heat Transfer Coefficient Around a Cylinder Normal to an Air Stream. M.S. Thesis, Oregon State College, Corvallis, OR, June1950.

12. Schnautz, J.A.: Effect of Turbulence Intensity on Mass Transfer from Plates, Cylinders, and Spheres in Air Streams. PhD Thesis, Oregon State College, Corvallis, OR, June 1958.

13. Smith, M.C.; and Kuethe, A.M.: Effects of Turbulence onLaminar Skin Friction and Heat Transfer. Phys. Fluids, vol. 9, no. 12, Dec. 1966, pp. 2337-2344.

14. Kestin, J.; and Wood, R.T.: The Influence of Turbulence on Mass Transfer From Cylinders. J. Heat Transfer, vol. 93, Nov. 1971, pp. $321-327$.

15. Mehendale, A.B.; Han, J.C.; and Ou, S.: Influence of High Mainstream Turbulence on Leading Edge Heat Transfer. J. Heat Transfer, vol. 113, Nov. 1991, pp. 843-850.

16. Lowery, G.W.; and Vachon, R.I.: Effect of Turbulence on Heat Transfer From Heated Cylinders. Int. J. Heat Mass Transfer, vol. 18, no. 11, 1975, pp. 1229-1242.

17. O'Brien, J.E.; and Van Fossen, G. J.: The Influence of Jet-Grid Turbulence on Heat Transfer from the Stagnation Region of a Cylinder in Crossflow. NASA TM-87011, 1985.

18. Yardi, N.R.; and Sukhatme, S.P.: Effects of Turbulence Intensity and Integral Length Scale of a Turbulent Free Stream on Forced Convection Heat Transfer From a Circular Cylinder in Cross Flow. International Heat Transfer Conference, 6th, Proceedings, General Papers, vol. 5: Nuclear Reactor Heat Transfer, Forced Convection, Paper FC(b)-29, Hemisphere Publ., Washington, D.C., 1978, pp. 347-352.

19. Dyban, YE.P.; Epic, E.YA.; and Kozlova L.G.: Heat Transfer in the Vicinity of the Front Stagnation Point of a Cylinder in Transverse Flow. Heat Transfer-Soviet Research, vol. 7, no. 2, Mar.-Apr., 1975, pp. 70-73.

20. Ames, F.E.: Heat Transfer with High Intensity, Large Scale Turbulence: The Flat Plate Turbulent Boundary Layer and the Cylindrical Stagnation Point. PhD Thesis, Stanford University, Stanford, CA, 1990.

21. Hunt, J.C.R.: A Theory of Turbulent Flow Round Two-Dimensional Bluff Bodies. J. Fluid Mech., vol. 61, pt. 4, Dec. 18, 1973, pp. 625-706.
22. Hunt, J.C.R.; and Graham, J.M.R.: Free-Stream Turbulence Near Plane Boundaries. J. Fluid Mech., vol. 84, Jan. 30, 1978, pp. 209-235.

23. McFarland, E.R.: A FORTRAN Computer Code for Calculating Flows in Multiple-Blade-Element Cascades. NASA TM-87104, 1985.

24. Van Fossen, G.J., et al.: Heat Transfer Distributions Around Nominal Ice Accretion Shapes Formed on a Cylinder in the NASA Lewis Icing Research Tunnel. AIAA Paper 84-0017, 1984 (also NASA TM-83557, 1984).

25. Miller, R.L.: ESCORT: A Data Acquisition and Display System to Support Research Testing. NASA TM-78909, 1978.

26. DISA Type 55M25 Linearizer Instruction Manual, published by DISA Information Department, p. 7, example 1.

27. Champagne, F.H.; Sleicher, C.A.; and Wehrmann, O.H.: Turbulence Measurements with Inclined Hot Wires. J. Fluid Mech., vol. 28, Apr. 12, 1967, pp. 153-182.

28. Dryden H.L., et al.: Measurements of Intensity and Scale of Wind-Tunnel Turbulence and their Relation to the Critical Reynolds Number of Spheres. NACA Report No. 581, 1937.

29. Comte-Bellot, G.; and Corrsin, S.: Simple Eulerian Time Correlation of Full and Narrow-Band Velocity Signals in Grid-Generated, 'Isotropic' Turbulence. J. Fluid Mech., vol. 48, pt. 2, 1971, pp. 273-337, Appendix E.

30. Wiegland, R.A.: Grid Generated Turbulence With and Without Rotation About the Streamwise Direction. PhD Thesis, Illinois Institute of Technology, Chicago, IL, 1978.

31. Tan-Atichat, J.: Effects of Axisymmetric Contractions on Turbulence of Various Scales. PhD Thesis, Illinois Institute of Technology, Chicago, IL, 1980.

32. Rigby, D.L.; and Van Fossen G.J.: Increased Heat Transfer to Elliptical Leading Edges Due to Spanwise Variations in the Freestream Momentum: Numerical and Experimental Results. AIAA Paper 92-3070, 1992.

33. Eckert, E.R.G.; and Drake, R.M.: Heat and Mass Transfer. McGraw-Hill Book Co., New York, 2nd ed., 1959, p. 266.

34. Hillsenrath, J., et al.: Tables of Thermal Properties of Gases. NBS Circular 564, Nov. 1955.

35. Kline, S.J.; and McClintock, F.A.: Describing Uncertainties in SingleSample Experiments. Mech. Eng., vol. 75, Jan. 1953, pp. 3-8.

36. Yavuzkurt, S.: A Guide to Uncertainty Analysis of Hot-Wire Data. J. Fluids Eng., vol. 106, 1984, pp. 181-186.

37. Baines, W.D..; and Peterson, E.G.: An Investigation of Flow Through Screens. Trans. ASME, vol. 72, July 1951, pp. 468-480.

38. Roach, P.E.: The generation of Nearly Isotropic Turbulence By Means of Grids. Int. J. Heat Fluid Flow, vol. 8 no. 2, June 1987, pp 82-92.

39. Naudascher, E.; and Farell, C.: Unified Analysis of Grid Turbulence. Proc. ASCE, J. Eng. Mech. Div., vol. 96, Apr. 1970, pp. 121-141.

40. Bearman, P.W.: Some Measurements of the Distortion of Turbulence Approaching a Two-Dimensional Bluff Body. J. Fluid Mech., vol. 53, pt. 3, June 13,1972 , pp. $451-467$ 
TABLE I.-TURBULENCE GRID DIMENSIONS

\begin{tabular}{|c|c|c|c|}
\hline Grid & $\begin{array}{c}\text { Bar width, } b, \\
\text { cm (in.) }\end{array}$ & $\begin{array}{c}\text { Mesh spacing } \\
\text { to bar width } \\
\text { ratio, } M / b\end{array}$ & $\begin{array}{c}\text { Open area, } \\
\text { percent }\end{array}$ \\
\hline G0 & No grid & - & - \\
\hline G1 & $1.270(0.500)$ & 4.5 & 60.5 \\
\hline G2 & $0.635(0.250)$ & 4.5 & 60.5 \\
\hline G3 & $0.318(0.125)$ & 4.5 & 60.5 \\
\hline G4 & $0.159(0.630)$ & 4.5 & 60.5 \\
\hline G5 ${ }^{\mathrm{a}}$ & $0.051(0.020)$ & 12.5 & 92.0 \\
\hline
\end{tabular}

${ }^{\mathrm{a}}$ Array of parallel wires

TABLE II.-DIMENSIONLESS SURFACE DISTANCES TO CENTER OF HEAT FLUX GAUGES MEASURED FROM STAGNATION POINT, $s / R$

\begin{tabular}{|c|c|c|c|c|c|}
\hline \multirow[t]{3}{*}{ Gauge } & \multirow[t]{2}{*}{$s / R$} & \multirow[t]{3}{*}{ Gauge } & \multicolumn{3}{|c|}{$s / R$} \\
\hline & & & \multicolumn{3}{|c|}{ Model ratio } \\
\hline & $\begin{array}{c}\text { Model } \\
\text { ratio } \\
1: 1\end{array}$ & & $1.5: 1$ & $2.25: 1$ & $3: 1$ \\
\hline 10 & 0.000 & 15 & 0.000 & 0.000 & 0.000 \\
\hline 9,11 & \pm 0.152 & 14,16 & \pm 0.151 & \pm 0.152 & \pm 0.151 \\
\hline 8,12 & \pm 0.303 & 13,17 & \pm 0.303 & \pm 0.304 & \pm 0.301 \\
\hline 7,13 & \pm 0.455 & 12,18 & \pm 0.456 & \pm 0.457 & \pm 0.452 \\
\hline 6,14 & \pm 0.607 & 11,19 & \pm 0.607 & \pm 0.610 & \pm 0.604 \\
\hline 5,15 & \pm 0.759 & 10,20 & \pm 0.759 & \pm 0.762 & \pm 0.755 \\
\hline 4,16 & \pm 0.910 & 9,21 & \pm 0.910 & \pm 0.915 & \pm 0.907 \\
\hline 3,17 & \pm 0.062 & 8,22 & \pm 1.062 & \pm 1.068 & \pm 1.058 \\
\hline 2,18 & \pm 1.214 & 7,23 & \pm 1.214 & \pm 1.221 & \pm 1.210 \\
\hline $1^{\mathrm{a}}, 19^{\mathrm{a}}$ & \pm 1.365 & 6,24 & \pm 1.366 & \pm 1.374 & \pm 1.361 \\
\hline & & 5,25 & \pm 1.518 & \pm 1.527 & \pm 1.512 \\
\hline & & 4,26 & \pm 1.670 & \pm 1.680 & \pm 1.664 \\
\hline & & 3,27 & \pm 1.822 & \pm 1.833 & \pm 1.816 \\
\hline & & 2,28 & \pm 1.975 & \pm 1.986 & \pm 1.968 \\
\hline & & $1^{a}, 29^{a}$ & \pm 2.127 & \pm 2.140 & \pm 2.119 \\
\hline
\end{tabular}

${ }^{\mathrm{a}}$ Guard heaters. 
TABLE III.-UNCERTAINTY IN FRÖSSLING NUMBER

\begin{tabular}{|c|c|c|c|c|}
\hline \multirow{3}{*}{$\begin{array}{c}\text { Error } \\
\text { component at } \\
20: 1 \text { odds, } \\
\text { percent }\end{array}$} & \multicolumn{2}{|c|}{ Bias error } & \multicolumn{2}{|c|}{ Precision error } \\
\hline & \multicolumn{4}{|c|}{ Experimental velocity range } \\
\hline & Maximum & Minimum & Maximum & Minimum \\
\hline$\delta\left(q_{E I}\right) / q_{E I}$ & 0.21 & 0.25 & 3.04 & 2.97 \\
\hline$\delta\left(q_{\mathrm{rad}}\right) / q_{\mathrm{rad}}$ & 20.47 & 20.47 & 0.76 & 0.64 \\
\hline$\delta\left(q_{\text {gap }}\right) / q_{\text {gap }}$ & 13.80 & 13.40 & 0.76 & 0.67 \\
\hline$\delta\left(q_{\text {net }}\right) / q_{\text {net }}$ & 1.24 & 1.70 & 3.31 & 3.35 \\
\hline$\delta(d) / d$ & 0.12 & 0.12 & 0.00 & 0.00 \\
\hline$\delta(A) / A$ & 1.08 & 1.08 & 0.00 & 0.00 \\
\hline$\delta(\Delta T) / \Delta T$ & 4.68 & 4.68 & 0.77 & 0.68 \\
\hline$\delta(k) / k$ & 0.00 & 0.00 & 0.00 & 0.00 \\
\hline$\delta\left(R e_{d}\right) / R e_{d}$ & 5.76 & 11.91 & 0.10 & 2.15 \\
\hline$\delta(F r) / F r$ & 5.74 & 7.84 & 3.40 & 3.58 \\
\hline $\begin{array}{c}\text { Combined } \\
\text { uncertainty in } \\
F r(s / R) \text {, percent }\end{array}$ & 6.67 & 8.62 & --- & $\ldots$ \\
\hline
\end{tabular}

TABLE IV.- TURBULENCE INTENSITY AND LENGTH SCALE (HOT WIRE) DATA UNCERTAINTY

\begin{tabular}{|c|c|c|c|c|}
\hline \multirow{2}{*}{$\begin{array}{c}\text { Error component at } \\
20: 1 \text { odds, } \\
\text { percent }\end{array}$} & \multicolumn{3}{|c|}{ Bias error } & \multicolumn{2}{c|}{ Precision error } \\
\cline { 2 - 5 } & \multicolumn{4}{|c|}{ Experimental velocity range } \\
\cline { 2 - 5 } & Maximum & Minimum & Maximum & Minimum \\
\hline$\delta\left(U_{\text {caljet }}\right)$ & 3.41 & 15.34 & 0.10 & 0.32 \\
\hline$\delta($ linearizer fit) & 0.77 & 0.77 & 0.77 & 0.77 \\
\hline$\delta\left(T u, \Lambda_{x}\right)$ & 3.50 & 15.36 & --- & - \\
\hline
\end{tabular}


TABLE V.-POWER LAW CURVE FITS OF TURBULENCE INTENSITY AND INTEGRAL LENGTH SCALE DATA

$$
T u=a\left(\frac{x}{b}\right)^{m} \quad \frac{\Lambda_{x}}{b}=\mathrm{I}\left(\frac{x}{b}\right)^{p}
$$

\begin{tabular}{|c|c|c|c|c|c|c|c|c|}
\hline Grid & $\begin{array}{c}\text { Velocity, } \\
\mathrm{m} / \mathrm{sec}\end{array}$ & $\begin{array}{c}\text { Reynolds } \\
\text { number, } \\
R e_{b}\end{array}$ & $a$ & $m$ & $r_{T u}$ & $I$ & $p$ & $r_{\Lambda_{x} J}$ \\
\hline \multirow{2}{*}{$\mathrm{G} 1$} & 43.9 & 38650 & 206.10 & -0.875 & 0.9950 & 0.240 & 0.500 & 0.6668 \\
& 22.5 & 18000 & 206.10 & -0.875 & 0.9950 & 0.240 & 0.500 & 0.6668 \\
& 10.9 & 7934 & 206.10 & -0.875 & 0.9950 & 0.240 & 0.500 & 0.6668 \\
\hline \multirow{2}{*}{ G2 } & 43.9 & 17190 & 146.3 & -0.780 & 0.9987 & 0.272 & 0.500 & 0.8564 \\
& 22.5 & 9514 & 135.3 & -0.758 & 0.9989 & 0.272 & 0.500 & 0.8564 \\
& 10.9 & 4452 & 138.9 & -0.778 & 0.9986 & 0.272 & 0.500 & 0.8564 \\
\hline \multirow{2}{*}{ G3 } & 43.9 & 8935 & 132.2 & -0.765 & 0.9997 & 0.264 & 0.500 & 0.9799 \\
& 22.5 & 4780 & 156.3 & -0.824 & 0.9995 & 0.264 & 0.500 & 0.9799 \\
& 10.9 & 2470 & 149.4 & -0.830 & 0.9992 & 0.264 & 0.500 & 0.9799 \\
\hline \multirow{2}{*}{ G4 } & 43.9 & 4571 & 80.15 & -0.665 & 0.9998 & 0.303 & 0.500 & 0.8838 \\
& 22.5 & 2297 & 89.46 & -0.693 & 0.9995 & 0.303 & 0.500 & 0.8838 \\
& 10.9 & 1174 & 75.05 & -0.677 & 0.9997 & 0.303 & 0.500 & 0.8838 \\
\hline \multirow{2}{*}{ G5 } & 43.9 & 1634 & 23.68 & -0.470 & 0.9852 & 4.658 & 0.116 & 0.8560 \\
& 22.5 & 792 & 23.38 & -0.453 & 0.9848 & 3.255 & 0.199 & 0.9572 \\
& 10.9 & 340 & 52.73 & -0.568 & 0.9975 & 10.011 & 0.051 & 0.4359 \\
\hline
\end{tabular}


TABLE VI.-FRÖSSLING NUMBER FOR CIRCULAR LEADING-EDGE MODEL (1:1).

\begin{tabular}{|c|c|c|c|c|c|c|c|c|c|c|c|c|c|c|c|c|c|c|c|c|c|}
\hline & & & & \multirow[t]{3}{*}{ /d } & \\
\hline & & & & & & 3 & 4 & 5 & 6 & 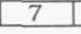 & 8 & 9 & & h & 2 & 3 & 4 & 15 & 6 & 7 & 8 \\
\hline & & & & & & & & & & & & & & & & & & & & & \\
\hline & & & & & & & & & & & 913 & 0.936 & 913 & 912 & & & & & & & 655 \\
\hline & & & & & & 724 & 303 & 358 & 834 & 907 & 894 & 904 & & 887 & & & 879 & & 833 & 704 & \\
\hline & & & & & & 716 & & 353 & 863 & & & 918 & & & & & & & & & \\
\hline & & & & & & & & & & & & 907 & & & & & & & & & \\
\hline & & & & & & & & & & & & & & & & & & & & & \\
\hline & & & & & & 02 & & & & & & 921 & & & & & & & & & \\
\hline 5 & 50 & & & 308 & 506 & 674 & 763 & 829 & 0.819 & 880 & 392 & 893 & & 861 & 885 & 876 & 859 & 781 & 189 & 686 & \\
\hline 38 & 56 & & & 308 & 512 & 692 & 786 & 821 & 0.858 & 885 & 898 & 0.912 & & 907 & 910 & 887 & 854 & .816 & 783 & 6914 & .010 \\
\hline & 4] & & & 308 & 330 & 716 & 793 & 834 & 871 & 899 & 918 & 0.927 & & 921 & 930 & 908 & 857 & 830 & .80 & 718 & 0 \\
\hline & & & & & & & & & & & & & & & & & & & & & \\
\hline & & & & & & 29 & & & 378 & 03 & & & & & 930 & & & & & & \\
\hline & & & & 223 & & 067 & 162 & 205 & 257 & 346 & & 450 & & 1.460 & 412 & 1 & 284 & 227 & & & \\
\hline & 2 & 1 & & 223 & 51 & 037 & 139 & 180 & 230 & 303 & 327 & 398 & & 1.418 & 403 & 357 & 286 & 217 & 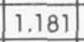 & 070 & \\
\hline & 8 & 1 & & 223 & 446 & 001 & 131 & 161 & \begin{tabular}{|l|}
1.221 \\
\end{tabular} & 292 & 317 & 406 & & 405 & 388 & 349 & 265 & 198 & 63 & 050 & 969 \\
\hline & 35 & 6 & & 223 & 08 & 985 & 119 & 143 & 1.202 & 278 & 274 & 373 & & 362 & 353 & 328 & 241 & 67 & & 014 & 4 \\
\hline & & & & 0 & & & & & & & & & & & & & & & & & \\
\hline & & & & & & & & & & & & & & & & & & & & & \\
\hline & & & & & & 4 & & & 205 & & & & & & & & & & & & \\
\hline & & & & & & & & & 232 & & & 399 & & & 397 & & & & & & \\
\hline & 5 & 1 & & 223 & 30 & 335 & .132 & 75 & 242 & 305 & & 424 & & 446 & 422 & & 292 & 231 & & & \\
\hline & & & & 223 & 974 & 363 & 1.144 & 98 & 1.264 & 335 & 55 & 455 & & 473 & 433 & 53 & 286 & 233 & & & \\
\hline & & & & 232 & 022 & 99 & 1.214 & 58 & 1.316 & 106 & & 524 & & & 488 & & & 72 & & & \\
\hline & & & & & 82 & & 1.176 & & & & & & & & & & & & & & \\
\hline & & & & & & & & & & & & & & & & & & & & & \\
\hline & & & & & & 4 & & & 5 & 62 & & & & & & & & & & & \\
\hline & & & & & & 28 & 045 & & 122 & 86 & & 234 & & & 217 & & & & & & \\
\hline & & 1 & & 232 & 828 & 931 & 1.030 & 073 & 131 & 1.171 & 180 & 1.224 & & 222 & 229 & 1.208 & 135 & 088 & & 83 & \\
\hline & & & & c & 378 & 885 & 1.071 & 119 & 190 & 1.244 & 263 & 321 & & & 20 & 1.271 & & 54 & & & \\
\hline & & & & & & & & & & & & & & & & & & & & & \\
\hline & & & & & & & & & & & & & & & & & & & & & \\
\hline & & & & & & & & & & & & 99 & & & & & & & & & \\
\hline & & & & & & & & & & & & 97 & & & & & & & & & \\
\hline & & & & & & 8 & 1.197 & & & 349 & 1.409 & 483 & & 1.491 & 475 & & & & & & \\
\hline & & 1 & & C & & 064 & 1.166 & 223 & 258 & 1.320 & 1.374 & 427 & & 1.449 & 431 & 1.370 & 1.316 & & & & וט \\
\hline & & & & 202 & & 029 & \begin{tabular}{|l|l|} 
\\
\end{tabular} & & 43 & 296 & & 371 & & 1.389 & & 369 & 269 & & & & 의 \\
\hline & & & & & & 49 & 1.065 & & & & & & & & & & & & & & \\
\hline & & & & & & & 1.0 & & & 1.192 & & & & & & & & & & & \\
\hline & & & & & 934 & & 1.126 & & & 1.298 & & & & & & & & & & & \\
\hline & & & & & 981 & 064 & 1.169 & 1.221 & & 1.333 & 1.379 & 453 & & \begin{tabular}{|l|}
1.478 \\
\end{tabular} & & 473 & 1.32 & & & 0 & \\
\hline & & & & & & & 1.201 & & & & & & & & & & 1.348 & & 4 & 13 & 06 \\
\hline & 75 & & & 202 & 050 & 130 & 217 & 272 & 336 & 389 & 1.424 & 514 & & 1.545 & 520 & & 1.37 & & & & \\
\hline & & & & & & & 1.2 & & & & & & & & & & & & & & \\
\hline & & & & & & & & & & & & & & & & & & & & & \\
\hline & & & & & & & & 30 & & & & & & & & & & & & & \\
\hline & & & & & 932 & 026 & 1.1 & 1.194 & & & & & & & & & 45 & & & & 95 \\
\hline & & & & & 840 & 839 & 1.039 & 1.086 & & & & & & & & & 1.156 & 1 & & 94 & 86 \\
\hline & & & & 212 & 842 & 845 & 33 & 1.089 & & & & & & 1.246 & 66 & 9 & 1.152 & 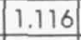 & & 95 & 87 \\
\hline & & & & & & & & & & & & & & & & & & & & & \\
\hline & & & & & & & & & & & 1.379 & & & & & & & & & & \\
\hline & & & & & & & & & & & & & & & & & & & & & \\
\hline & & & & & 014 & 1.098 & & 1.254 & & & 1.431 & 1.515 & & 1.512 & 174 & 389 & 1 & 61 & 4 & & 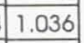 \\
\hline & & & & & 894 & 0.985 & & 1.128 & 1.196 & 1.250 & 1.279 & 1.358 & & 1.357 & 1.322 & 274 & 1.18 & .143 & & 99 & 90 \\
\hline & & & & & 873 & 0.969 & .060 & 1.140 & & & & & & & 31 & & 1. & 44 & & & 92 \\
\hline & & & & & & & & & & & & & & & & & & & & & \\
\hline & & & & & & & & & & & & & & & & 4 & & & & & \\
\hline & & & & & & 0.895 & & & & & & & & & & & & & & & \\
\hline & & & & & 780 & 0.892 & 17 & 37 & & & & 1.192 & & & & & & & & & \\
\hline & 3014 & & & & 822 & 0.940 & 1.024 & 1.083 & 1.151 & & 1.227 & 1.281 & & 1.272 & 1.269 & & & & & & \\
\hline & 89 & & & i & 856 & 0.963 & 1.059 & 1.116 & \begin{tabular}{|l|}
1.184 \\
\end{tabular} & 1.226 & 1.267 & 1.328 & 334 & 1.326 & 1.312 & 1.257 & 1.179 & 1.133 & .08 & 97 & .88 \\
\hline & & & & & & 0.977 & & & & 1.240 & 1.283 & 1.354 & & & & & & & & 91 & 90 \\
\hline & & & & & & & & & & & & & & & & & & & & & \\
\hline
\end{tabular}


TABLE VI.-CONTINUED.

\begin{tabular}{|c|c|c|c|c|c|c|c|c|c|c|c|c|c|c|c|c|c|c|c|c|c|}
\hline & \multirow[t]{3}{*}{$e_{d}$} & \multirow[t]{3}{*}{ Grid } & & \multirow[t]{3}{*}{$\Lambda_{\mathrm{x}} / \mathrm{d}$} & \multicolumn{17}{|c|}{ Gauge } \\
\hline & & & & & 2 & 3 & 4 & 5 & 6 & 7 & 8 & & & & 12 & 13 & 14 & 15 & $\sqrt{16}$ & 17 & \\
\hline & & & & & & & & & & & & Fröss] & ling $\mathrm{nu}$ & umber & & & & & & & \\
\hline 264 & 801 & G1 & 44 & 269 & 902 & \begin{tabular}{|l|}
1.005 \\
\end{tabular} & & 1.148 & 1.210 & & & 1.366 & 1.399 & 1.361 & 1.342 & 1.297 & 1.222 & & & & \\
\hline & & & & & 890 & 976 & & 1.143 & & & .294 & & & & & & & & & & \\
\hline & & & & & & & & & & & & & & & & & & & & & \\
\hline & & & & & & & & & & & & & & & & & & & & & \\
\hline & & & & & 29 & 921 & .039 & & & & 1.188 & 1.222 & & .203 & & & 153 & .072 & & 935 & \\
\hline 269 & 450 & & 62 & 269 & 82 & 909 & .027 & .059 & 134 & & 177 & 1.214 & 1.221 & 1.201 & 1.222 & 195 & 135 & .083 & 041 & 942 & 84 \\
\hline 270 & & & 45 & 269 & 842 & 959 & .043 & .088 & & & 231 & .268 & 294 & 271 & .276 & & & .122 & & 96 & 8 \\
\hline 271 & & & & 269 & 661 & 954 & 056 & 107 & & & & & & & & & & & & & \\
\hline 72 & & & & & & & 068 & & & & & & & & & & & & & & \\
\hline & & & & & & & & & & & & & & & & & & & & & \\
\hline & & & & & 04 & & & & & & & & & & & & & & & & \\
\hline & & & & & 344 & 347 & & 103 & & & 265 & 297 & 320 & & & & 183 & & & 96 & \\
\hline 997 & & & & 290 & 829 & 942 & 034 & 1.102 & & 206 & 247 & 1.286 & 294 & 283 & 279 & 249 & 160 & .108 & 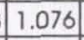 & 94 & 86 \\
\hline 98 & & & 27 & 290 & 821 & 917 & 019 & 1.093 & & & & & & & & & & & & & \\
\hline 99 & & & & & 78 & & & & & & & & & & & & & & & & \\
\hline & & & & & $6 c$ & & 70 & & & & & & & & & & & & & & \\
\hline & & & & & & & & & & & & & & & & & & & & & \\
\hline & & & & & 324 & 831 & 233 & 1.084 & & & 1.232 & & & 288 & & & & & & & \\
\hline & & & & 90 & 343 & 942 & 037 & 1.097 & & 215 & 1.254 & 16 & & 322 & & 242 & 170 & & & 96 . & 87 \\
\hline 04 & 88 & & & 290 & 63 & & & 1. & & & & & & & & & & & & & \\
\hline & & & & & & & & & & & & & & & & & & & & & \\
\hline & & & & & & & & & & & & & & & & & & & & & \\
\hline & & & & & & & 7 & 992 & & & & & & & & & & & & & \\
\hline & & & & & & & & 072 & & & & & & & & & & & & & \\
\hline & & & & ( & 59 & 370 & 962 & 009 & & & & & & & & & & & & & \\
\hline & & & & 297 & 766 & 859 & 961 & .998 & & 1.090 & & & & & & & & & & & 78 \\
\hline & & & & 997 & & 908 & 1.015 & 1.054 & & & & & & & & & & & & 9 & \\
\hline & & & & & & 920 & 1.022 & & & & & & & & & & & & & & \\
\hline & & & & & & & & & & & & & & & & & & & & & \\
\hline & & & & & & & & & & & & & & & & & & & & & \\
\hline & & & & & & & & & & & & & & & & & & & & & \\
\hline & & & & & & & 111 & & & & & & & & & & & & & 22 & \\
\hline & & & & & & & 34 & & & & & & & & & & & & & 2 & \\
\hline & & & & & & & 1.072 & & & & & & & & & & 91 & & & & \\
\hline & & & & & & & 1.0 & & & & & & & & & & & & & & \\
\hline & & & & & & & 1.0 & & & & & & & & & & 6 & & & & \\
\hline & & & & & & & & & & & & & & & & & & & & & \\
\hline & & & & & & & 1.061 & & & & & & & & & & & & & 11 & 363 \\
\hline & & & & & & & 558 & & & & & & & & & & & & & 86 & 855 \\
\hline & & & & & & & 1.036 & & & & & & & & & & 61 & & 4 & & \\
\hline & & & & & & & 1.00 & & & & & & & & & & 37 & & & & \\
\hline & & & & & & & 0.95 & & & & & & & & & & 37 & & & & \\
\hline & & & & & & & 5 & & & & & & & & & & 5 & & & & \\
\hline & & & & & & & & & & & & & & & & & & & & & \\
\hline & & & & & & & 1.017 & & & & & & & & & & & & & 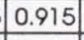 & \\
\hline & & & & & & & & & & & & & & & & & 75 & & 8 & & \\
\hline & & & & & & & 1.060 & & & & & & & & & & 74 & & & & \\
\hline & & & & & & & & & & & & & & & & & 9 & & & 1 & \\
\hline & & & & & & & 1.034 & & & & & & & & & & 63 & & & & \\
\hline & & & & & & & 1.006 & & & & & & & & & & 43 & & 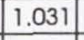 & $\underline{0}$ & 830 \\
\hline & & & & & 756 & \begin{tabular}{|l|}
0.850 \\
\end{tabular} & 0.950 & 995 & & & 099 & & & 149 & & 1.127 & .079 & & 0 & 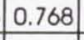 & 774 \\
\hline & & & & & & & 1.0 & & & & & & & & & & 09 & & & 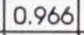 & \\
\hline & & & & & & & & & & & & & & & & & 06 & & & 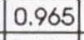 & \\
\hline & & & & & & & & & & & & & & & & & & & & & \\
\hline & & & & & & & & & & & & & & & & & 67 & & & & \\
\hline & & & & & & & 995 & & & & 1.141 & & & & & & .104 & & & 1 & 93 \\
\hline & & & & & & & 0.987 & 033 & & & 160 & & & 189 & & & .098 & & & 393 & 798 \\
\hline & & & & & & \begin{tabular}{|l|}
0.918 \\
\end{tabular} & 1.021 & .068 & & & & & & & & & & & & 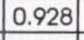 & 848 \\
\hline & & & & & & & 1.035 & 36 & & & & & & & & & & & & & \\
\hline & & & & & & & 1.040 & \begin{tabular}{|l|}
1.097 \\
\end{tabular} & & & & & & & & & & & & & \\
\hline & & & & & & & & 1.102 & & & & & & & & & & & & & \\
\hline
\end{tabular}


TABLE VI.-CONTINUED

\begin{tabular}{|c|c|c|c|c|c|c|c|c|c|c|c|c|c|c|c|c|c|c|c|c|c|}
\hline & & & & & \multicolumn{17}{|c|}{ Gau } \\
\hline & & & & & 2 & 3 & 4 & 5 & 6 & 7 & 8 & & & hat & 12 & 13 & 14 & 15 & 16 & 17 & 8 \\
\hline & & & & & & & & & & & & Frössli & s nur & Imber & & & & & & & \\
\hline & & & & & 837 & 26 & & .088 & 156 & 1.236 & & 305 & 1.299 & 1.301 & 82 & & 162 & 092 & 1.067 & 7 & .865 \\
\hline & & & & & 46 & 17 & & .095 & & .238 & 230 & 304 & & 1.309 & & & & & & & \\
\hline & & & & & & & & 1.086 & & & & & & & & & & & & & \\
\hline & & & & & & & & 070 & & & & & & & & & & & & & \\
\hline & & & & & 97 & & & 1.026 & & & & & & & & & & & & & \\
\hline & & & & 90 & 766 & & & 1.014 & & & & & & 1.171 & & & & & & & \\
\hline & & & & 90 & 807 & 809 & 014 & 1.075 & & 200 & 214 & & & 1.257 & & 206 & & & 035 & 72 & 020 \\
\hline & & & & 90 & 820 & 921 & 029 & 1.091 & 159 & 219 & 237 & 1.295 & & 1.292 & 287 & 242 & 157 & 115 & 056 & 94 & 850 \\
\hline & & & & 0 & 830 & 941 & 38 & 1.098 & & 223 & & & & 1.326 & 298 & 254 & 173 & 124 & 065 & 95 & .861 \\
\hline & & & & & 42 & 953 & & 12 & & & & & & & & & & & & & \\
\hline & & & & & 31 & & & & & & & & & & & & & & & & \\
\hline & & & & & 904 & 999 & 05 & 1.159 & & 88 & 325 & 93 & & 1.410 & 390 & 307 & 288 & 183 & & & 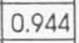 \\
\hline & 89 & & & 61 & 875 & 948 & 584 & 119 & 177 & 237 & \begin{tabular}{|l|}
1.277 \\
\end{tabular} & 1.324 & & 1.345 & 1.329 & 314 & .229 & 137 & 127 & 981 & .905 \\
\hline & & & & & 865 & 932 & 60 & 094 & & 219 & 1.238 & 282 & & 1.288 & 1.307 & 265 & 1.208 & .127 & 102 & 95 & 880 \\
\hline & & & & & 09 & 891 & & & & & & & & & & & & & & & \\
\hline & & & & & 96 & 382 & & 034 & & & & & & & & & & & & & \\
\hline & & & & & 27 & 34 & & 091 & & & & 292 & & .303 & & & & & & & \\
\hline & & & & & 58 & 44 & 53 & 106 & & & & 327 & & 1.350 & & & & 154 & & & \\
\hline & & & & & 373 & 977 & 774 & 127 & & & .299 & & & .402 & & & & .180 & & & \\
\hline & 861 & & & & 396 & 001 & 089 & 45 & 212 & 269 & 1.309 & 398 & & 1.426 & 398 & & 255 & 191 & & & \\
\hline & 865 & & & & 913 & 006 & 120 & 170 & 38 & & & 1.408 & & 405 & & & 246 & 162 & & & 92 \\
\hline & 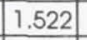 & & & & 98 & 989 & 092 & & & & & 1.361 & & & & & 207 & 47 & & & \\
\hline & & & & & & 943 & & & & & & & & & & & & & & & \\
\hline & & & & & & 226 & & & & & & & & & & & & & & & \\
\hline & & & & & & 88 & 08 & & & & & & & & & & & & & & \\
\hline & & & & & 888 & 880 & 990 & 045 & 1.106 & 57 & & 1.201 & & 195 & 191 & & & & & & \\
\hline & & & & & 831 & 940 & 040 & 990 & 1.169 & 223 & & 1.296 & & & & & 73 & & & & \\
\hline & & & & & 346 & 954 & 050 & & & 50 & & 1.339 & & 328 & 1.315 & 263 & 82 & 1. & 80 & & \\
\hline & & & & & & 966 & 063 & & 1.206 & & & & & & & & & 1 & & & \\
\hline & & & & & & 881 & 082 & & & & & & & & & & & & & & \\
\hline & & & & & & 45 & & 5 & & & & & & & & & & & & & \\
\hline & & & & & 0 & 917 & 015 & 883 & & 186 & & & & & 259 & & & & & & \\
\hline & & & & & 807 & 900 & 995 & 059 & 1.127 & 169 & & 1.250 & & & 224 & 1.185 & & & & & \\
\hline & & & & & & 907 & 001 & 770 & & 175 & & 1.248 & & & & & 61 & 7 & & & \\
\hline & & & & & & 367 & 946 & & & 04 & & & & & & & & 7 & & & \\
\hline & & & & & & & 943 & & & & & & & & & & & 94 & & & \\
\hline & & & & & & & & & & & & & & & & & & & & & \\
\hline & & & & & & 908 & 006 & 2 & & & & & & & & & & & & & \\
\hline & & & & & & 912 & 0.997 & 32 & & 77 & & & & & 259 & 1.208 & & 1 & & & \\
\hline & & & & & & & 1.020 & & & 200 & & 293 & & 295 & 281 & 225 & 58 & & 550 & & 85 \\
\hline & & & & & 25 & 924 & 1.018 & 075 & & & & 270 & & 260 & & 207 & & & & & \\
\hline & & & & & & 3 & 1.013 & & & & & & & & & & & & & & \\
\hline & & & & & & 397 & 989 & & & & & & & & & & & & & & \\
\hline & & & & & & & & & & & & & & & & & & & & & \\
\hline & & & & & & & 58 & & & & & & & & & & & 011 & 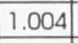 & & I \\
\hline & & & & & & 849 & 0.938 & 994 & \begin{tabular}{|l|}
1.057 \\
\end{tabular} & 1.094 & 105 & 137 & & 1.129 & 1.133 & 1.115 & .050 & .008 & .96 & & \\
\hline & & & & & & 391 & 1.002 & & & & & & & & & & 1 & 1 & & & \\
\hline & & & & & & & & & & & & & & & & & t & & & & \\
\hline & & & & & & & 1.010 & & & & & & & & & & & & & & \\
\hline & & & & & & 927 & 1.018 & & & & & & & & & & & & & & \\
\hline & & & & & & & 1.031 & & & & & & & & 261 & 1.225 & 1.145 & .085 & 1.03 & & 84 \\
\hline & & & & & 814 & 0.917 & 1.016 & 078 & & & 220 & 1.264 & & 253 & 254 & 1.220 & 147 & 086 & 05 & 72 & 84 \\
\hline & & & & & & 897 & 1.005 & 1.057 & & & & & & & & 189 & 20 & 5 & 1.02 & 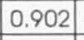 & \\
\hline & & & & & & & 1.013 & & & & & & & & & 01 & & & 1 & & \\
\hline & & & & & & & 0.986 & & & & & & & & & & & & & & \\
\hline & & & & & & 878 & 0.971 & 1.008 & & & & & & & & 1.170 & & .025 & 0.98 & & \\
\hline & & & & & & & 0.989 & 1.047 & & & & & & 1.208 & 1.217 & 1.172 & .108 & 065 & 1.01 & 90 & 81 \\
\hline & & & & 232 & 788 & .901 & 1.001 & 1.054 & 1.127 & 1.169 & 1.189 & 1.235 & & 1.236 & 1.228 & 1.190 & 1.128 & 1.076 & 1.022 & 91 & 82 \\
\hline & & & & & 802 & 912 & 1.005 & 1.069 & & 1.185 & \begin{tabular}{|l|}
1.211 \\
\end{tabular} & 267 & & 1.262 & 1.251 & 1.217 & 1.145 & 1.088 & 1.03 & .92 & 83 \\
\hline & & & & & & & 1.019 & 1.080 & & 1.200 & & & & 1.275 & & 1.216 & 1.135 & 1.092 & 1.03 & 0.92 & 83 \\
\hline & & & & & & & 1.008 & 1.070 & & & & & & & & & & & & & \\
\hline
\end{tabular}


TABLE VI.-CONTINUED.

\begin{tabular}{|c|c|c|c|c|c|c|c|c|c|c|c|c|c|c|c|c|c|c|c|c|c|}
\hline \multirow{3}{*}{$\begin{array}{l}\text { Rd'g } \\
\text { no. }\end{array}$} & \multirow[t]{3}{*}{$e_{d}$} & & \multirow{3}{*}{0} & & \\
\hline & & & & & & & & 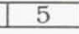 & & & & \begin{tabular}{|l|}
9 \\
\end{tabular} & & 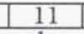 & 12 & 13 & 14 & 15 & 16 & 17 & \\
\hline & & & & & & & & & & & & Fröss & sling nu & umber & & & & & & & \\
\hline & 331 & 2 & 68 & 41] & 300 & 375 & .994 & 1.054 & 117 & 170 & 185 & 1.217 & .214 & 1.212 & & & 1.120 & & & 0.883 & 82 \\
\hline & & & & 241 & 792 & & 1.006 & 1.073 & & & & 1.232 & & 1.220 & & & 1.131 & 1.070 & .040 & 0.905 & \\
\hline 288 & 663 & & & 24 & 778 & .891 & 0.986 & 1.043 & & 1.142 & 1.167 & 1.192 & & 1.188 & & & & 1.042 & 020 & 0.878 & \\
\hline 289 & 144 & & & 241 & 741 & .824 & .935 & 0.987 & & .076 & 1.100 & 1.101 & & 1.097 & & & & & & & \\
\hline & 144 & & & ( & 728 & & & & & & & & & & & & & & & & \\
\hline & & & & & & & 979 & & & & & & & & & & & & & & \\
\hline & & & & & & & 998 & .049 & & & 192 & & & 1.225 & & & .122 & & & 898 & \\
\hline & 37 & & & 241 & 799 & 910 & .003 & .069 & 138 & 188 & 211 & 250 & & 1.250 & 242 & 191 & .126 & .083 & 022 & 909 & 821 \\
\hline 94 & 94 & G2 & & 241 & 800 & .905 & 1.006 & .073 & 136 & 190 & .218 & 258 & & 1.262 & 248 & 202 & .135 & 079 & 022 & 912 & 820 \\
\hline 16 & 387 & G2 & & 130 & 008 & .098 & 1.191 & 1.258 & .327 & 409 & 1.448 & .559 & & 1.541 & 481 & 404 & .319 & & 208 & 089 & \\
\hline & 528 & & & 130 & 888 & & & & & & & & & & & & & & & & \\
\hline & & & & & & & & & & & & & & & & & & & & & \\
\hline & & & & & & & & & & & & & & & & & & & & & \\
\hline & & & & ( & 36 & & 059 & & & & & & & 278 & & & 172 & & & $y<0$ & \\
\hline & 133 & 2 & & 30 & 840 & 943 & 1.055 & 109 & 187 & 227 & & 313 & & 293 & & 261 & 168 & 15 & 076 & 949 & 857 \\
\hline & 355 & 52 & & 130 & 900 & 999 & 1.113 & 178 & 260 & & & & & .427 & & & 45 & & 27 & 05 & 923 \\
\hline & 91 & 52 & & (c & 937 & 037 & 1.151 & 210 & & & & & & & & & & & & & \\
\hline & 26 & 2 & & 30 & & & & & & & & & & & & & & & & & \\
\hline & & & & & & 6 & & & & & & & & & & & & & & & \\
\hline & & & & E & & & & & & & & & & & & & & & & & \\
\hline & & & & 78 & & 38 & 236 & 94 & & 08 & & 298 & & & & & & & 072 & 49 & 865 \\
\hline & & & & 78 & 859 & 958 & 1.060 & 117 & & 233 & & 341 & & & & & 87 & & 080 & 972 & 392 \\
\hline & 377 & & & 122 & 817 & 930 & 1.019 & & & & & 286 & & 1.270 & & & 126 & & 24 & 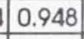 & \\
\hline & & & & & & & & & & & & & & & & & & & & & \\
\hline & & & & & & & & & & & & & & & & & & & & & \\
\hline & & & & 2 & & & 993 & & & & & & & & & & & & 1 & & \\
\hline & & & & & & & 939 & & & & & & & & & & & & & & \\
\hline & & & & & & 943 & .029 & 097 & 6 & & & & & & & & & & & & \\
\hline & & & & $12 ?$ & & 939 & 1.031 & 107 & 1.162 & & & 290 & & & & & & & & & \\
\hline & & & & 122 & 316 & 923 & 1.022 & & 45 & & & 263 & & 42 & & & & & 28 & & \\
\hline & & & & & & 77 & 1.001 & & & & & & & & & & & & & & \\
\hline & & & & & & & 0 & 94 & & & & & & & & & & & & & \\
\hline & & & & & & & 3 & & & & & & & & & & & & & & \\
\hline & & & & & & & & & & & & & & & & & & & & & \\
\hline & & & & & & 5 & .027 & & & & & & & & & & & & & & \\
\hline & & & & & & & & & & & & 55 & & & & & & & 010 & & \\
\hline & & & & & & & & & & & & & & & & & & & & & \\
\hline & & & & & & & 8 & & & & & & & & & & & & & & \\
\hline & & & & & & & & & & & & & & & & & & & & & \\
\hline & & & & & & & & & & & & & & & & & & & & & \\
\hline & & & & & & & & & & & & & & & & & & & 990 & & \\
\hline & & & & & & & 925 & & & & & & & & & & & & 29 & & \\
\hline & & & & & & 3 & .019 & & & & & & & & & & & & 33 & & \\
\hline & & & & & & 8 & 1.030 & & & & & & & & & & & & & & \\
\hline & & & & & & & & & & & & & & & & & & & & & \\
\hline & & & & & & & & & & & & & & & & & & & & & \\
\hline & & & & & & & & & & & & & & & & & & & 44 & & \\
\hline & & & & & & & 1.020 & & & & & & & & & & & & & & 317 \\
\hline & & & & & & & .029 & & & & & & & & & 7 & & & & & \\
\hline & & & & & & & & & & & & & & & & & & & & & \\
\hline & & & & & & & & & & & & & & & & 6 & & & & & \\
\hline & & & & & & & & & & & & & & & & & & & & & \\
\hline & & & & & & & & & & & & & & & & & & & & & \\
\hline & & & & & & & 1.027 & & & & & & & & & & & 94 & & & \\
\hline & & & & & & 4 & .022 & & & & & & & & & & & & & & \\
\hline & & & & & & & & & & & & & & & & & & & & & \\
\hline & & & & & & & & & & & & & & & & & & & & & \\
\hline & & & & & & & 944 & & & & & & & & & 087 & & & & & \\
\hline & & & & & & 941 & 047 & & 72 & & & & & & & & & & & & \\
\hline & 523 & G3 & & & & 0.931 & 1.049 & & 1.171 & 1.241 & 1.252 & 1.295 & & 1.319 & 1.280 & 1.236 & 1.154 & 1.099 & 1.056 & 1.879 & 0.40 \\
\hline & 185 & & & & & 0.926 & 1.035 & & 1.153 & & & & & & & & & 1.091 & & & \\
\hline
\end{tabular}


TABLE VI.-CONTINUED

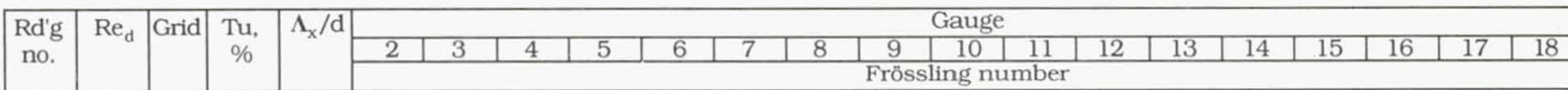

\begin{tabular}{|l|l|l|l|l|l|l|l|l|l|l|l|l|l|l|l|l|l|l|l|l|l|}
\hline \hline 1937 & 0.865 & G3 & 4.33 & 0.110 & 0.801 & 0.904 & 1.008 & 1.065 & 1.123 & 1.179 & 1.194 & 1.225 & 1.232 & 1.237 & 1.229 & 1.184 & 1.122 & 1.062 & 1.023 & 0.854 & 0.810 \\
\hline
\end{tabular} \begin{tabular}{|l|l|l|l|l|l|l|l|l|l|l|l|l|l|l|l|l|l|l|l|l|l|l|l|l|l|l|l|l|l|}
\hline 1938 & 0.442 & $G 3$ & 4.06 & 0.110 & 0.748 & 0.841 & 0.953 & 1.005 & 1.053 & 1.103 & 1.114 & 1.128 & 1.135 & 1.143 & 1.138 & 1.103 & 1.049 & 1.006 & 0.963 & 0.760 & 0.769 \\
\hline
\end{tabular}

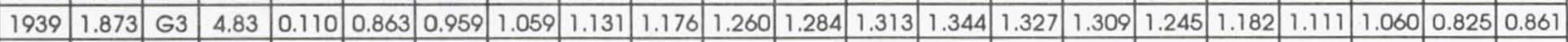

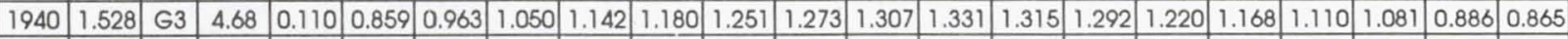

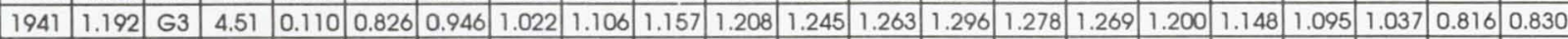
\begin{tabular}{|l|l|l|l|l|l|l|l|l|l|l|l|l|l|l|l|l|l|l|l|l|l|}
\hline 1942 & 0.858 & G3 & 4.33 & 0.110 & 0.817 & 0.906 & 1.019 & 1.079 & 1.125 & 1.192 & 1.204 & 1.219 & 1.242 & 1.226 & 1.231 & 1.168 & 1.123 & 1.065 & 1.024 & 0.756 & 0.825 \\
\hline
\end{tabular} \begin{tabular}{|l|l|l|l|l|l|l|l|l|l|l|l|l|l|l|l|l|l|l|l|l|l|l|l|l|l|l|l|}
\hline 1943 & 0.446 & G3 & 4.07 & 0.110 & 0.759 & 0.824 & 0.958 & 1.013 & 1.033 & 1.098 & 1.134 & 1.128 & 1.137 & 1.123 & 1.140 & 1.100 & 1.046 & 1.000 & 0.937 & 0.902 & 0.740 \\
\hline
\end{tabular}

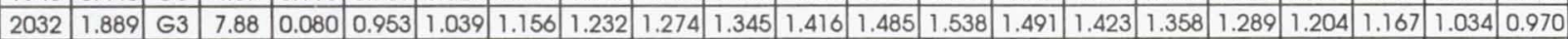
\begin{tabular}{|l|l|l|l|l|l|l|l|l|l|l|l|l|l|l|l|l|l|l|l|l|l|}
\hline 2033 & 1.518 & G 3 & 7.79 & 0.080 & 0.929 & 1.025 & 1.136 & 1.202 & 1.270 & 1.346 & 1.389 & 1.469 & 1.517 & 1.451 & 1.417 & 1.350 & 1.284 & 1.193 & 1.148 & 1.019 & 0.944 \\
\hline
\end{tabular} \begin{tabular}{|l|l|l|l|l|l|l|l|l|l|l|l|l|l|l|l|l|l|l|l|l|l|l|l|l|l|l|l|l|l|l|l|l|l|}
\hline 2034 & 1.198 & $G 3$ & 7.62 & 0.080 & 0.911 & 1.009 & 1.111 & 1.186 & 1.236 & 1.309 & 1.375 & 1.421 & 1.476 & 1.414 & 1.380 & 1.346 & 1.248 & 1.167 & 1.134 & 1.000 & 0.904 \\
\hline
\end{tabular} \begin{tabular}{|l|l|l|l|l|l|l|l|l|l|l|l|l|l|l|l|l|l|l|l|l|l|}
\hline 2035 & 0.853 & G3 & 7.35 & 0.080 & 0.890 & 0.972 & 1.084 & 1.170 & 1.211 & 1.285 & 1.340 & 1.383 & 1.408 & 1.376 & 1.351 & 1.308 & 1.228 & 1.136 & 1.115 & 0.955 & 0.888 \\
\hline
\end{tabular} \begin{tabular}{|l|l|l|l|l|l|l|l|l|l|l|l|l|l|l|l|l|l|l|l|l|l|l|l|l}
\hline 2036 & 0.432 & $G 3$ & 6.90 & 0.080 & 0.830 & 0.886 & 1.036 & 1.083 & 1.105 & 1.191 & 1.209 & 1.222 & 1.243 & 1.205 & 1.240 & 1.179 & 1.148 & 1.037 & 1.063 & 0.863 & 0.818 \\
\hline
\end{tabular} \begin{tabular}{|l|l|l|l|l|l|l|l|l|l|l|l|l|l|l|l|l|l|l|l|l|l|l|}
\hline 2037 & 0.433 & G 3 & 6.91 & 0.080 & 0.800 & 0.905 & 1.012 & 1.063 & 1.135 & 1.178 & 1.210 & 1.239 & 1.235 & 1.233 & 1.225 & 1.192 & 1.121 & 1.062 & 1.023 & 0.886 & 0.817 \\
\hline
\end{tabular} \begin{tabular}{|l|l|l|l|l|l|l|l|l|l|l|l|l|l|l|l|l|l|l|l|l|l}
\hline 2038 & 0.860 & G3 & 7.36 & 0.080 & 0.875 & 0.977 & 1.084 & 1.149 & 1.220 & 1.285 & 1.325 & 1.387 & 1.405 & 1.379 & 1.359 & 1.270 & 1.208 & 1.157 & 1.094 & 0.970 & 0.875 \\
\hline
\end{tabular} \begin{tabular}{|l|l|l|l|l|l|l|l|l|l|l|l|l|l|l|l|l|l|l|l|l|l|}
\hline 2039 & 1.184 & $G 3$ & 7.61 & 0.080 & 0.887 & 0.990 & 1.101 & 1.165 & 1.239 & 1.307 & 1.351 & 1.429 & 1.465 & 1.421 & 1.392 & 1.314 & 1.243 & 1.165 & 1.118 & 0.988 & 0.900 \\
\hline
\end{tabular}

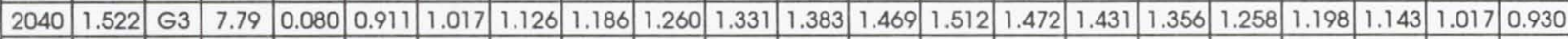

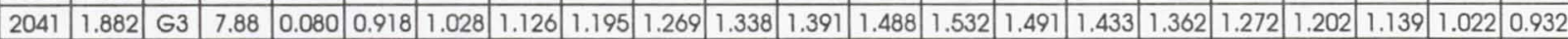
\begin{tabular}{|l|l|l|l|l|l|l|l|l|l|l|l|l|l|l|l|l|l|l|l|l|l|l|l|l|l|}
\hline 2042 & 0.440 & $G 3$ & 10.56 & 0.062 & 0.881 & 0.985 & 1.109 & 1.165 & 1.230 & 1.295 & 1.229 & 1.237 & 1.274 & 1.326 & 1.403 & 1.383 & 1.277 & 1.197 & 1.137 & 0.975 & 0.886 \\
\hline
\end{tabular}

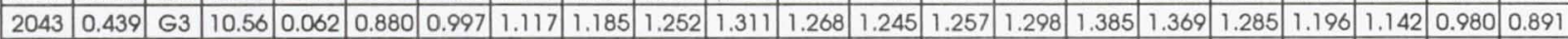
\begin{tabular}{|l|l|l|l|l|l|l|l|l|l|l|l|l|l|l|l|l|l|l|l|l|l}
\hline 2044 & 1.879 & G3 & 6.36 & 0.092 & 0.893 & 0.998 & 1.090 & 1.158 & 1.205 & 1.281 & 1.325 & 1.390 & 1.432 & 1.379 & 1.333 & 1.294 & 1.218 & 1.138 & 1.110 & 0.967 & 0.908 \\
\hline
\end{tabular}

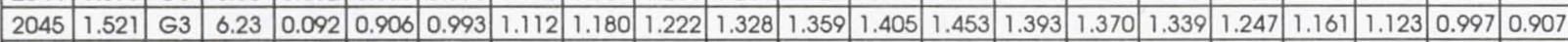
\begin{tabular}{|l|l|l|l|l|l|l|l|l|l|l|l|l|l|l|l|l|l|l|l|l|l|l|l|l|l|}
\hline 2046 & 1.180 & $G 3$ & 6.05 & 0.092 & 0.883 & 0.953 & 1.087 & 1.154 & 1.187 & 1.274 & 1.314 & 1.369 & 1.391 & 1.351 & 1.335 & 1.286 & 1.211 & 1.128 & 1.113 & 0.951 & 0.900 \\
\hline
\end{tabular} \begin{tabular}{|l|l|l|l|l|l|l|l|l|l|l|l|l|l|l|l|l|l|l|l|l|l|}
\hline 2047 & 0.852 & $G 3$ & 5.83 & 0.092 & 0.859 & 0.931 & 1.063 & 1.124 & 1.162 & 1.250 & 1.265 & 1.304 & 1.340 & 1.291 & 1.284 & 1.247 & 1.175 & 1.102 & 1.074 & 0.943 & 0.861 \\
\hline
\end{tabular} \begin{tabular}{|l|l|l|l|l|l|l|l|l|l|l|l|l|l|l|l|l|l|l|l|l|l|l|}
\hline 2048 & 0.441 & $G 3$ & 5.48 & 0.092 & 0.794 & 0.901 & 1.001 & 1.047 & 1.087 & 1.151 & 1.169 & 1.177 & 1.228 & 1.156 & 1.179 & 1.174 & 1.099 & 1.022 & 1.025 & 0.858 & 0.801 \\
\hline
\end{tabular} \begin{tabular}{|l|l|l|l|l|l|l|l|l|l|l|l|l|l|l|l|l|l|l|l|l|l|l|l|l|l|}
\hline 2049 & 0.440 & $G 3$ & 5.48 & 0.092 & 0.774 & 0.879 & 0.986 & 1.032 & 1.090 & 1.105 & 1.209 & 1.174 & 1.192 & 1.174 & 1.189 & 1.180 & 1.096 & 1.030 & 0.993 & 0.867 & 0.790 \\
\hline
\end{tabular} \begin{tabular}{|l|l|l|l|l|l|l|l|l|l|l|l|l|l|l|l|l|l|l|l|l|l|l|l|l|l|l|l|l|l|l|l|}
\hline 2050 & 0.861 & G3 & 5.83 & 0.092 & 0.828 & 0.936 & 1.049 & 1.104 & 1.167 & 1.230 & 1.265 & 1.317 & 1.328 & 1.310 & 1.294 & 1.251 & 1.175 & 1.117 & 1.060 & 0.937 & 0.851 \\
\hline
\end{tabular} \begin{tabular}{|l|l|l|l|l|l|l|l|l|l|l|l|l|l|l|l|l|l|l|l|l|l|l|}
\hline 2051 & 1.186 & $G 3$ & 6.05 & 0.092 & 0.855 & 0.953 & 1.060 & 1.130 & 1.196 & 1.253 & 1.306 & 1.363 & 1.388 & 1.355 & 1.330 & 1.289 & 1.184 & 1.133 & 1.078 & 0.953 & 0.865 \\
\hline
\end{tabular} \begin{tabular}{|l|l|l|l|l|l|l|l|l|l|l|l|l|l|l|l|l|l|l|l|l|l|l|}
\hline 2052 & 1.514 & $G 3$ & 6.23 & 0.092 & 0.875 & 0.971 & 1.085 & 1.147 & 1.221 & 1.282 & 1.329 & 1.404 & 1.434 & 1.395 & 1.362 & 1.300 & 1.210 & 1.151 & 1.087 & 0.976 & 0.882 \\
\hline
\end{tabular}

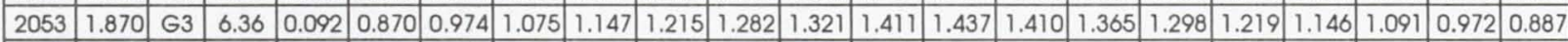

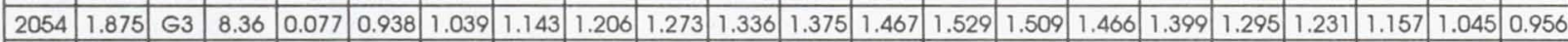
\begin{tabular}{|l|l|l|l|l|l|l|l|l|l|l|l|l|l|l|l|l|l|l|l|l|l|}
\hline 2055 & 1.526 & G3 & 8.29 & 0.077 & 0.919 & 1.022 & 1.128 & 1.198 & 1.262 & 1.326 & 1.363 & 1.441 & 1.495 & 1.486 & 1.457 & 1.381 & 1.291 & 1.220 & 1.147 & 1.034 & 0.943 \\
\hline
\end{tabular}

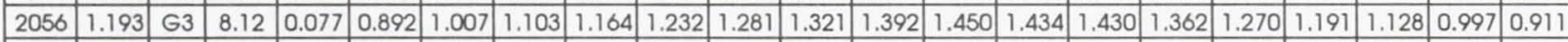

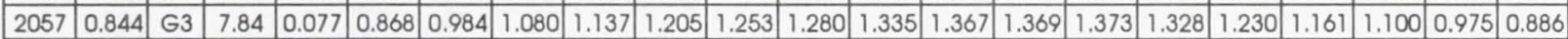
\begin{tabular}{|l|l|l|l|l|l|l|l|l|l|l|l|l|l|l|l|l|l|l|l|l|l|}
\hline 2058 & 0.440 & $G 3$ & 7.38 & 0.077 & 0.809 & 0.908 & 1.013 & 1.062 & 1.120 & 1.157 & 1.182 & 1.209 & 1.229 & 1.239 & 1.251 & 1.238 & 1.149 & 1.089 & 1.035 & 0.904 & 0.819 \\
\hline
\end{tabular}

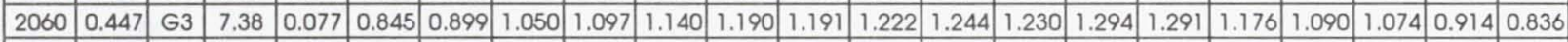
\begin{tabular}{|l|l|l|l|l|l|l|l|l|l|l|l|l|l|l|l|l|l|l|l|l|l|}
\hline 2061 & 0.864 & $G 3$ & 7.86 & 0.077 & 0.889 & 0.955 & 1.094 & 1.153 & 1.198 & 1.262 & 1.293 & 1.337 & 1.381 & 1.362 & 1.388 & 1.347 & 1.257 & 1.160 & 1.112 & 0.992 & 0.880 \\
\hline
\end{tabular}

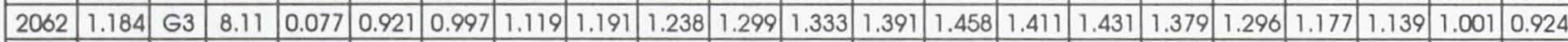

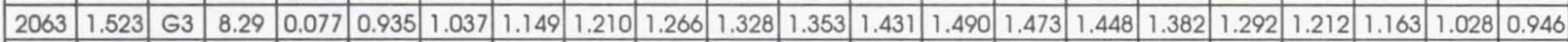

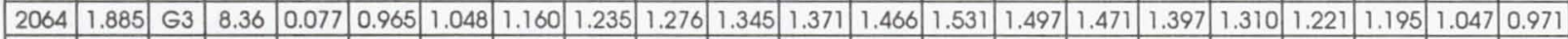

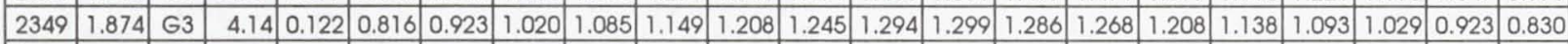
\begin{tabular}{|l|l|l|l|l|l|l|l|l|l|l|l|l|l|l|l|l|l|l|l|l|l|l|l|l|}
\hline 2350 & 1.172 & G3 & 3.82 & 0.122 & 0.799 & 0.896 & 1.005 & 1.065 & 1.132 & 1.183 & 1.208 & 1.244 & 1.242 & 1.238 & 1.242 & 1.176 & 1.133 & 1.068 & 1.017 & 0.896 & 0.816 \\
\hline 2351 & 0.43 & $G 3$ & 3.44 & 0.122 & 0.734 & 0.83 & 0.924 & 0.667 & 1.02 & 1.06 & 1.06 & 106 & 1.12 & 1.091 & 1.106 & 1.064 & 0.999 & 0.975 & 0.926 & 0.815 & 0.737 \\
\hline
\end{tabular}

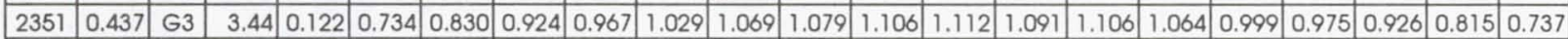

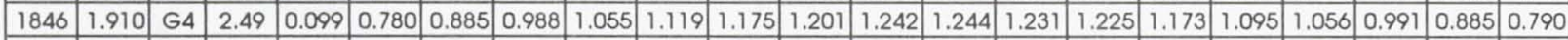

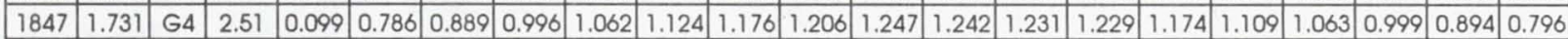

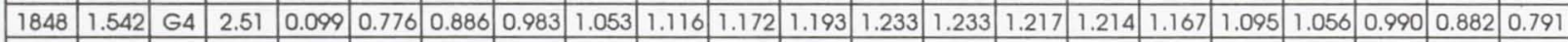

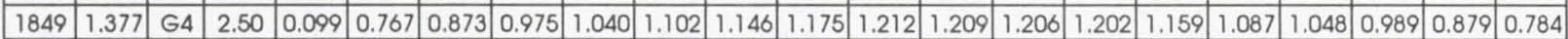
\begin{tabular}{|l|l|l|l|l|l|l|l|l|l|l|l|l|l|l|l|l|l|l|l|l|l|l|l|}
\hline 1850 & 1.195 & G4 & 2.47 & 0.099 & 0.770 & 0.872 & 0.971 & 1.038 & 1.097 & 1.150 & 1.172 & 1.201 & 1.202 & 1.185 & 1.187 & 1.142 & 1.076 & 1.033 & 0.982 & 0.872 & 0.773 \\
\hline
\end{tabular} \begin{tabular}{|l|l|l|l|l|l|l|l|l|l|l|l|l|l|l|l|l|l|l|l|l|l|l|l|l|l|l|}
\hline 1851 & 1.029 & G4 & 2.42 & 0.099 & 0.756 & 0.866 & 0.959 & 1.021 & 1.088 & 1.133 & 1.157 & 1.197 & 1.189 & 1.171 & 1.179 & 1.128 & 1.066 & 1.026 & 0.965 & 0.859 & 0.769 \\
\hline 1852 & 0.875 & $G$ & 2.37 & 0.099 & 0.749 & 0.85 & 0.942 & 1.09 & 1.063 & 1.06 & 1.12 & 1.170 & 1.156 & 1.137 & 1.12 & 1.105 & 1.037 & 1.013 & 0.947 & 0.837 & 0.756 \\
\hline
\end{tabular} \begin{tabular}{|l|l|l|l|l|l|l|l|l|l|l|l|l|l|l|l|l|l|l|l|l|l|}
\hline 1852 & 0.875 & G4 & 2.37 & 0.099 & 0.749 & 0.855 & 0.942 & 1.000 & 1.063 & 1.106 & 1.121 & 1.170 & 1.156 & 1.137 & 1.152 & 1.105 & 1.037 & 1.013 & 0.947 & 0.837 & 0.754 \\
\hline
\end{tabular}

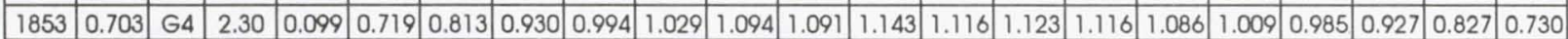

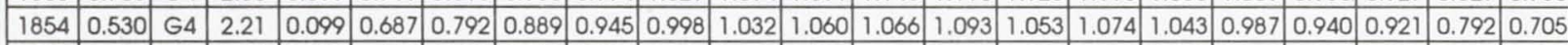

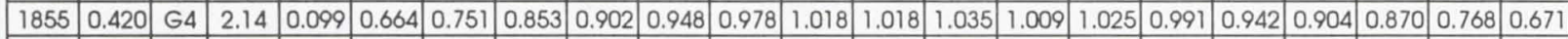
\begin{tabular}{|l|l|l|l|l|l|l|l|l|l|l|l|l|l|l|l|l|l|l|l|l|l|l|}
\hline 1856 & 1.903 & G4 & 2.49 & 0.099 & 0.785 & 0.884 & 0.999 & 1.054 & 1.124 & 1.176 & 1.202 & 1.245 & 1.249 & 1.227 & 1.227 & 1.179 & 1.096 & 1.058 & 0.996 & 0.884 & 0.797 \\
\hline
\end{tabular} \begin{tabular}{l|l|l|l|l|l|l|l|l|l|l|l|l|l|l|l|l|l|l|l|l|l|l|l|}
1857 & 1.541 & $G 4$ & 2.51 & 0.099 & 0.783 & 0.890 & 0.988 & 1.052 & 1.114 & 1.166 & 1.192 & 1.241 & 1.230 & 1.210 & 1.218 & 1.171 & 1.088 & 1.049 & 0.996 & 0.881 & 0.796 \\
\hline
\end{tabular} \begin{tabular}{|l|l|l|l|l|l|l|l|l|l|l|l|l|l|l|l|l|l|l|l|l|l|l|l|l}
1858 & 1.193 & $G 4$ & 2.47 & 0.099 & 0.775 & 0.867 & 0.973 & 1.038 & 1.095 & 1.145 & 1.168 & 1.210 & 1.190 & 1.173 & 1.191 & 1.144 & 1.068 & 1.036 & 0.976 & 0.865 & 0.782 \\
\hline
\end{tabular} \begin{tabular}{l|l|l|l|l|l|l|l|l|l|l|l|l|l|l|l|l|l|l|l|l|l|l|l|l|l|l|l|l|}
\hline 1859 & 0.873 & G4 & 2.37 & 0.099 & 0.754 & 0.846 & 0.952 & 1.006 & 1.056 & 1.113 & 1.129 & 1.164 & 1.158 & 1.134 & 1.151 & 1.110 & 1.045 & 0.998 & 0.954 & 0.841 & 0.756 \\
\hline 1860 & 0.445 & $G 4$ & 2.16 & 0.099 & 0.662 & 0.786 & 0.843 & 0.92 & 0.947 & 0.99 & 1.006 & 1.03 & 1.036 & 1.011 & 1.02 & 0.999 & 0.927 & 0.93 & 0.863 & 0.762 & 0.693 \\
\hline
\end{tabular} \begin{tabular}{l|l|l|l|l|l|l|l|l|l|l|l|l|l|l|l|l|l|l|l|l|l|l|}
1860 & 0.445 & $G 4$ & 2.16 & 0.099 & 0.662 & 0.784 & 0.843 & 0.926 & 0.947 & 0.995 & 1.006 & 1.030 & 1.036 & 1.011 & 1.027 & 0.999 & 0.927 & 0.930 & 0.863 & 0.762 & 0.693 \\
\hline
\end{tabular} \begin{tabular}{|l|l|l|l|l|l|l|l|l|l|l|l|l|l|l|l|l|l|l|l|l|l|l|l|l|l|l|l|l|}
\hline 1861 & 1.902 & $G 4$ & 2.49 & 0.099 & 0.810 & 0.906 & 1.015 & 1.105 & 1.141 & 1.199 & 1.234 & 1.277 & 1.264 & 1.253 & 1.254 & 1.211 & 1.109 & 1.085 & 1.028 & 0.899 & 0.822 \\
\hline
\end{tabular} \begin{tabular}{l|l|l|l|l|l|l|l|l|l|l|l|l|l|l|l|l|l|l|l|l|l|l|l|l|l|l|l|l|l|l|}
\hline 1862 & 1.538 & $G 4$ & 2.51 & 0.099 & 0.804 & 0.896 & 0.992 & 1.088 & 1.123 & 1.187 & 1.216 & 1.247 & 1.238 & 1.223 & 1.238 & 1.184 & 1.113 & 1.057 & 1.020 & 0.886 & 0.803 \\
\hline
\end{tabular}

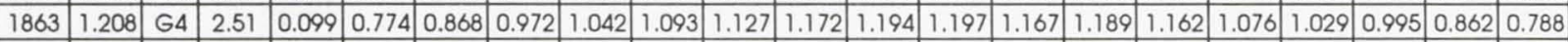
\begin{tabular}{|l|l|l|l|l|l|l|l|l|l|l|l|l|l|l|l|l|l|l|l|l|l|l|l|l|l|}
\hline 1864 & 0.868 & G4 & 2.37 & 0.099 & 0.758 & 0.839 & 0.958 & 1.014 & 1.058 & 1.105 & 1.141 & 1.160 & 1.166 & 1.125 & 1.154 & 1.116 & 1.051 & 0.997 & 0.965 & 0.841 & 0.770 \\
\hline
\end{tabular} 
TABLE VI.-CONTINUED.

\begin{tabular}{|c|c|c|c|c|c|c|c|c|c|c|c|c|c|c|c|c|c|c|c|c|c|}
\hline \multirow{3}{*}{$\begin{array}{c}\text { Rd'g } \\
\text { no. }\end{array}$} & \multirow[t]{3}{*}{$\mathrm{Re}_{\mathrm{d}}$} & \multirow[t]{3}{*}{ Grid } & & \multirow[t]{3}{*}{$/ \mathrm{d}$} & \multicolumn{17}{|c|}{ Gad } \\
\hline & & & & & 2 & 3 & 4 & 5 & 6 & 7 & 8 & & & 2. & 12 & 13 & 14 & 15 & 16 & 17 & \\
\hline & & & & & & & & & & & & sli & lin & & & & & & & & \\
\hline & & & & 063 & 785 & 884 & 971 & 1.040 & .083 & & 1.194 & 1.179 & 1.216 & 1.146 & 1.192 & & 1.107 & 0.981 & & 0.848 & .768 \\
\hline 00 & & & & 250 & 03 & 012 & & 1.187 & 246 & & & 451 & & 1.460 & & & & & & 0.996 & \\
\hline & & & & & 397 & & & & & & & & & 1.468 & & & & & & 00 & \\
\hline & & & & 50 & 866 & 987 & & 158 & 213 & & \begin{tabular}{|l|}
1.349 \\
\end{tabular} & & & \begin{tabular}{|l|}
1.431 \\
\end{tabular} & 376 & & .227 & & & & \\
\hline 003 & 347 & 4 & .01 & 0.050 & 0.851 & 0.946 & 060 & 1.133 & 183 & 262 & 1.300 & 1.337 & 390 & 1.345 & 356 & & .197 & 098 & 085 & 93 & 85 \\
\hline 204 & & & & 0.050 & \begin{tabular}{|l|}
0.812 \\
\end{tabular} & 0.903 & 1.010 & 1.071 & 1.149 & 181 & 1.229 & 1.267 & 275 & 1.248 & 256 & 210 & 1.116 & .046 & 036 & 863 & 81 \\
\hline 05 & & & & 050 & .793 & \begin{tabular}{|l|}
0.903 \\
\end{tabular} & 002 & 1.066 & 141 & 188 & 1.221 & .258 & & 1.250 & 247 & & 1.112 & .049 & 01 & 88 & \\
\hline 06 & & & & 050 & 339 & 955 & & & & & 1.281 & & & & & & & & & & \\
\hline & & & & 50 & 353 & 0.964 & 881 & \begin{tabular}{|l|}
1.138 \\
\end{tabular} & 1.216 & & 1.331 & 410 & & 1.439 & 396 & & & & & & \\
\hline & & & & 250 & 875 & 0.988 & 094 & 1.157 & 1.245 & & 1.343 & .440 & & 1.460 & .408 & & .228 & .165 & & 70 & \\
\hline 009 & & & 6 & 050 & 883 & 0.991 & 098 & 1.168 & 1.241 & 317 & 1.359 & .460 & & 1.484 & .422 & 333 & .231 & .166 & 107 & 98 & 896 \\
\hline 010 & & G4 & 4.3 & 0.066 & 0.872 & 0.971 & 1.080 & 1.140 & 1.185 & 262 & 1.283 & 1.341 & & 1.344 & 1.343 & 290 & 220 & .141 & 113 & 95 & 91 \\
\hline 11 & & 4 & & 066 & 867 & 0.951 & 1.059 & 1.136 & 1.182 & 251 & 1.287 & 1.343 & & 1.331 & 346 & 280 & 229 & .142 & & 970 & 88 \\
\hline 12 & & & & 36 & 845 & 0.939 & 047 & 1.106 & & & & 292 & & & 1.309 & & & & & & \\
\hline & & & & 66 & 31. & 0.911 & 27 & & 1.126 & & 206 & & & & \begin{tabular}{|l|}
1.252 \\
\end{tabular} & & & & & & \\
\hline 14 & & & & & 772 & 0.874 & 861 & 235 & \begin{tabular}{|l|}
1.071 \\
\end{tabular} & & 130 & 154 & & 151 & 158 & & 050 & 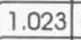 & 70. & & \\
\hline 15 & & & & 166 & 755 & 0.872 & 970 & 022 & 1,081 & & 131 & 160 & & 137 & 170 & & 072 & 014 & $9 / 9$ & 80 & 1 \\
\hline 116 & & & & 066 & 797 & 0.914 & 012 & 066 & 1.132 & 176 & 196 & 1.246 & & 240 & 265 & 199 & 156 & 097 & 042 & 929 & 82 \\
\hline 017 & 192 & G4 & & 066 & 0.822 & 0.929 & 034 & 093 & 1.162 & 205 & 236 & 1.295 & & 296 & 1.299 & 244 & 174 & 116 & .05 & 948 & 84 \\
\hline 18 & & 4 & & 066 & .829 & 0.944 & .035 & 103 & 1.170 & 218 & 255 & 1.319 & & 319 & 314 & 257 & 196 & 132 & & 8 & 8 \\
\hline 19 & & & & 366 & 840 & 0.954 & 245 & & \begin{tabular}{|l|}
1.173 \\
\end{tabular} & & & & & & & & 192 & & & & \\
\hline 21 & & & & & 6 & 213 & 321 & & .459 & 532 & 45 & 563 & & 339 & 000 & & 494 & & & & \\
\hline 22 & & & & 250 & 073 & .175 & 277 & 99 & .423 & 482 & 493 & .521 & & 594 & 620 & & 481 & 347 & 29 & 2 & U \\
\hline 023 & & & & 050 & 032 & 1.131 & 241 & 327 & 1.390 & 464 & 463 & 1.476 & & 545 & 572 & 556 & 424 & 317 & 263 & 10 & 02 \\
\hline 2024 & & G4 & & 050 & 984 & 1.063 & 193 & 284 & 1.348 & 441 & 416 & 1.392 & & 442 & 1.511 & .502 & 376 & 262 & 20 & 054 & 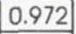 \\
\hline 2025 & & G4 & & 050 & 924 & 1.004 & 116 & 200 & 1.263 & .305 & 276 & 1.256 & & .302 & 1.399 & & 303 & 196 & 5 & .990 & 8 \\
\hline 26 & & G & & 050 & 393 & 1.000 & 121 & & \begin{tabular}{|l|}
1.267 \\
\end{tabular} & 309 & & & & & & & 84 & 212 & & .90 & Oy \\
\hline 27 & & & & & & 1.085 & 189 & 0 & 1.353 & 412 & 33 & 1.411 & & 63. & 510 & 456 & 361 & & & & \\
\hline 28 & & & & 550 & 001 & 120 & 221 & 0 & 385 & 440 & 436 & 464 & & 546 & 591 & 508 & $4 \mid 4$ & & & & \\
\hline 29 & & $c$ & & 050 & 051 & 1.155 & 264 & & 1.424 & .485 & 488 & 1.512 & & .614 & 1.640 & 1.554 & .455 & 355 & 277 & .14 & 05 \\
\hline 330 & & 4 & & 050 & 083 & 1.181 & 289 & 67 & 1.446 & 507 & 1.517 & 1.552 & & 642 & 1.656 & 1.574 & 466 & 375 & 300 & 16 & \\
\hline 65 & & & & 066 & 867 & \begin{tabular}{|l|}
0.972 \\
\end{tabular} & .080 & 54 & 1.195 & 288 & 263 & \begin{tabular}{|l|}
1.317 \\
\end{tabular} & & 313 & 310 & 264 & 211 & 135 & 103 & 958 & 8 \\
\hline 66 & & & & 066 & 350 & 961 & 079 & 30 & 80 & 261 & 61 & 300 & & 296 & 292 & 1.243 & 203 & .117 & 1.080 & $95 \%$ & 86 \\
\hline 67 & & & & 0 & 345 & .930 & 044 & 26 & 170 & & & \begin{tabular}{|l|}
1.274 \\
\end{tabular} & & 63 & 261 & 234 & & & & & \\
\hline 68 & & & & & & 111 & 009 & & & & 196 & & & 19 & & 83 & 155 & & & & \\
\hline 169 & & & & & & 813 & 931 & 16 & 067 & & & & & & & & 047 & 5 & c & & \\
\hline 70 & & 6 & & 103 & 732 & 830 & 0.948 & .990 & 1.064 & .100 & 118 & 1.158 & & 129 & \begin{tabular}{|l|}
1.138 \\
\end{tabular} & 1.113 & .045 & 005 & 96 & 337 & \\
\hline 71 & & 6 & & 0 & 305 & 917 & 1.023 & 082 & 1.152 & 194 & 218 & 1.253 & & 232 & 244 & 1.203 & .150 & .090 & 041 & 91 & 821 \\
\hline 72 & & & & 0 & & 942 & \begin{tabular}{|l|}
1.049 \\
\end{tabular} & & 182 & 227 & 35 & 1.288 & & 277 & 1.279 & 1.232 & 1.177 & .115 & 1.06 & & 85 \\
\hline 173 & & & & 066 & 337 & .964 & 1.060 & & 191 & & & & & & 98 & 261 & 19 & 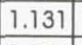 & & & \\
\hline 174 & & & & & & 1961 & \begin{tabular}{|l|}
1.068 \\
\end{tabular} & & \begin{tabular}{|l|}
1.202 \\
\end{tabular} & & & & & & 313 & & .198 & & & & \\
\hline 75 & & & & & & .945 & 1.065 & 1.136 & 1.168 & .260 & & 1.292 & & 1.280 & 285 & 1.237 & .173 & 112 & 1 & 947 & 801 \\
\hline 776 & & & & 688 & & 58 & \begin{tabular}{|l|}
1.062 \\
\end{tabular} & & 174 & 252 & & 299 & & 293 & 282 & 240 & 206 & 15 & 081 & 950 & 00 \\
\hline 777 & & & & 073 & 324 & .927 & 1.038 & 998 & 149 & 217 & & 252 & & 233 & 253 & 214 & 145 & 086 & 1 & 91 & 83 \\
\hline 78 & & & & 083 & 303 & 920 & 1.030 & 077 & 140 & & & & & & & & & & & 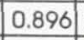 & 8 \\
\hline 79 & & & & & & 826 & 0.948 & 996 & 1.05 & 087 & & & & & & 99 & 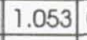 & & & & \\
\hline 80 & & & & & & 827 & 947 & & & & & & & & & & & & & & \\
\hline & & & & & & 206 & & & & & & & & & 24 & 84 & 30 & 064 & $t$ & 90 & 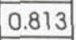 \\
\hline 082 & & & & 73 & & 22 & 027 & & 156 & 00 & 22 & 264 & & 251 & 250 & 206 & 48 & 094 & 0 & 93 & 8 \\
\hline 083 & 521 & & & 068 & 828 & 0.957 & 1.038 & & 1.175 & 1.227 & 254 & 1.292 & 87 & 284 & 278 & 1.225 & 171 & 114 & .056 & 945 & 82 \\
\hline 884 & & & & 068 & 330 & 947 & 1.049 & & 182 & 1.230 & & 55 & & 291 & & 42 & 67 & & 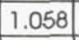 & & \\
\hline 8 & & & & & & 25 & 1.132 & & & & & & & & & 36 & & & & & \\
\hline 08 & & & & & & .010 & 1.124 & & 59 & & & 2 & & & & & & & & & \\
\hline 089 & & & & un & 873 & .984 & \begin{tabular}{|l|}
1.089 \\
\end{tabular} & & 1.215 & 1.277 & & 1.326 & & & & & & & 1 & 968 & $8 / 4$ \\
\hline 090 & 863 & & & 076 & 855 & 956 & 1.068 & 1.146 & 1.191 & 1.253 & 1.275 & 1.304 & 311 & .301 & 1.280 & 1.247 & 197 & 124 & 10 & 94 & 86 \\
\hline 091 & 138 & & & 100 & 798 & 863 & 0.997 & 1.052 & 1.112 & 1.178 & 1.168 & 1.207 & & 174 & 1.190 & 164 & 114 & 042 & 02 & 866 & 79 \\
\hline 092 & & & & 099 & .773 & 890 & 0.999 & \begin{tabular}{|l|}
1.057 \\
\end{tabular} & 1.126 & 76 & & 216 & & & 264 & 42 & 17 & 059 & & 89 & 7 \\
\hline 093 & & & & I & & & 067 & & & 243 & & 302 & & 92 & 92 & 259 & 95 & & & 98 & \\
\hline 094 & & & & 005 & 858 & 0.982 & 1.093 & 1.151 & 1.227 & .278 & 1.305 & 1.344 & & 1.009 & 1.333 & .201 & 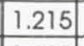 & . 100 & & 0.976 & 81 \\
\hline 095 & .524 & G5 & & .060 & 878 & 0.994 & 1.105 & 1.170 & 1.242 & 1.296 & \begin{tabular}{|l|}
1.321 \\
\end{tabular} & 1.381 & .371 & 1.367 & 1.356 & 1.316 & 1.235 & .176 & .118 & 0.991 & .89 \\
\hline 096 & .916 & G5 & 2.03 & .063 & 0.881 & 1.004 & 1.106 & 1.176 & 1.246 & 1.301 & 1.334 & 1.383 & 1.398 & 1.378 & 1.363 & 1.314 & 1.239 & 1.181 & 1.119 & 1.003 & 0.90 \\
\hline
\end{tabular}


TABLE VI.-CONCLUDED.

\begin{tabular}{|c|c|c|c|c|c|c|c|c|c|c|c|c|c|c|c|c|c|c|c|c|c|}
\hline \multirow{3}{*}{$\begin{array}{c}\text { Rd'g } \\
\text { no. }\end{array}$} & \multirow[t]{3}{*}{$\mathrm{Re}_{\mathrm{d}}$} & \multirow[t]{3}{*}{ Grid } & \multirow{3}{*}{$\begin{array}{l}\text { Tu, } \\
\%\end{array}$} & \multirow[t]{3}{*}{$\Lambda_{x} / d$} & \multicolumn{17}{|c|}{ Gauge } \\
\hline & & & & & 2 & 3 & 4 & 5 & 6 & 7 & 8 & 9 & & 111 & 12 & 13 & 14 & 15 & 16 & 17 & \\
\hline & & & & & \multicolumn{17}{|c|}{ Frössling number } \\
\hline 2097 & 1.924 & G5 & 1.86 & 0.065 & 0.904 & 0.996 & 1.114 & 1.183 & 1.243 & 1.298 & 1.323 & 1.374 & 1.368 & & 1.349 & & & & & & \\
\hline 2098 & .532 & G5 & 1.86 & .063 & .884 & 0.992 & 1.107 & 1.172 & 1.228 & 1.312 & 1.318 & 1.355 & & & 1.335 & & & & & & \\
\hline 099 & 199 & & $\mathrm{~S}_{1}$ & 067 & 872 & 0.971 & 1.095 & & 211 & 1.281 & 289 & 332 & & 328 & & & & & & & \\
\hline & 86 & & & 078 & 831 & 946 & & & 1.165 & & & & & 258 & & & & & 1.072 & .939 & \\
\hline & & 55 & 43 & 101 & 780 & 0.861 & .990 & 032 & 1.086 & 1.149 & 161 & .172 & 1.189 & .150 & .179 & 1.156 & .092 & .022 & 0.994 & .861 & .789 \\
\hline 102 & 434 & G5 & 2.43 & 101 & 763 & 0.859 & 0.982 & 1.026 & 1.098 & 1.124 & 1.162 & 1.180 & 1.194 & 1.169 & 1.181 & 1.158 & .087 & .041 & 0.999 & .866 & .781 \\
\hline 2103 & 868 & G5 & 2.01 & .078 & 0.827 & 0.929 & 041 & 1.101 & 1.173 & 1.219 & 1.241 & 1.279 & 1.266 & 1.269 & 1.270 & 1.235 & .152 & .121 & 1.056 & .939 & .84 \\
\hline 2104 & 193 & G5 & 2.01 & 068 & 844 & 0.951 & 065 & 1.131 & 1.200 & 1.251 & 1.271 & 1.318 & & 1.303 & & & & & & & 4 \\
\hline 2105 & 522 & G5 & 1.86 & 063 & 855 & 0.983 & & & .220 & & & & & & & & & & & & \\
\hline 106 & 91 & G5 & 1.86 & 065 & 861 & 0.975 & 083 & 1.145 & 221 & 1.278 & & & & & & 1.287 & & & 1.094 & .981 & 891 \\
\hline & 1 & 5 & & 074 & 308 & 900 & 011 & 1.057 & 1.130 & .175 & 1.194 & .216 & 1.221 & .210 & .213 & 1.168 & .112 & .057 & 1.018 & 891 & 814 \\
\hline 100 & 527 & G5 & 20 & 076 & 805 & 0.870 & 991 & 1.051 & 1.100 & .149 & 1.176 & 194 & 1.203 & 183 & .193 & 1.155 & .107 & .040 & 1.008 & .877 & .800 \\
\hline 2109 & 191 & G5 & 39 & 082 & 770 & 0.876 & 968 & 1.029 & 1.073 & .125 & 149 & 175 & 171 & 1.155 & 1.173 & 1.135 & .075 & .017 & 0.986 & .860 & .775 \\
\hline 2110 & 859 & G5 & 1.39 & .090 & 0.738 & 0.831 & .918 & 0.982 & 1.024 & 1.068 & .088 & 1.117 & & 1.100 & 1.103 & 1.082 & 034 & 957 & .944 & 821 & 725 \\
\hline 111 & 443 & G5 & 52 & 105 & 0.688 & \begin{tabular}{|l|} 
\\
\end{tabular} & 858 & 911 & 0.955 & 0.995 & 020 & & & .005 & 1.046 & .999 & & 902 & 386 & & \\
\hline 113 & 14 & G5 & 52 & 105 & 0.665 & .767 & 68 & 99 & .965 & & & & & & & & & & & & \\
\hline 114 & 6 & & & 990 & 728 & 828 & 923 & .982 & 039 & 080 & 092 & 129 & & .112 & 1.135 & .094 & 033 & 988 & .941 & 022 & \\
\hline 15 & 8 & & & 282 & 752 & 858 & 964 & .009 & .072 & 123 & 1.133 & 167 & & 1.157 & 1.169 & 1.129 & .062 & 017 & 0.970 & .004 & 10 \\
\hline 16 & 52 & 35 & & 076 & 774 & 875 & 986 & .033 & 101 & 145 & 1.160 & 200 & & .195 & 1.195 & 1.159 & .094 & .044 & 0.999 & .879 & .789 \\
\hline 117 & 90 & 5 & 26 & 074 & 768 & 0.881 & .978 & 1.037 & 1.100 & .151 & 1.156 & 1.206 & 1.198 & 1.198 & 1.196 & 1.143 & 1.088 & .043 & 0.991 & 876 & 1.78 \\
\hline 2118 & 905 & G5 & .22 & 075 & 0.781 & 0.858 & 967 & 042 & 1.076 & .140 & 152 & 178 & & 183 & 174 & 1.136 & 068 & .026 & 0.982 & & 790 \\
\hline & 519 & 6 & & 078 & 772 & 0.873 & 990 & 1.0 & .083 & & & & & 1.195 & 1.182 & 1.155 & 110 & 027 & & & \\
\hline 2120 & 194 & G5 & & 083 & 766 & 824 & 961 & 1.010 & .052 & & 1.121 & 145 & & 1.134 & 1.155 & 1.107 & .063 & 991 & 0.976 & & \\
\hline 12 & 351 & & & 092 & .720 & 813 & 919 & 1.973 & 009 & 1.055 & 1.077 & 095 & & 1.080 & .111 & 1.064 & .040 & 949 & 0.936 & & .735 \\
\hline 12 & & & & 106 & 674 & 756 & 876 & 915 & 947 & .976 & 1.016 & .022 & & 1.013 & .039 & 0.988 & .929 & 892 & .89 & .44 & .674 \\
\hline 123 & 433 & & & 106 & 676 & .757 & 861 & 0.897 & .957 & 0.991 & 0.997 & 1.029 & & 1.015 & 1.026 & 1.001 & .930 & 909 & .858 & 75 & .674 \\
\hline 124 & 855 & $c$ & & 091 & 0.721 & .820 & 922 & 0.971 & 1.027 & 079 & 087 & 1.113 & & 102 & 1.114 & 1.076 & 016 & 975 & .927 & & 732 \\
\hline 2125 & 190 & & & 083 & 740 & 854 & 943 & 001 & 663 & 110 & 1 & & & & & & 055 & & 558 & & \\
\hline 2126 & 52 & & & 078 & .759 & 859 & 967 & 1.014 & 083 & 734 & 149 & & & 1.174 & .173 & 1.140 & .075 & .024 & 0.968 & 804 & 77 \\
\hline 12 & 03 & & & 075 & 763 & 867 & 971 & 027 & 089 & 39 & 149 & & & .184 & 183 & .140 & .080 & .029 & 0.98 & 8 & 777 \\
\hline 12 & 2 & & & 076 & 757 & 869 & 966 & 025 & 081 & & 152 & & & .164 & 176 & & .080 & 016 & 0.977 & & 777 \\
\hline & & & & 280 & 761 & 839 & 963 & 015 & 072 & & 138 & & & 1.150 & 161 & 17 & 071 & 10 & .964 & 6 & .775 \\
\hline 131 & 199 & & & 085 & 752 & 838 & 951 & 985 & .048 & 1.095 & 107 & 142 & & 1.141 & 1.138 & .105 & .053 & .990 & .953 & 836 & .747 \\
\hline 132 & & & & 993 & .708 & 803 & 918 & 955 & 016 & 1.059 & 068 & 102 & 1.0 & 1.087 & 106 & .080 & 019 & 956 & .932 & 814 & 728 \\
\hline 133 & 440 & & & 107 & .660 & 756 & 862 & 894 & 949 & 0.983 & 998 & & & 0 & 024 & 1.0 & 938 & & 86 & & 68 \\
\hline 134 & & & & 107 & 654 & 743 & & 888 & 39 & 71 & 0 & & & 1.002 & 014 & 73 & 930 & & & 1 & \\
\hline 135 & & & & & 701 & 812 & & 957 & 113 & 59 & 62 & & & 1.093 & 992 & 66 & 08 & 956 & .921 & & \\
\hline 136 & & & & 385 & 716 & 835 & 933 & 0.984 & 342 & 1.0 & 1.102 & & & 30 & .130 & & 1.036 & & 37 & 1 & 1.734 \\
\hline 2137 & 529 & & & 880 & 744 & 843 & 948 & 1.001 & 067 & 1.114 & 1.128 & .165 & & 1.157 & 1.164 & 1.115 & 1.060 & 1.009 & .962 & 843 & 756 \\
\hline 2138 & 918 & & & 376 & 750 & 858 & 952 & 1.014 & 074 & 1.127 & 1.143 & .179 & 75 & 173 & .176 & 136 & 1.068 & & .967 & .853 & 760 \\
\hline 2139 & 91 & & & 077 & 774 & 886 & 998 & 1.047 & 103 & 55 & 1. & & & 1. & & & .110 & & & & 79 \\
\hline 140 & & & & & 780 & 847 & 972 & .030 & 082 & & & & & & & & .080 & & & 4 & \\
\hline 41 & & & & & 753 & & & .984 & & 1.0 & & & & & & & & & & & \\
\hline 142 & & & & & 710 & 790 & 909 & .958 & 995 & 1.049 & 1.066 & & 1.0 & & .098 & .048 & 1.012 & & . 741 & & .723 \\
\hline 143 & & & & 107 & 671 & 741 & 866 & 0.889 & .932 & 0.985 & 0.978 & .000 & 1.008 & 0.983 & .005 & .982 & 0.936 & 864 & 894 & 722 & .681 \\
\hline 144 & 435 & & & 107 & 651 & 752 & 842 & 0.877 & .941 & 0.963 & 0.976 & 1.001 & 1.012 & 0.985 & .002 & .963 & 0.928 & 889 & 845 & .73 & .660 \\
\hline 145 & & & & & 703 & 809 & .902 & 0.950 & .002 & 1.0 & 1.050 & 1.089 & 1.080 & 1.075 & 86 & 1.052 & 0.993 & 951 & ( & 1.79 & .707 \\
\hline 146 & & & & & & & & & & & & & & & & & & & & & \\
\hline 147 & 522 & & & 01 & .746 & 855 & \begin{tabular}{|l|}
0.948 \\
\end{tabular} & 1.000 & 1.066 & 1.110 & 1.126 & .159 & 1.157 & & .154 & 1.112 & 1.060 & 1.008 & .959 & 049 & 0.756 \\
\hline 148 & 907 & G5 & 13 & 777 & 751 & 857 & .954 & 1.010 & 1.074 & 1.120 & 1.137 & 1.182 & 1.168 & 1.168 & \begin{tabular}{|l|}
1.172 \\
\end{tabular} & 1.125 & \begin{tabular}{|l|}
1.062 \\
\end{tabular} & 1.018 & .963 & 850 & .764 \\
\hline 352 & 436 & G5 & & 107 & .708 & 832 & 928 & 0.971 & 1.020 & 1.058 & 1.073 & 1.090 & 1.102 & \begin{tabular}{|l|} 
\\
\end{tabular} & 1.091 & 1.061 & 0.999 & 0.966 & .927 & 0.802 & 0.716 \\
\hline 353 & 173 & G5 & & 386 & \begin{tabular}{|l|}
0.752 \\
\end{tabular} & 856 & 0.951 & 1.009 & 1.067 & 1.103 & 1.1 & 1.151 & 1.1 & 1.141 & & 1.120 & \begin{tabular}{|l|}
1.057 \\
\end{tabular} & 1.012 & 0.961 & 0.846 & 0.76 \\
\hline 354 & 874 & G5 & 16 & 076 & 0.762 & 866 & 0.952 & 1.015 & 1.072 & 1.115 & 1.141 & 1.174 & 1.161 & 1.158 & 1.161 & 1.121 & \begin{tabular}{|l|}
1.059 \\
\end{tabular} & 1.023 & 0.965 & 0.856 & 0.77 \\
\hline
\end{tabular}


TABLE VII.-FRÖSSLING NUMBER FOR 1.5:1 MODEL.

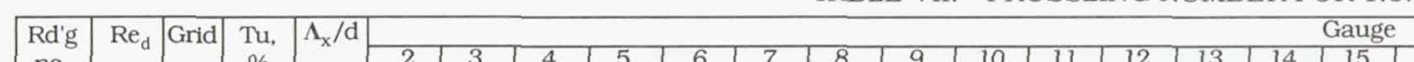

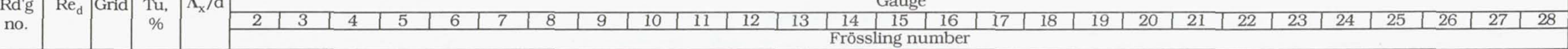

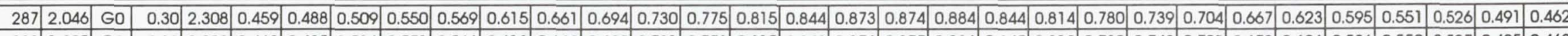

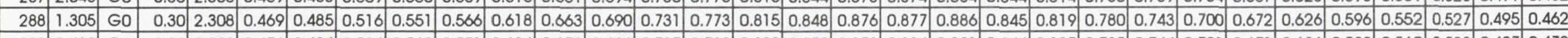

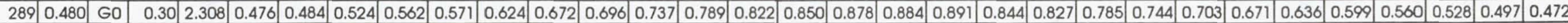

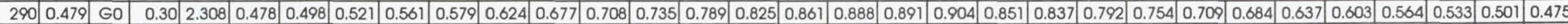

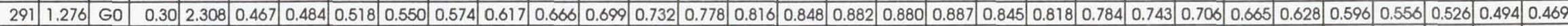

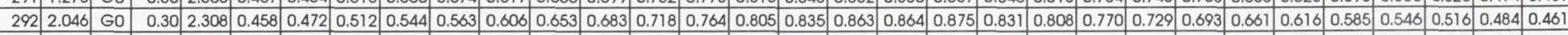

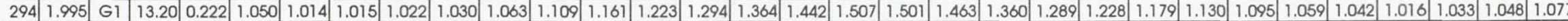

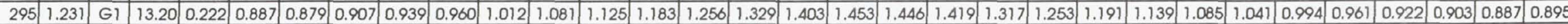

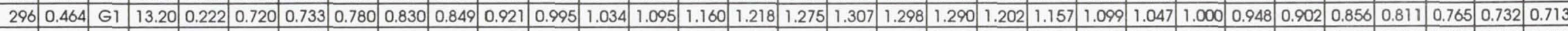

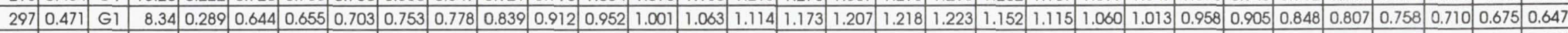

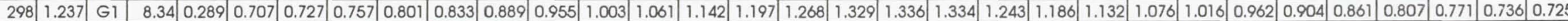

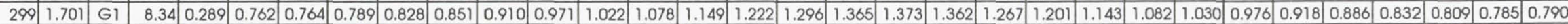

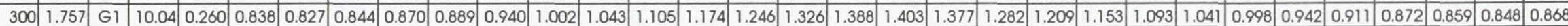

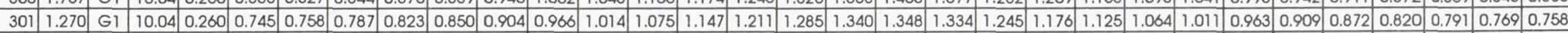

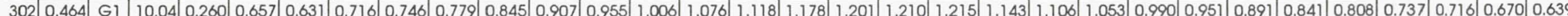

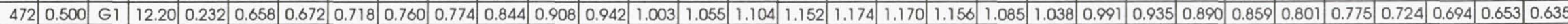

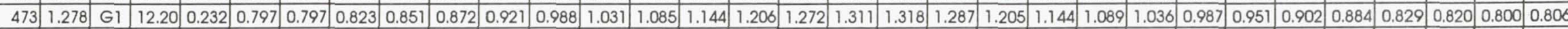

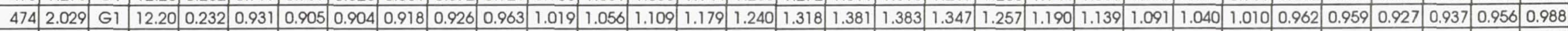

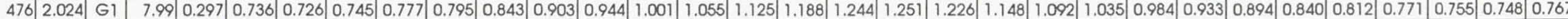

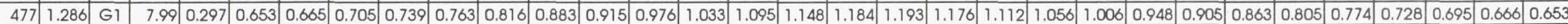

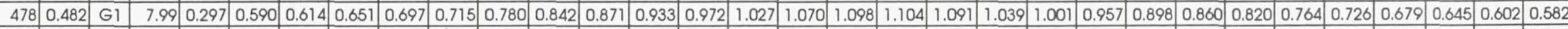

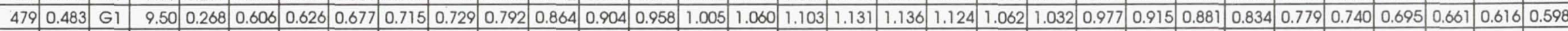

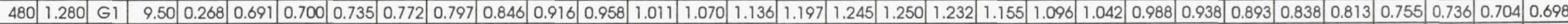

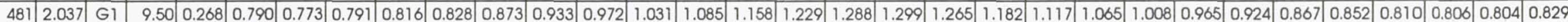

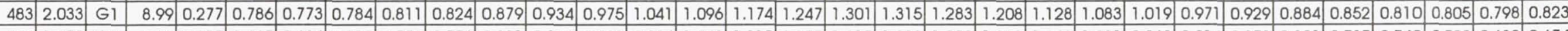

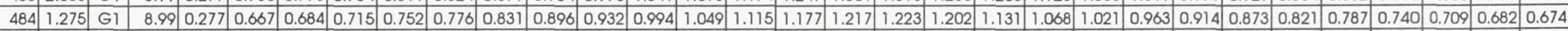

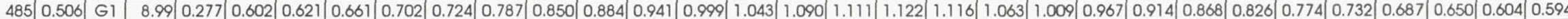

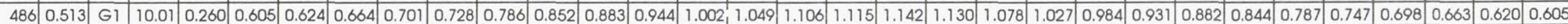

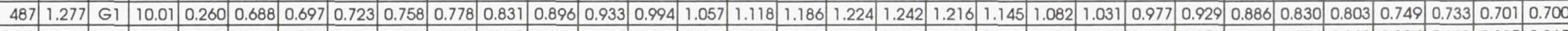

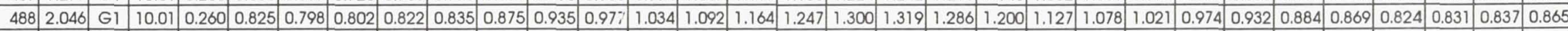

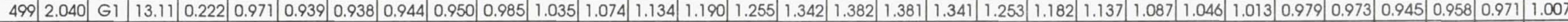

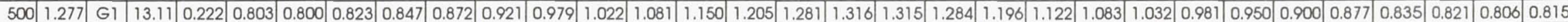

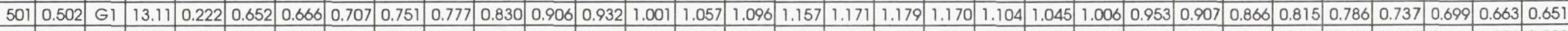

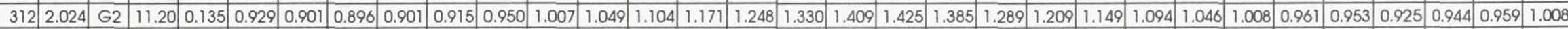

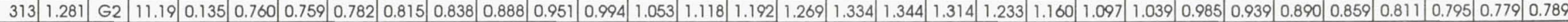

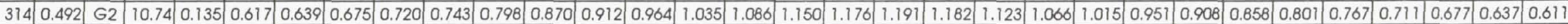

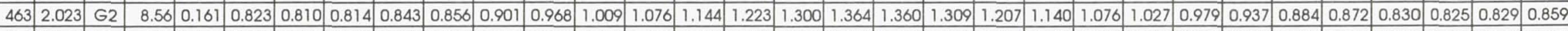

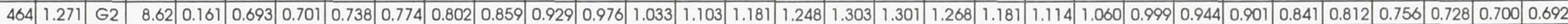

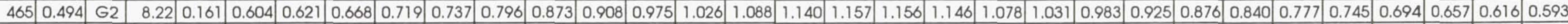

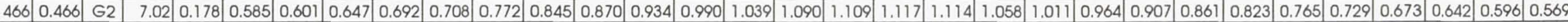

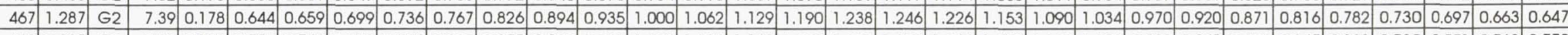

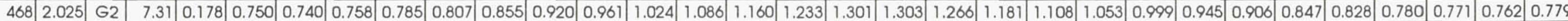


TABLE VII.-CONCLUDED.

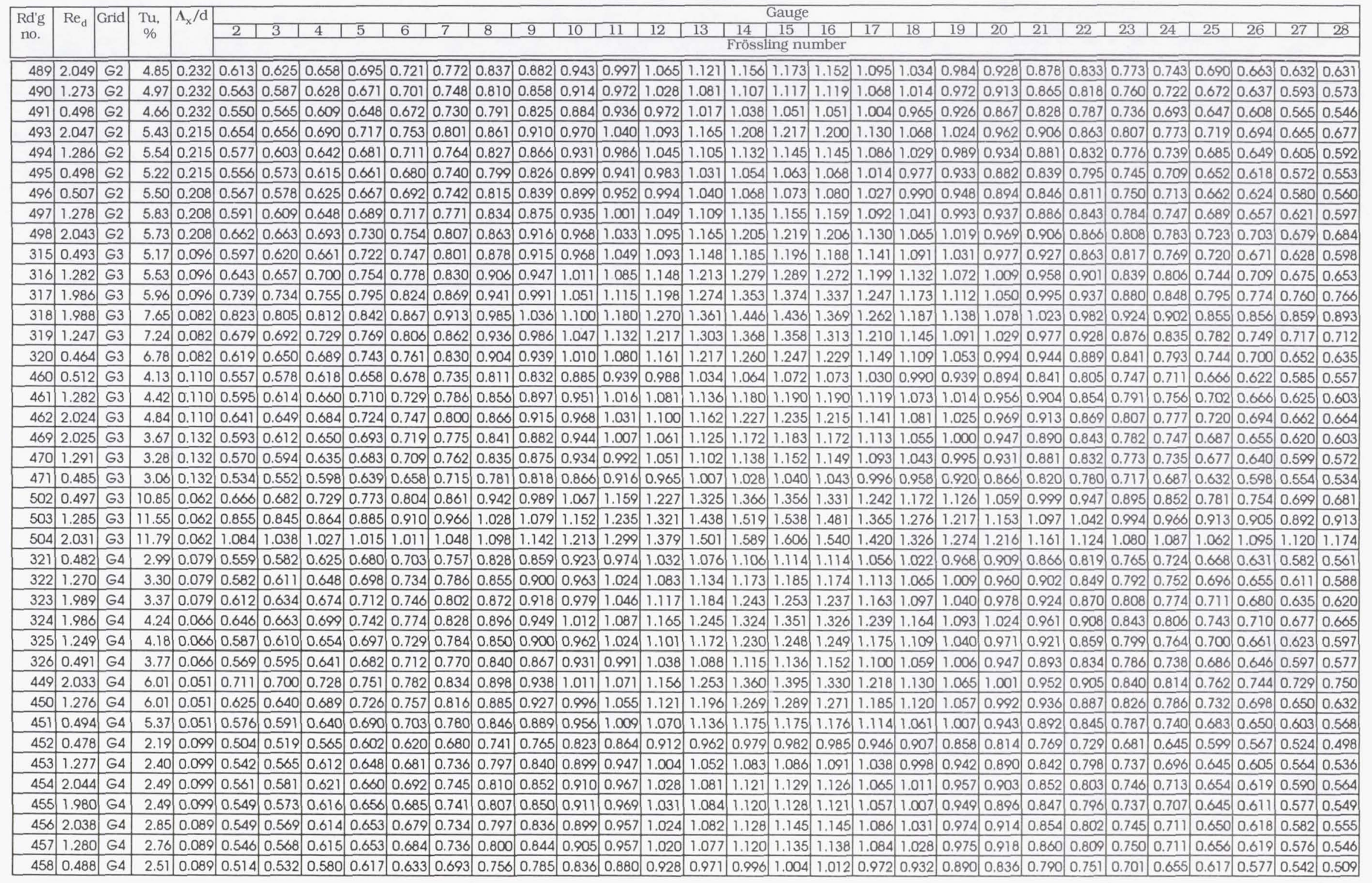


TABLE VIII.-FRÖSSLING NUMBER FOR 2.25:1 MODEL.

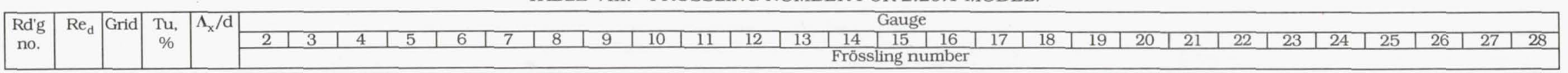

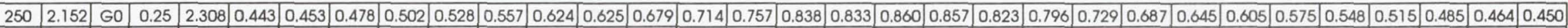

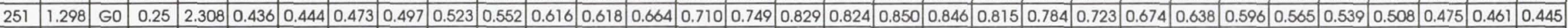

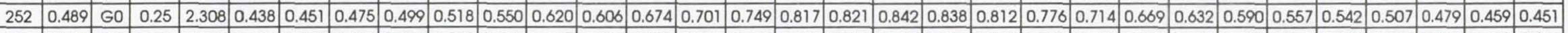

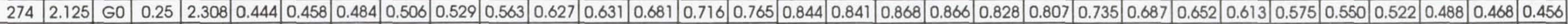

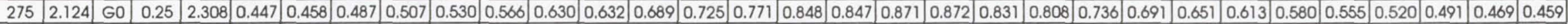

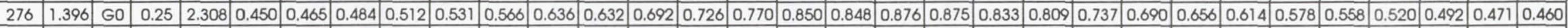

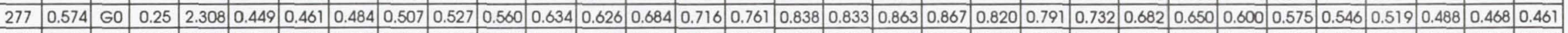

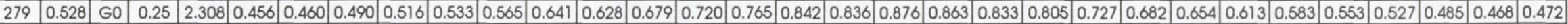

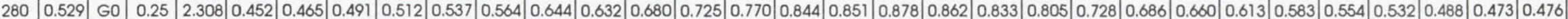

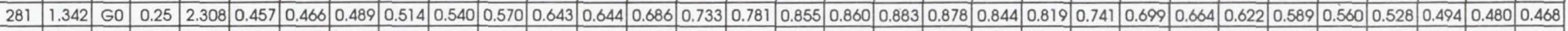

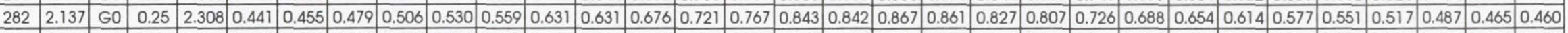

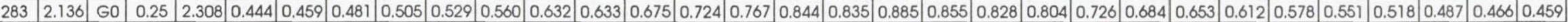

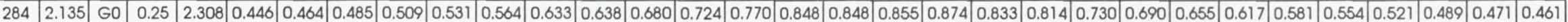

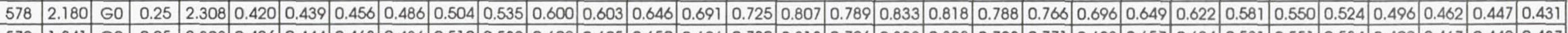

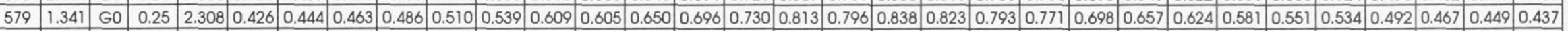

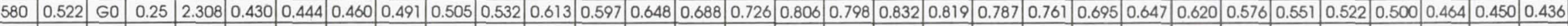

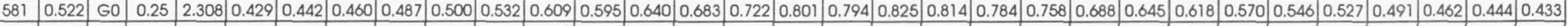

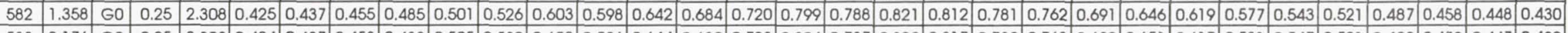

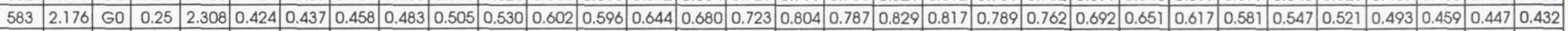

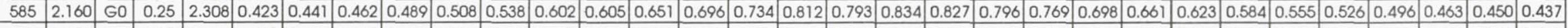

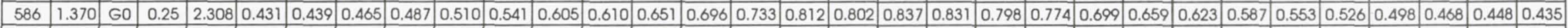

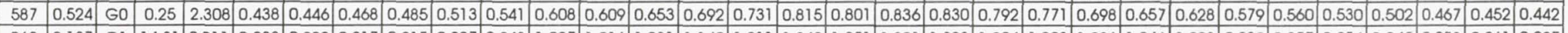

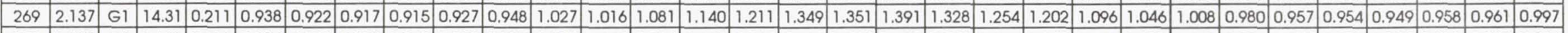

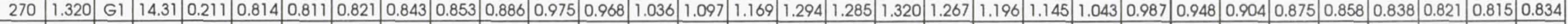

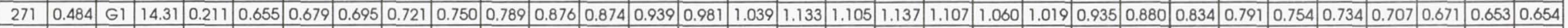

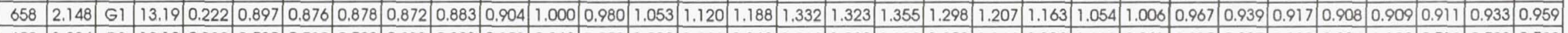

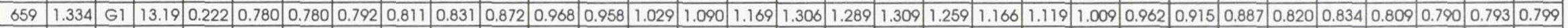

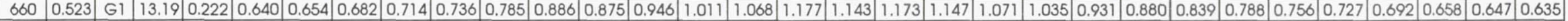

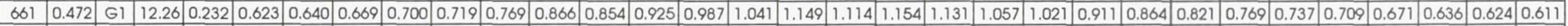

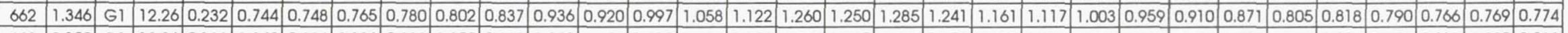

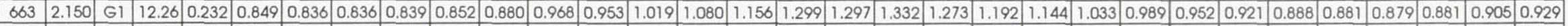

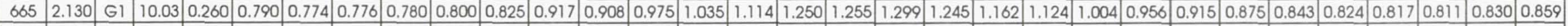

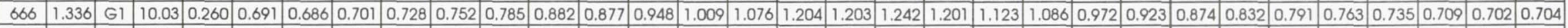

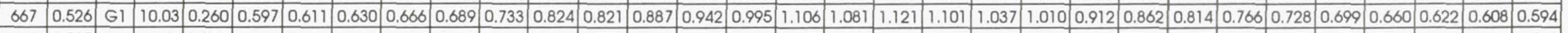

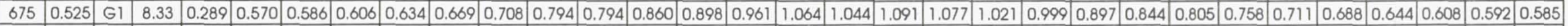

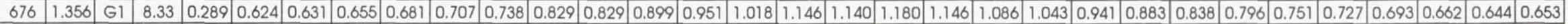

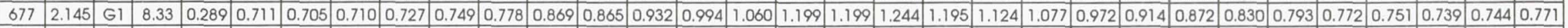

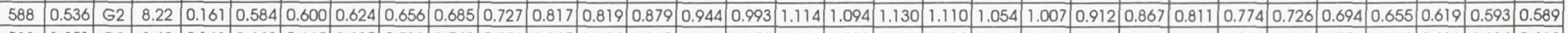

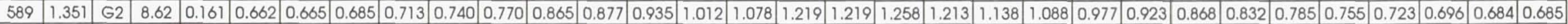

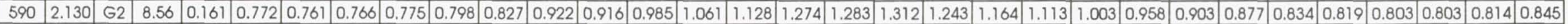

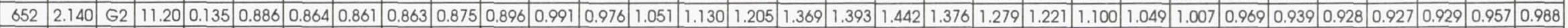

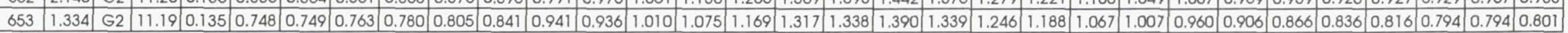




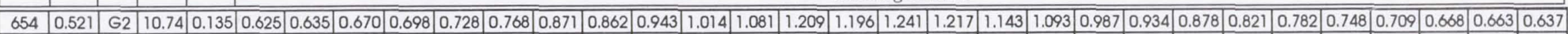

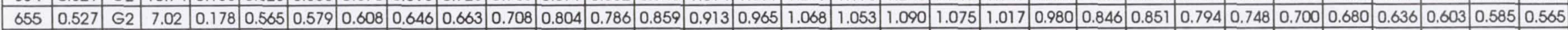

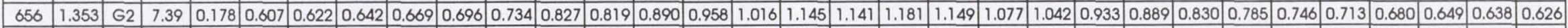

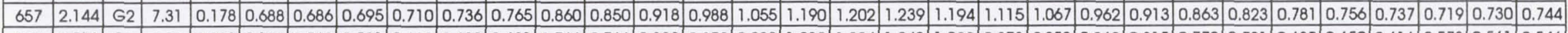

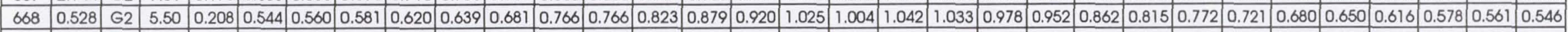

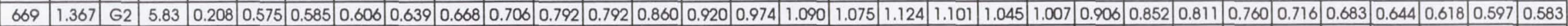

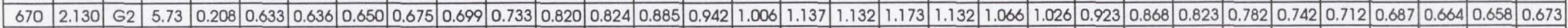

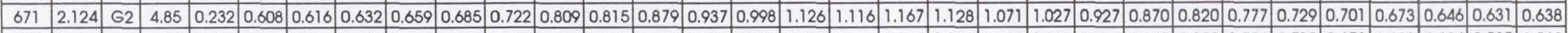

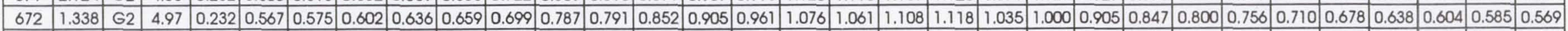

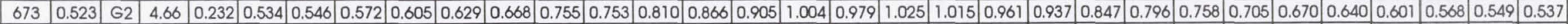

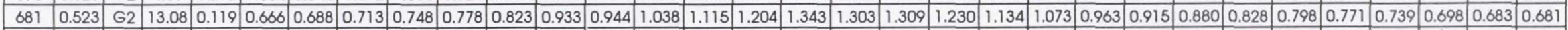
\begin{tabular}{|l|l|l|l|l|l|l|l|l|l|l|l|l|l|l|l|l|l|l|l|l|l|l|l|l|l|l|l|l|l|l|l|l|l|l|l|}
\hline 682 & 1.351 & $G 2$ & 13.56 & 0.119 & 0.841 & 0.844 & 0.855 & 0.873 & 0.896 & 0.934 & 1.047 & 1.050 & 1.146 & 1.243 & 1.346 & 1.521 & 1.482 & 1.476 & 1.355 & 1.239 & 1.176 & 1.063 & 1.017 & 0.982 & 0.950 & 0.921 & 0.900 & 0.888 & 0.873 & 0.873 & 0.892 \\
\hline
\end{tabular}

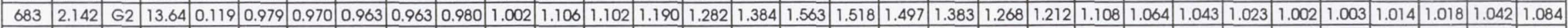

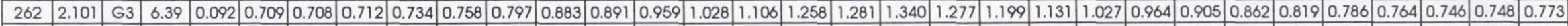

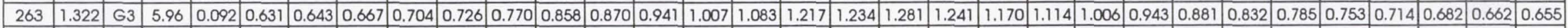

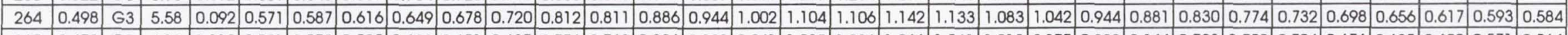

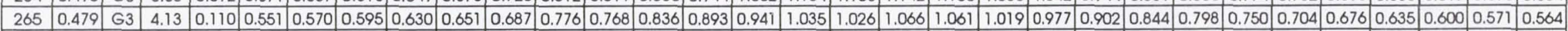

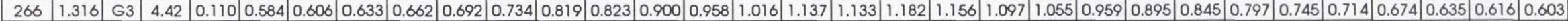

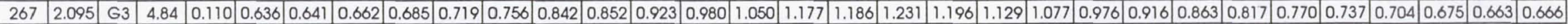

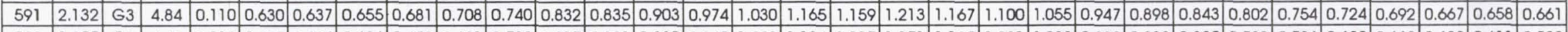

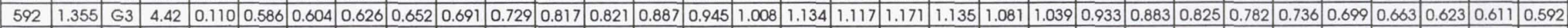

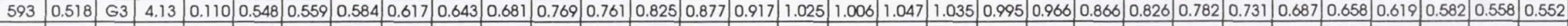

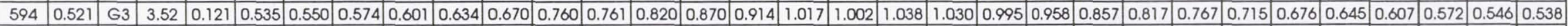

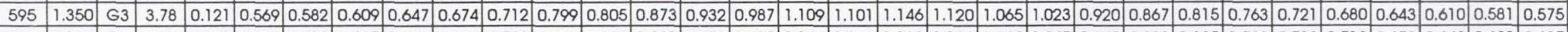

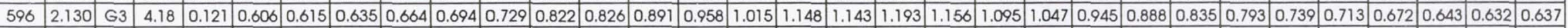

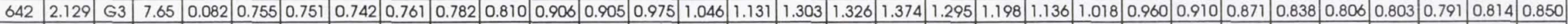

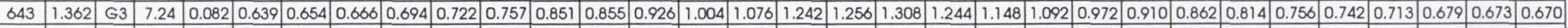

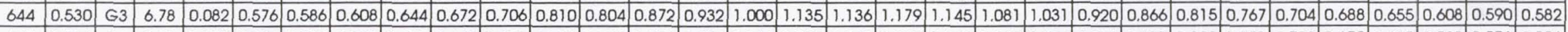

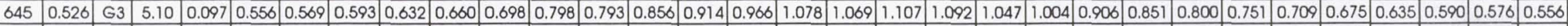

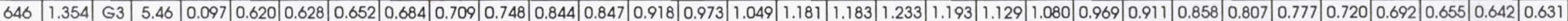

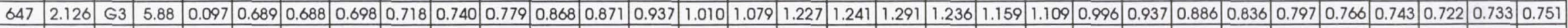

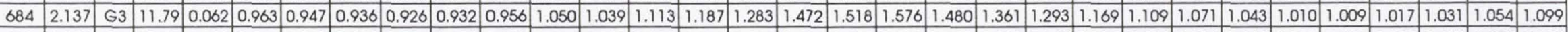

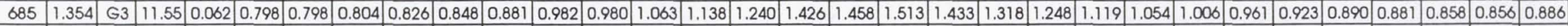

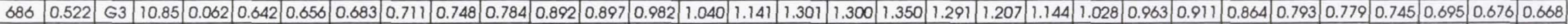

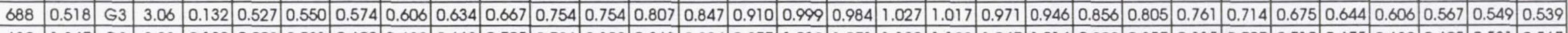

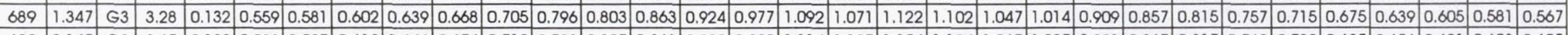

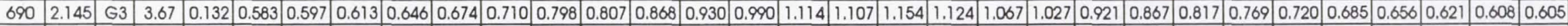

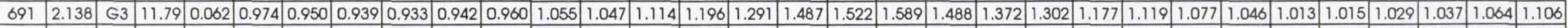

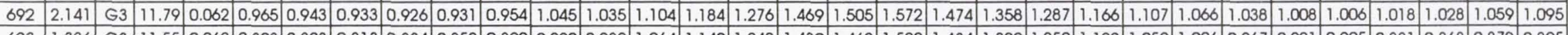
\begin{tabular}{l|l|l|l|l|l|l|l|l|l|l|l|l|l|l|l|l|l|l|l|l|l|l|l|l|l|l|l|l|l|l|l|l|l|l|l|l}
\hline 693 & 1.386 & $G$ & 11.55 & 0.062 & 0.808 & 0.803 & 0.813 & 0.834 & 0.852 & 0.890 & 0.990 & 0.989 & 1.064 & 1.140 & 1.242 & 1.430 & 1.462 & 1.522 & 1.434 & 1.322 & 1.250 & 1.122 & 1.059 & 1.006 & 0.967 & 0.921 & 0.905 & 0.881 & 0.868 & 0.872 & 0.895 \\
\hline
\end{tabular}

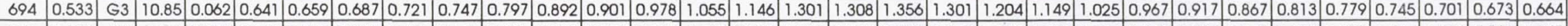

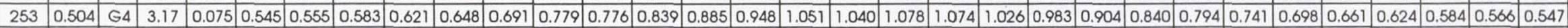

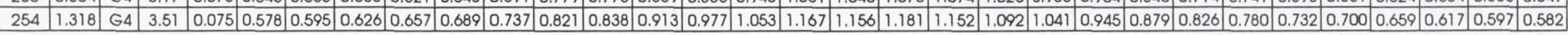


TABLE VIII.-CONCLUDED.

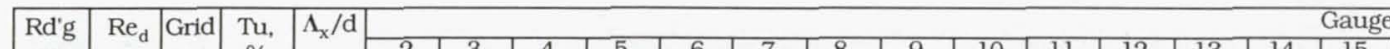

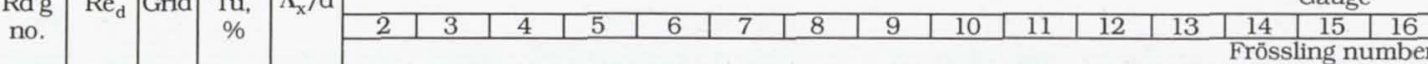

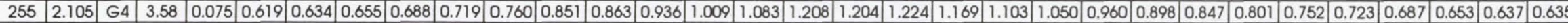
\begin{tabular}{llllllllllllllllllllllllllllllllll}
256 & 2.107 & $G 4$ & 4.61 & 0.062 & 0.650 & 0.655 & 0.675 & 0.702 & 0.723 & 0.768 & 0.850 & 0.858 & 0.923 & 0.981 & 1.046 & 1.181 & 1.201 & 1.265 & 1.238 & 1.178 & 1.121 & 1.023 & 0.950 & 0.892 & 0.836 & 0.790 & 0.755 & 0.721 & 0.690 & 0.679 & 0.686 \\
\hline
\end{tabular}

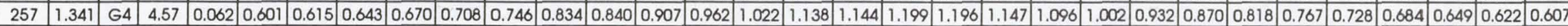

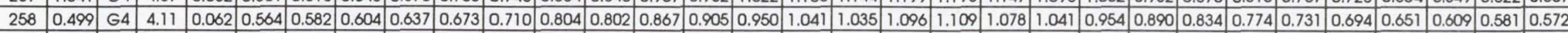

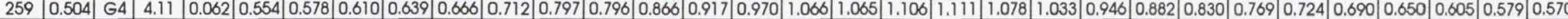

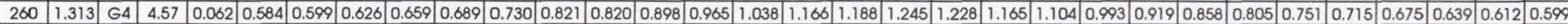

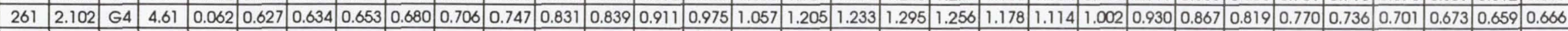

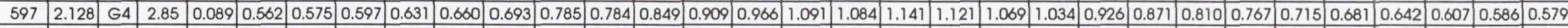

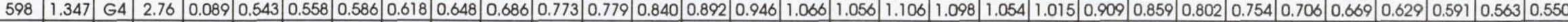

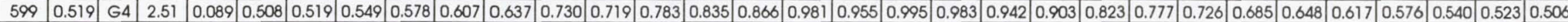

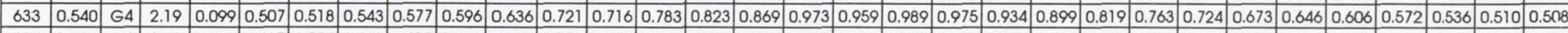

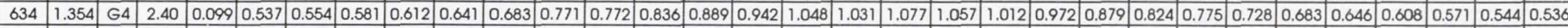

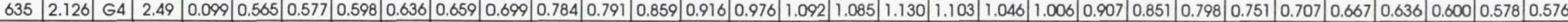

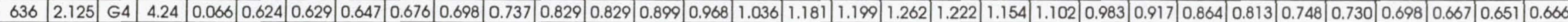

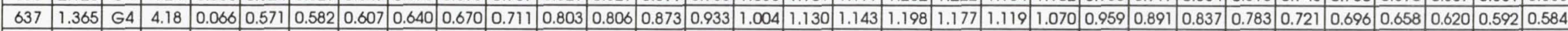

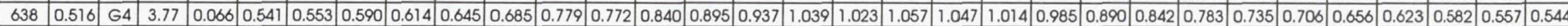

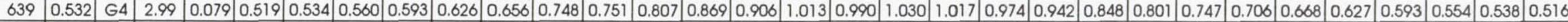

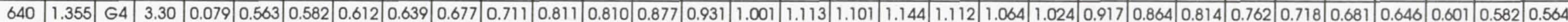

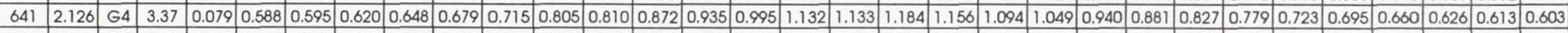

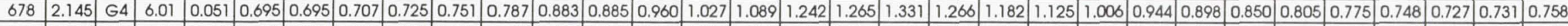
\begin{tabular}{l|l|l|l|l|l|l|l|l|l|l|l|l|l|l|l|l|l|l|l|l|l|l|l|l|l|l|l|l|l|l|l|l|l|l|l}
679 & 1.365 & G4 & 6.01 & 0.051 & 0.617 & 0.639 & 0.664 & 0.696 & 0.732 & 0.770 & 0.872 & 0.876 & 0.954 & 1.013 & 1.081 & 1.217 & 1.217 & 1.271 & 1.235 & 1.158 & 1.109 & 0.994 & 0.934 & 0.882 & 0.829 & 0.779 & 0.739 & 0.707 & 0.663 & 0.650 & 0.638 \\
\hline
\end{tabular}

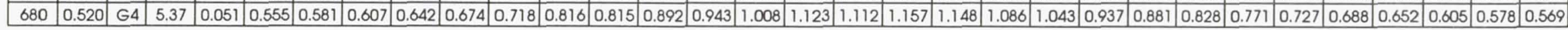


TABLE IX.-FRÖSSLING NUMBER FOR 3:1 MODEL.

\begin{tabular}{|c|c|c|c|c|c|c|c|c|c|c|c|c|c|c|c|c|c|c|c|c|c|c|c|c|c|c|c|c|c|c|c|}
\hline \multirow{2}{*}{$\begin{array}{l}\mathrm{Rd}^{\prime} \mathrm{g} \\
\text { no. }\end{array}$} & \multirow{2}{*}{$\mathrm{Re}_{\mathrm{d}}$} & \multirow{2}{*}{ Grid } & \multirow{2}{*}{$\begin{array}{l}\text { Tu, } \\
\%\end{array}$} & \multirow{2}{*}{$\Lambda_{\mathrm{x}} / \mathrm{d}$} & \multicolumn{27}{|c|}{ Gauge } \\
\hline & & & & & \multicolumn{27}{|c|}{\begin{tabular}{|l|l|l|}
14 & 15 & 16 \\
Frössling number \\
\end{tabular}} \\
\hline 16 & & GO & 0.30 & 308 & 0.412 & 0.409 & 444 & 0.468 & $|0.463|$ & 513 & 0.546 & 0.571 & 041 & 643 & \begin{tabular}{l|l|}
0.672 \\
\end{tabular} & 0.740 & 0.746 & 0.749 & $0.755 \mathrm{C}$ & 0.71 & 0.680 & 0.646 & 0.606 & 0.587 & 0.538 & .528 & 0.494 & 0.469 & 0.453 & .412 & 0.425 \\
\hline 17 & 083 & GO & 0.30 & 308 & 0.408 & 0.412 & 438 & 0.467 & 0.468 & 0.512 & 0.547 & 0.568 & 602 & 640 & 0.676 & 738 & 0.747 & 49 & $0.752 \mathrm{C}$ & & 685 & 645 & $604 \mathrm{C}$ & 585 & 541 & 526 & .496 & .468 & 0.452 & 414 & 0.422 \\
\hline 18 & 516 & 50 & 0.30 & 308 & 0.409 & \begin{tabular}{|l|}
0.418 \\
\end{tabular} & 442 & 0.473 & 0.476 & 0.516 & 0.561 & 0.569 & 0.614 & 644 & 0.691 & 0.743 & 0.764 & 0.770 & $0.756 \mathrm{C}$ & 0.728 & 0.689 & 0.655 & 0.622 & 0.591 & 550 & 532 & .500 & 0.475 & 456 & 421 & 0.422 \\
\hline 19 & 513 & 50 & 0.30 & 308 & 0.408 & \begin{tabular}{|l|l|}
0.422 \\
\end{tabular} & .445 & 0.475 & 0.477 & 0.523 & 0.561 & 0.570 & 0.618 & 649 & 0.691 & 0.743 & 0.767 & 0.769 & $0.758 \mathrm{C}$ & 0.731 & 0.692 & 0.656 & $0.620 \mathrm{C}$ & 0.588 & 550 & \begin{tabular}{ll|}
0.533 \\
\end{tabular} & 0.502 & 0.477 & 459 & 421 & .424 \\
\hline 20 & 388 & 50 & 0.30 & 308 & 0.409 & 0.417 & 449 & 0.476 & 0.479 & 0.525 & 0.567 & 0.571 & 0.620 & .653 & 0.698 & 0.746 & 0.771 & 0.772 & 0.759 & 0.731 & 0.698 & 0.660 & $0.624 \mathrm{C}$ & 0.592 & 0.553 & 0.535 & 0.504 & 0.479 & 0.460 & .423 & 0.425 \\
\hline 21 & 388 & GO & 0.30 & 308 & 0.412 & 422 & 0.449 & 0.475 & 0.481 & 0.523 & 0.567 & 0.569 & 0.622 & .654 & 0.698 & 0.748 & 0.774 & 0.777 & 0.757 & 0.739 & 0.700 & 0.661 & 0.625 & 0.594 & 0.555 & $0.537 \mid$ & 0.505 & 0.480 & 0.461 & .425 & 0.427 \\
\hline 22 & 27 & GO & 30 & 308 & 0.408 & 413 & .440 & 0.471 & \begin{tabular}{|l|}
0.477 \\
\end{tabular} & 0.513 & 0.558 & 0.569 & 0.612 & 0.647 & 0.691 & 0.738 & 0.761 & 0.764 & 0.752 & 0.726 & 0.685 & 0.651 & 0.615 & 0.584 & 0.550 & 0.525 & \begin{tabular}{|l|}
0.499 \\
\end{tabular} & \begin{tabular}{|l|}
0.475 \\
\end{tabular} & 0.449 & .421 & \begin{tabular}{|l|} 
\\
\end{tabular} \\
\hline 23 & 32 & GO & & .308 & 0.409 & 0.414 & .440 & 0.470 & \begin{tabular}{|l|l|}
0.478 \\
\end{tabular} & 0.512 & 0.561 & 0.567 & 0.614 & .643 & 0.688 & 0.737 & 0.763 & 0.759 & 0.756 & 0.724 & 0.687 & 0.648 & 0.614 & 0.586 & 0.548 & 0.525 & \begin{tabular}{|l|}
0.499 \\
\end{tabular} & 0.474 & 0.451 & .420 & 0.418 \\
\hline 24 & 501 & Go & & 308 & 0.413 & 399 & 0.442 & 0.471 & \begin{tabular}{|l|l|}
0.465 \\
\end{tabular} & 2.512 & 0.543 & 0.564 & 0.598 & 0.632 & \begin{tabular}{|l|l|}
0.668 \\
\end{tabular} & 0.738 & 0.732 & 0.758 & $0.733 \mathrm{C}$ & 0.720 & .665 & 0.646 & 0.601 & \begin{tabular}{|l|}
0.591 \\
\end{tabular} & 0.534 & 521 & 0.495 & \begin{tabular}{|l|}
0.474 \\
\end{tabular} & 451 & 411 & \begin{tabular}{|l|} 
\\
\end{tabular} \\
\hline 25 & 502 & Go & & 308 & 414 & .402 & 0.444 & 0.468 & 0.465 & 0.513 & 0.546 & 0.566 & 0.601 & 0.635 & 0.674 & 0.745 & 0.738 & 0.757 & 0.734 & 0.724 & 0.668 & 0.648 & 0.605 & 0.591 & 0.537 & 0.511 & \begin{tabular}{|l|}
0.499 \\
\end{tabular} & .477 & 452 & 413 & 0.419 \\
\hline 26 & 055 & 0 & & 308 & 423 & 0.417 & .452 & 0.480 & 0.480 & 0.524 & 0.562 & 0.580 & 0.620 & 0.648 & 0.704 & 0.749 & 0.768 & 0.780 & 0.764 & 0.738 & 0.695 & 0.663 & 0.623 & 0.602 & 0.555 & .532 & 0.512 & .484 & 460 & 430 & 0.429 \\
\hline 27 & 1.059 & 0 & & 308 & 415 & .417 & 448 & 0.474 & 0.475 & 0.520 & 0.559 & 0.573 & 0.613 & .647 & 0.694 & 0.745 & 0.759 & 0.767 & 0.765 & 0.732 & 0.686 & 0.658 & 0.617 & 0.594 & 0.550 & .531 & 0.508 & 0.475 & 455 & .425 & .424 \\
\hline 28 & 1.521 & 80 & & 308 & 418 & .423 & 451] & 0.479 & 0.481 & 0.524 & 0.562 & 0.580 & 0.620 & .653 & \begin{tabular}{|l|l|}
0.702 \\
\end{tabular} & 0.753 & 0.769 & 0.774 & 0.772 & 0.73 & 0.696 & 0.662 & 0.623 & 0.600 & 0.556 & .538 & \begin{tabular}{|l|}
0.509 \\
\end{tabular} & .479 & 460 & 429 & 0.424 \\
\hline 29 & 1.522 & & & 308 & 418 & 419 & 148 & \begin{tabular}{l|l|l}
0.480 \\
\end{tabular} & 0.480 & 0.522 & 0.564 & 0.575 & 0.621 & .655 & \begin{tabular}{|l|l|}
0.702 \\
\end{tabular} & 0.747 & 0.770 & 76 & 0.762 & 0.74 & 694 & 0.663 & .6225 & 0.599 & 551 & .544 & 0.506 & 478 & 458 & 429 & .423 \\
\hline 30 & & & & 308 & 421 & 417 & 454 & 0.475 & 0.485 & 524 & 0.564 & 0.586 & 619 & 658 & 0.704 & 0.750 & 0.773 & 78 & 0.766 & 0.743 & 0.701 & 664 & 628 & 0.59 & 558 & 539 & \begin{tabular}{|l|} 
\\
\end{tabular} & 485 & 459 & 8 & .426 \\
\hline 31 & 865 & & & 308 & 423 & 422 & 457 & 479 & 491 & 528 & 0.572 & 587 & 625 & 663 & \begin{tabular}{|l|}
0.709 \\
\end{tabular} & 755 & 0.780 & & 0.771 & 0.747 & 0.703 & \begin{tabular}{|l|}
0.670 \\
\end{tabular} & 630 & 0.604 & 563 & .542 & 0.511 & 48 & 46 & 429 & .430 \\
\hline 32 & & & & 308 & 15 & 421 & 44 & 474 & 483 & 522 & 0.561 & 585 & 619 & 654 & \begin{tabular}{|l|l|}
0.703 \\
\end{tabular} & 747 & 0.772 & & 0.765 & 0.737 & 697 & 662 & 623 & 0.596 & .558 & 531 & \begin{tabular}{|l|} 
\\
\end{tabular} & 47 & 45 & 42 & 426 \\
\hline 33 & & & & 308 & 415 & 19 & 45 & 475 & 488 & 524 & .564 & 583 & 621 & 657 & 0.705 & 750 & 72 & & 766 & & 700 & 663 & 625 & 0.598 & 557 & 538 & 0.503 & & 4 & 6 & 427 \\
\hline 34 & & & & 308 & 414 & 119 & 450 & 481 & 488 & 525 & 563 & 585 & 625 & 655 & 706 & 756 & 773 & & 775 & 3 & 0.704 & 664 & 626 & 599 & 560 & 539 & 0.508 & 480 & 7 & & \\
\hline 114 & 87 & & & 308 & 426 & 100 & 467 & 461 & 479 & 517 & 543 & 581 & 616 & 629 & 703 & 723 C & 760 & & 751 & & 684 & .058 & 603 & 0.601 & 556 & 522 & 0.501 & 89 & 4 & & 433 \\
\hline & 390 & & & 308 & 419 & 385 & 457 & 450 & 471 & 504 & 533 & 574 & 597 & 331 & 0.691 & $714 \mathrm{C}$ & 754 & & 747 & & 679 & 645 & 599 & 0.591 & 545 & 512 & 0.495 & . & 2 & & 423 \\
\hline & & & & 8 & 410 & 394 & 450 & 460 & 168 & 509 & 540 & 567 & 612 & & 683 & $721 \mathrm{C}$ & 757 & & 755 & & 384 & 641 & 607 & 0.585 & 545 & 514 & \begin{tabular}{|l|l|} 
\\
\end{tabular} & 718 & 5 & & 117 \\
\hline & & & & 308 & 408 & 397 & 447 & 457 & 467 & 511 & 533 & 564 & 609 & 584 & 678 & 723 & & & 755 & & 0.681 & 644 & 603 & 0.585 & 546 & 513 & 0.495 & 467 & 5 & 3 & 411 \\
\hline & 66 & & & 308 & 407 & 400 & 4 & 153 & 468 & 508 & 532 & 562 & 606 & 38 & 677 & 718 & 748 & 43 & 751 & & 0.675 & 641 & 601 & 0.580 & 545 & 513 & 0.493 & 467 & 442 & 5 & 411 \\
\hline & 291 & & & 308 & 403 & 398 & 439 & 453 & 464 & 500 & 533 & 558 & 599 & 630 & 666 & 723 & 734 & 42 & 737 & & 672 & 638 & 596 & 0.577 & 540 & 506 & 0.489 & 463 & 440 & & 407 \\
\hline & 258 & & & 308 & 395 & 399 & 438 & 454 & 468 & 502 & 530 & 559 & 605 & 33 & 665 & 719 & & & 735 & & 669 & 636 & 596 & 0.573 & 539 & 509 & 0.487 & 162 & 441 & & 408 \\
\hline & 391 & & & 308 & 407 & 414 & 447 & 469 & 479 & 511 & 546 & 574 & 618 & 641 & 685 & & & & 55 & & 688 & 654 & 605 & 594] & 549 & 520 & 0.503 & 175 & 8 & & 422 \\
\hline 124 & 507 & & & 308 & 423 & 418 & 448 & \begin{tabular}{|l|}
0.468 \\
\end{tabular} & .477 & 510 & 551 & 571 & 616 & 643 & 680 & 39 & 64 & & 759 & & 683 & 656 & 613 & 0.590 & 558 & .525 & 0.501 & 478 & 452 & & 428 \\
\hline 29 & 330 & & & 308 & 428 & 424 & 466 & \begin{tabular}{|l|l|}
0.483 \\
\end{tabular} & .494 & 526 & 570 & 590 & 637 & \begin{tabular}{|l|}
0.667 \\
\end{tabular} & 712 & 760 & 0.774 & 794 & 0.777 & 0. & 710 & .685 & 6311 & 617 & 573 & 541 & .519 & 496 & 46 & & 438 \\
\hline 30 & 85 & & & 308 & 426 & 424 & 467 & 488 & 499 & 536 & 574 & 595 & 639 & .674 & 719 & 760 & .785 & 789 & 0.788 & 757 & 0.717 & .689 & .638 & 0.617 & 575 & .546 & 0.520 & 500 & .465 & .4 & 1.434 \\
\hline & 777 & & & 308 & 24 & 427 & 466 & 486 & 0.501 & 535 & 571 & 589 & 639 & 675 & 721 & 762 & 0.784 & 94 & 0.784 & 757 & 0.713 & 685 & .637 & 0.619 & 0.577 & .540 & 0.519 & 497 & .465 & 0.44 & .435 \\
\hline & & & & 308 & 113 & 15 & 452 & 468 & 488 & 524 & 554 & 581 & 623 & 658 & 701 & 747 & 0.775 & 73 & 0.766 & 734 & 0.703 & 0.667 & 619 & 0.597 & 0.562 & 0.529 & 0.506 & 479 & 451 & 0.42 & 423 \\
\hline & & 1 & & 296 & 16 & 997 & 707 & 720 & \begin{tabular}{|l|}
0.719 \\
\end{tabular} & 755 & 786 & 815 & 868 & 913 & 973 & 048 & 1.110 & & 1.135 & 1.075 & 1.004 & \begin{tabular}{|l|}
0.957 \\
\end{tabular} & .895 & 0.858 & .822 & \begin{tabular}{|l|}
0.782 \\
\end{tabular} & 0.760 & 731 & 71 & 0.6 & \\
\hline & & & & & 618 & & 646 & 669 & \begin{tabular}{|l|}
0.671 \\
\end{tabular} & 715 & 757 & 782 & 834 & 884 & 927 & 011 & 1.053 & 95 & 1.079 & 1.034 & 0.975 & \begin{tabular}{|l|l|}
0.922 \\
\end{tabular} & 0.866 & 0.840 & 784 & \begin{tabular}{|l|}
0.747 \\
\end{tabular} & 0.731 & 688 & 66 & 0.6 & \\
\hline & & G1 & & & 547 & 550 & 587 & \begin{tabular}{|l|}
0.607 \\
\end{tabular} & .618 & 664 & 710 & 725 & 780 & 828 & \begin{tabular}{|l|}
0.865 \\
\end{tabular} & & 0.968 & & 0.973 & 0.957 & 0.886 & \begin{tabular}{|l|l|}
0.868 \\
\end{tabular} & 0.813 & 0.789 & \begin{tabular}{|l|}
0.738 \\
\end{tabular} & .704 & 0.682 & 636 & 61 & \begin{tabular}{|l|}
0.573 \\
\end{tabular} & 0.567 \\
\hline & 262 & G) & & 270 & 762 & 743 & 745 & \begin{tabular}{|l|}
0.765 \\
\end{tabular} & 745 & 786 & 809 & 845 & .889 & 929 & 1.002 & .078 & 1.142 & & 1.171 & 1.111 & 1.033 & 0.980 & 0.909 & 0.883 & 837 & \begin{tabular}{|l|}
0.808 \\
\end{tabular} & \begin{tabular}{|l|} 
\\
\end{tabular} & 770 & 74 & 0.74 & 0.759 \\
\hline 130 & & G1 & & 270 & 640 & 643 & \begin{tabular}{|l|l|}
0.663 \\
\end{tabular} & \begin{tabular}{|l|l|}
0.690 \\
\end{tabular} & \begin{tabular}{|l|}
0.683 \\
\end{tabular} & 0.733 & \begin{tabular}{|l|}
0.763 \\
\end{tabular} & 803 & \begin{tabular}{|l|}
0.850 \\
\end{tabular} & 884 & \begin{tabular}{|l|}
0.958 \\
\end{tabular} & .029 & 1.088 & 109 & 1.103 & 1.061 & 0.984 & \begin{tabular}{|l|}
0.937 \\
\end{tabular} & 0.875 & 0.845 & 801 & \begin{tabular}{|l|}
0.761 \\
\end{tabular} & 0.737 & 703 & 681 & \begin{tabular}{|l|}
0.650 \\
\end{tabular} & 0.661 \\
\hline 131 & 505 & G1 & & 270 & 556 & .552 & 0.598 & 0.624 & 0.623 & 0.668 & .712 & 0.741 & 0.792 & 833 & \begin{tabular}{|l|}
0.884 \\
\end{tabular} & 0.959 & 0.984 & 1.003 & 0.997 & 0.969 & 0.915 & \begin{tabular}{|l|}
0.881 \\
\end{tabular} & 0.825 & 0.793 & .757 & .705 & 0.683 & 645 & .619 & \begin{tabular}{|l|}
0.572 \\
\end{tabular} & 0.575 \\
\hline 132 & 262 & G1 & .16 & 232 & 876 & 0.855 & 0.843 & \begin{tabular}{|l|l|}
0.846 \\
\end{tabular} & 0.833 & 0.860 & 0.877 & 0.902 & \begin{tabular}{|l|} 
\\
\end{tabular} & .990 & 1.058 & 1.148 & 1.221 & 1.262 & 1.252 & 181 & 1.103 & 1.043 & 0.979 & 0.949 & 0.909 & 1.880 & \begin{tabular}{|l|}
0.862 \\
\end{tabular} & 848 & 839 & \begin{tabular}{|l|}
0.833 \\
\end{tabular} & 0.853 \\
\hline 133 & 394 & GI & 18 & 232 & 716 & 0.709 & 724 & 0.744 & 0.742 & 0.782 & \begin{tabular}{|l|}
0.812 \\
\end{tabular} & 847 & \begin{tabular}{|l|}
0.897 \\
\end{tabular} & 934 & 1.000 & 1.088 & 1.142 & 1.179 & 1.169 & 122 & 1.050 & \begin{tabular}{|l|}
0.993 \\
\end{tabular} & 0.935 & 0.893 & 0.855 & .815 & 0.792 & 761 & 742 & 0.715 & 0.733 \\
\hline 134 & 0.502 & G1 & 12.42 & 232 & .586 & 0.594 & 625 & \begin{tabular}{|l|}
0.654 \\
\end{tabular} & 0.645 & 0.704 & \begin{tabular}{|l|}
0.742 \\
\end{tabular} & 0.775 & 0.830 & 861 & 0.925 & 0.997 & 1.023 & \begin{tabular}{|l|}
1.053 \\
\end{tabular} & 1.049 & & 0.956 & 0.912 & 0.866 & 0.828 & 0.783 & .752 & 0.712 & .688 & .056 & 0.605 & .615 \\
\hline 135 & 2.242 & G2 & 7.35 & 177 & 712 & 0.684 & 706 & 0.717 & 0.712 & 752 & 782 & 817 & 868 & 910 & 0.980 & .064 & 1.127 & \begin{tabular}{|l|l|}
1.180 \\
\end{tabular} & 168 & & 1.029 & 0.969 & 1.906 & 863 & 815 & .782 & 0.75 & 730 & 713 & \begin{tabular}{|l|l|}
0.689 \\
\end{tabular} & 0.70 \\
\hline
\end{tabular}


TABLE IX.-CONTINUED.

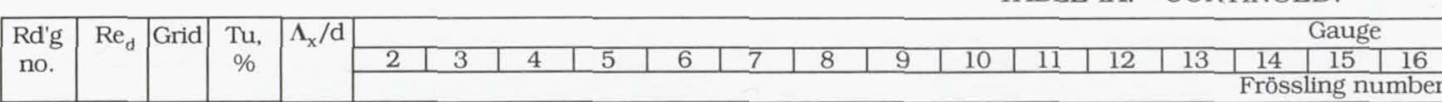

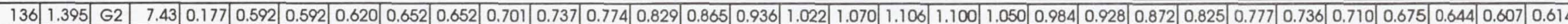

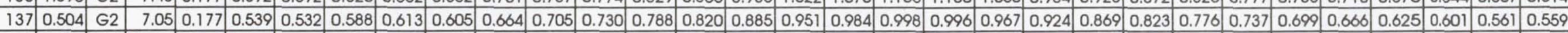

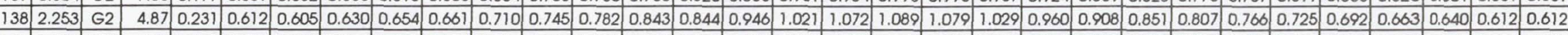

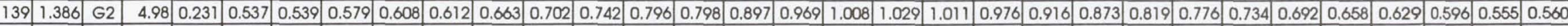
$\begin{array}{lllllllllllllllllllllllllllllllllllll}140 & 0.507 & \text { G2 } & 4.68 & 0.231 & 0.504 & 0.515 & 0.560 & 0.584 & 0.577 & 0.639 & 0.674 & 0.711 & 0.759 & 0.767 & 0.847 & 0.915 & 0.929 & 0.942 & 0.940 & 0.909 & 0.860 & 0.815 & 0.771 & 0.736 & 0.699 & 0.663 & 0.627 & 0.595 & 0.572 & 0.523 & 0.524\end{array}$

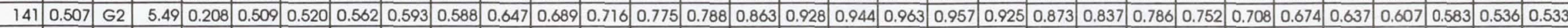

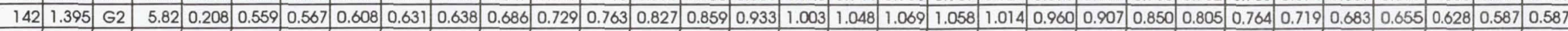

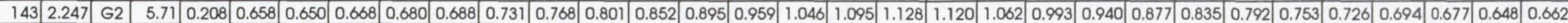

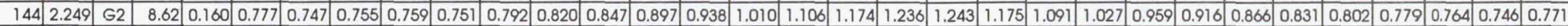

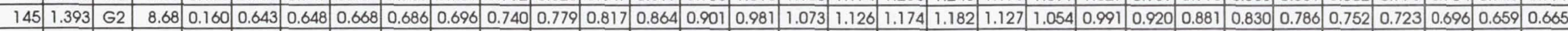

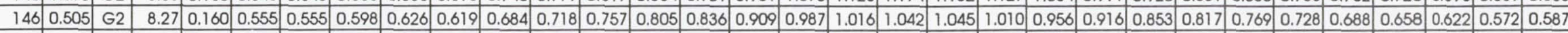

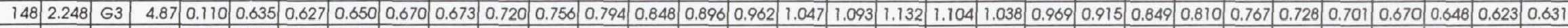

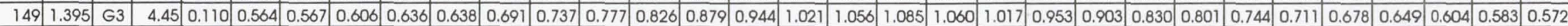

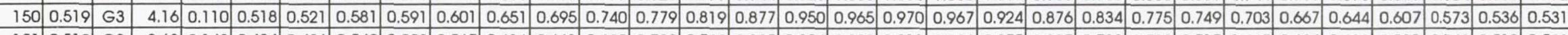

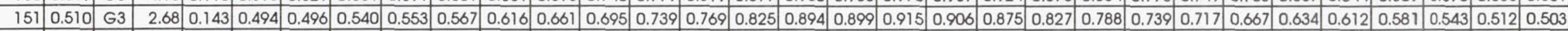

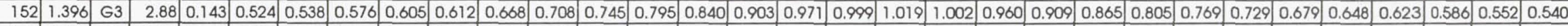

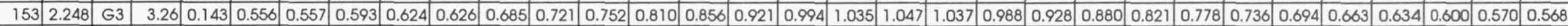

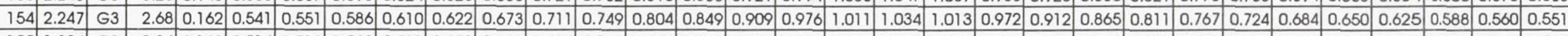

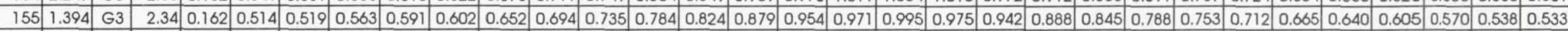

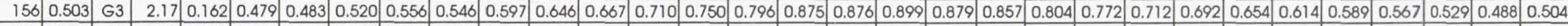

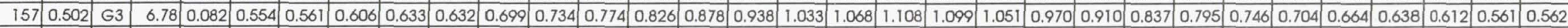

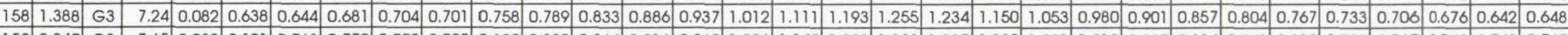

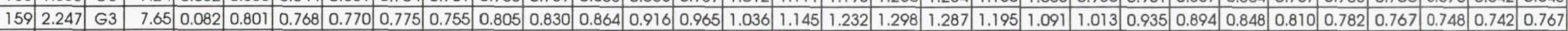

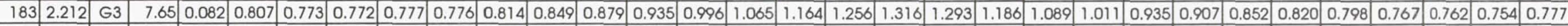

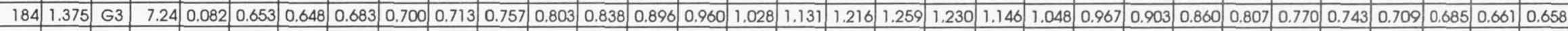

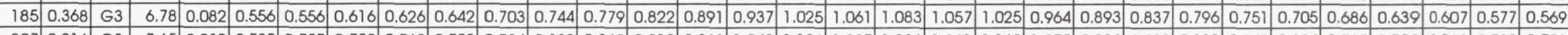

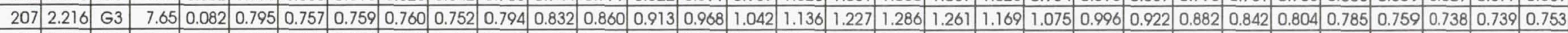

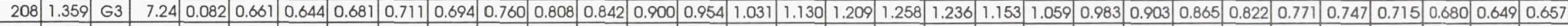

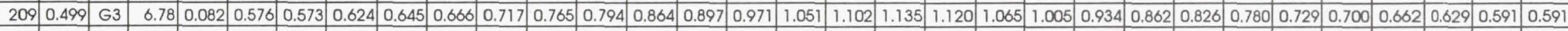

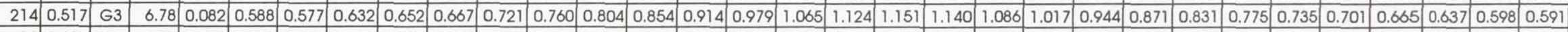

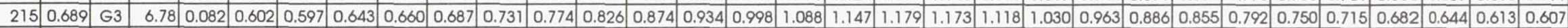

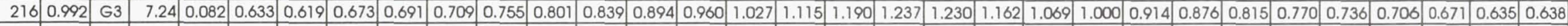

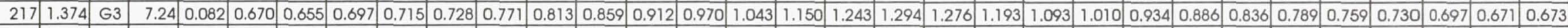

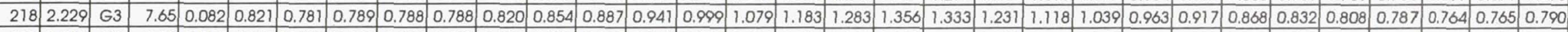

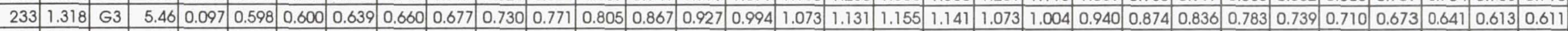

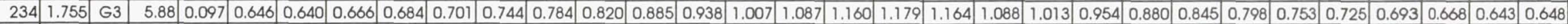

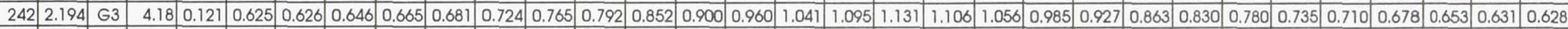

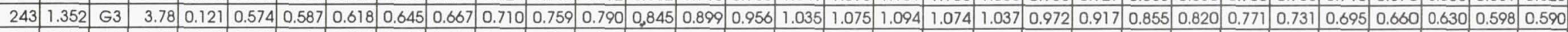

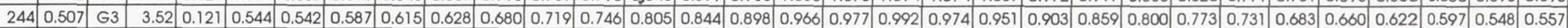

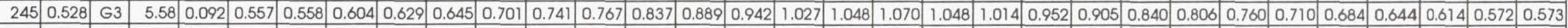

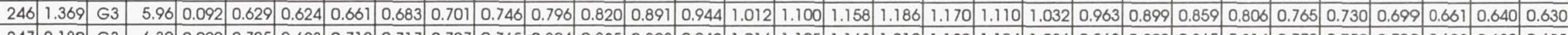

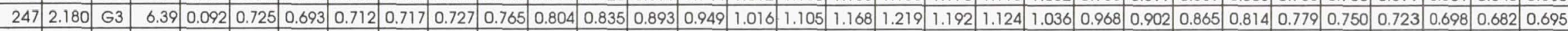

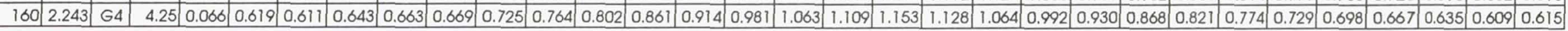


TABLE IX.-CONTINUED

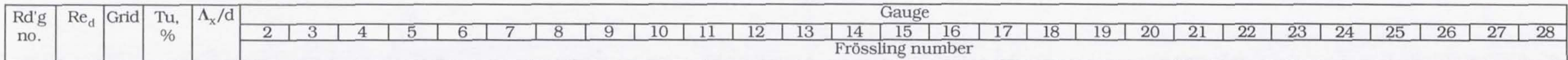

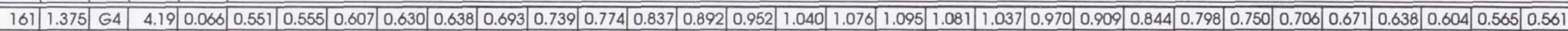

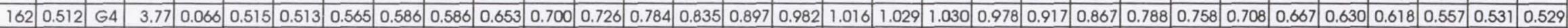

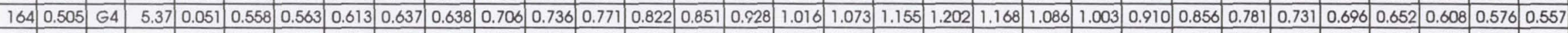

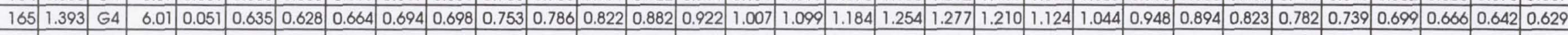

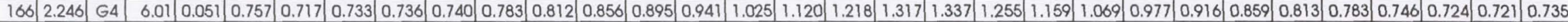

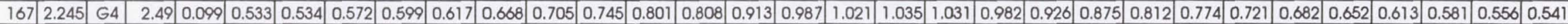

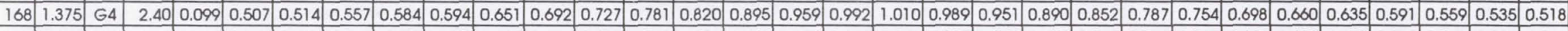

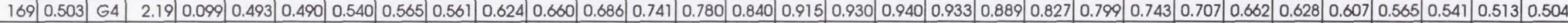

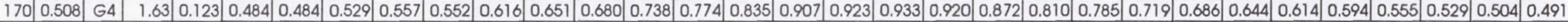

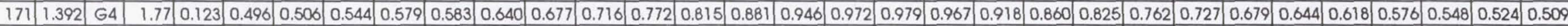

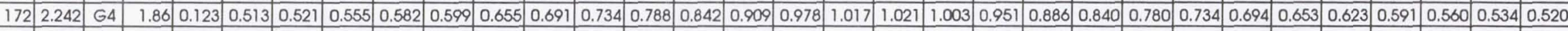

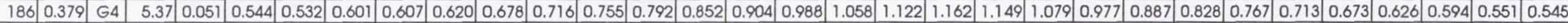

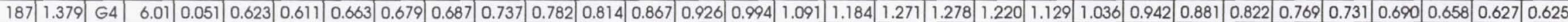

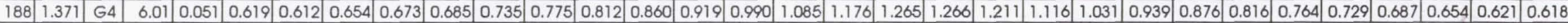

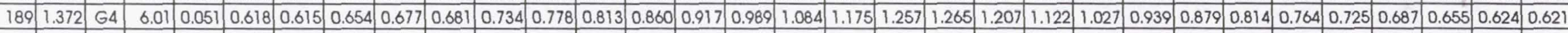

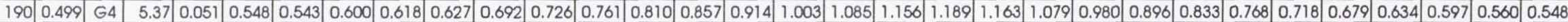

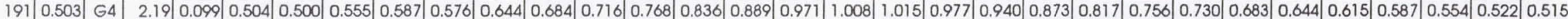

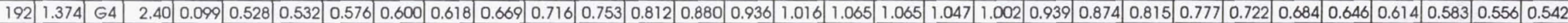

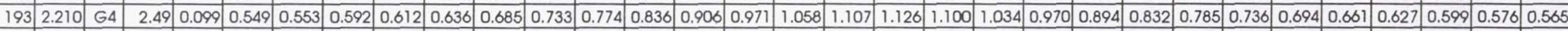

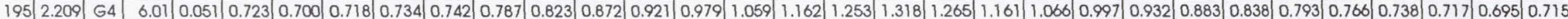

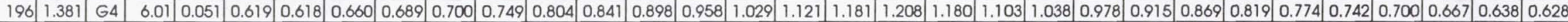

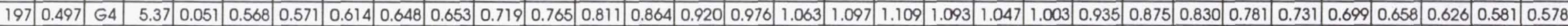

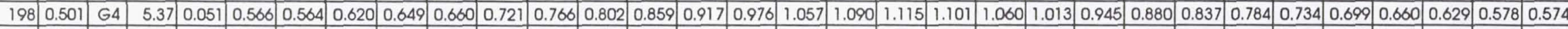

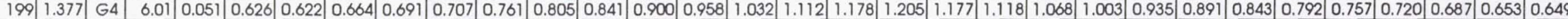

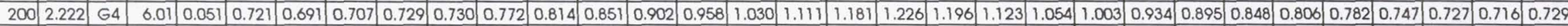

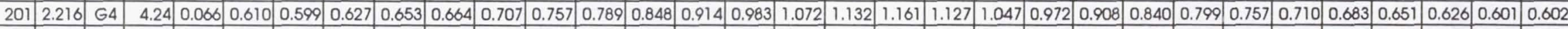

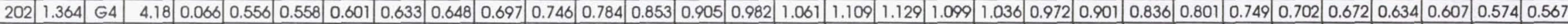

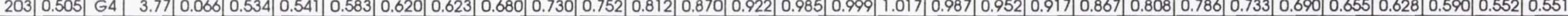

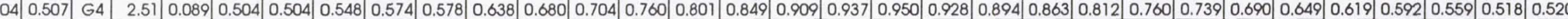

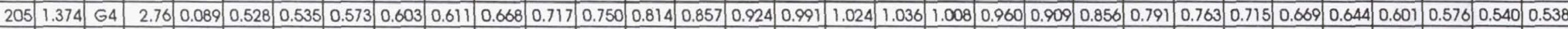

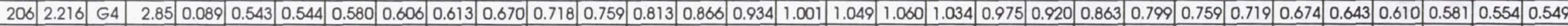

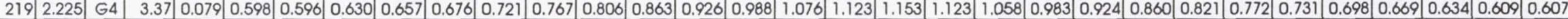

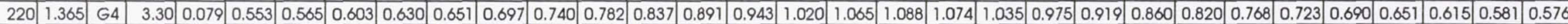

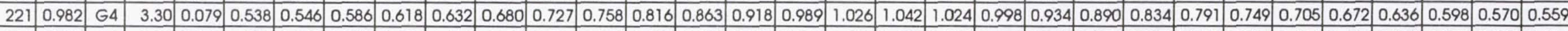

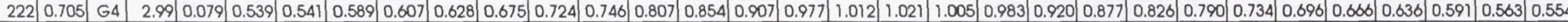

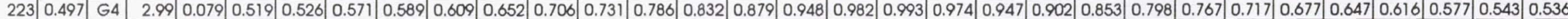

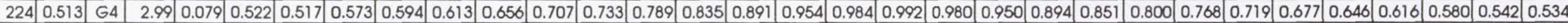

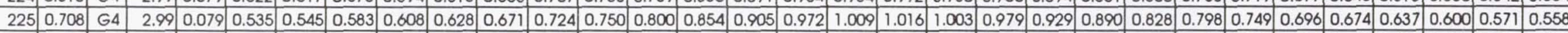

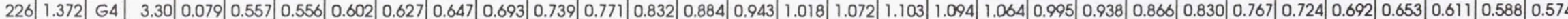

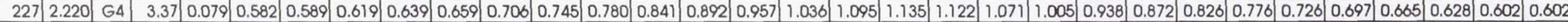

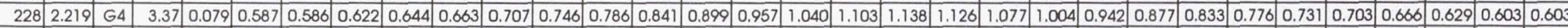

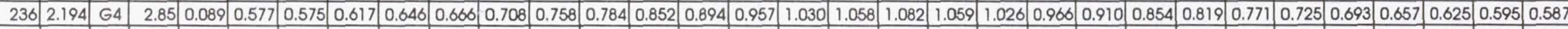

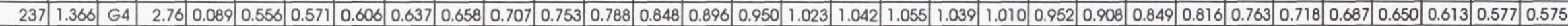


TABLE IX.-CONCLUDED.

\begin{tabular}{|c|c|c|c|c|c|c|c|c|c|c|c|c|c|c|c|c|c|c|c|c|c|c|c|c|c|c|c|c|c|c|c|c|}
\hline \multirow{2}{*}{$\begin{array}{c}\text { Rd'g } \\
\text { no. }\end{array}$} & \multirow{2}{*}{$\operatorname{Re}_{\mathrm{d}}$} & \multirow[t]{2}{*}{ Grid } & \multirow{2}{*}{$\begin{array}{l}\text { Tu, } \\
\%\end{array}$} & \multirow[t]{2}{*}{$\Lambda_{\mathrm{x}} / \mathrm{d}$} & \multicolumn{28}{|c|}{ Gauge } \\
\hline & & & & & \multirow{2}{*}{\multicolumn{28}{|c|}{ Frössling number }} \\
\hline & & & & & & & & & & & & & & & & & & & & & & & & & & & & & & & & \\
\hline 238 & \begin{tabular}{|l|}
0.528 \\
\end{tabular} & G4 & 2.51 & 0.089 & 0.521 & 0.523 & 0.571 & 0.590 & 0.602 & 0.658 & 0.706 & 0.725 & 0.783 & 0.824 & 0.87 & 0.93 & 0.949 & 0.96 & 0.95 & 0.9 & & .884 & 0.847 & \begin{tabular}{|l|l|}
0.791 \\
\end{tabular} & \begin{tabular}{|l|l|}
0.770 \\
\end{tabular} & 0.723 & 0.676 & 0.648 & 0.613 & 0.577 & 0.552 & 0.534 \\
\hline 239 & 526 & G4 & 2.21 & .098 & 0.507 & 0.508 & 0.557 & 0.577 & 0.582 & 0.638 & 0.683 & 0.699 & 0.758 & 0.806 & 0.85 & 0.91 & 0.938 & 0.945 & 0.93 & 0.9 & & .858 & 0.812 & 0.763 & 0.737 & 0.701 & 0.652 & 0.624 & 0.595 & 0.559 & .530 & .516 \\
\hline 240 & 371 & $\mathrm{G} 4$ & 2.42 & .098 & .529 & 0.541 & 0.577 & 0.610 & 0.624 & 0.677 & 0.719 & 0.757 & 0.804 & 0.860 & 0.92 & 0.99 & 1.035 & $1.05^{\circ}$ & 1.03 & 1.0 & & .943 & 0.892 & 0.828 & 0.788 & 0.742 & 0.694 & 0.664 & 0.626 & 0.591 & .562 & .550 \\
\hline 241 & 205 & G4 & 2.51 & .098 & .552 & 0.556 & 0.591 & 0.620 & 0.637 & 0.683 & 0.727 & 0.761 & 0.817 & 0.876 & 0.93 & .01 & 1.052 & 1.078 & 1.06 & 1.0 & & .966 & 0.904 & 0.842 & .803 & 0.750 & 0.702 & 0.676 & 0.634 & .606 & .579 & .567 \\
\hline 173 & 268 & 5 & 1.63 & 069 & .608 & 0.617 & 0.646 & 0.677 & 0.688 & 0.748 & 0.781 & 0.816 & 0.875 & .922 & 0.99 & .06 & 1.108 & 131 & 1.11 & .0 & & .000 & 0.952 & 891 & 851 & 0.802 & 0.762 & .730 & 0.689 & 0.660 & 633 & .678 \\
\hline 174 & 380 & 5 & 77 & 078 & 579 & 0.583 & 0.627 & 0.651 & 0.670 & 0.730 & 0.771 & 0.801 & 0.866 & .913 & 0.97 & 1.04 & 1.083 & 097 & 1.08 & .0 & & .980 & 0.940 & 877 & .840 & 0.787 & 0.745 & .714 & 0.674 & .635 & .611 & .591 \\
\hline 175 & 498 & 5 & 08 & 103 & 540 & 0.542 & 0.591 & 0.627 & 0.622 & 0.693 & .732 & 0.760 & 0.827 & .842 & 0.92 & 0.98 & 1.036 & 029 & 1.01 & 5 & & .921 & 0.887 & 0.821 & .800 & 0.748 & 0.703 & .685 & 0.636 & .604 & .570 & .563 \\
\hline 176 & 481 & G5 & 3.40 & 0.099 & 0.596 & 0.598 & 0.652 & .684 & 0.689 & 0.762 & 0.809 & 0.835 & 0.914 & .956 & 1.02 & 1.10 & 1.122 & 141 & 1.13 & .0 & & .026 & 0.978 & 0.908 & $\mid 0.871$ & 0.814 & 0.765 & .739 & 0.689 & 0.652 & .615 & .602 \\
\hline 177 & 1.384 & G5 & 2.62 & 0.065 & 0.617 & 0.620 & 0.670 & .705 & 0.719 & 0.782 & 0.822 & 0.862 & 0.927 & 0.975 & 1.038 & 1.12 & 1.168 & .190 & 1.18 & 1.1 & & .058 & 1.010 & 0.943 & 0.901 & 0.835 & 0.797 & 0.755 & 0.717 & 0.676 & .646 & 0.630 \\
\hline 178 & 2.262 & G5 & 2.45 & 0.063 & 0.672 & 0.671 & 0.705 & 0.727 & 0.744 & 0.803 & 0.843 & 0.885 & 0.945 & 0.995 & 1.06 & 1.14 & 1.197 & 1.229 & 1.21 & 1.1 & & .082 & 1.028 & 0.961 & 0.917 & 0.863 & 0.818 & 0.783 & 0.743 & 0.710 & .684 & 0.678 \\
\hline 179 & 2.262 & G5 & 1.09 & 0.077 & 0.510 & 0.523 & 0.556 & .582 & 0.600 & 0.650 & 0.689 & 0.723 & 0.770 & 0.825 & 0.87 & 0.94 & 0.981 & .985 & 0.97 & 0.9 & & .886 & 0.844 & \begin{tabular}{|l|l}
0.787 \\
\end{tabular} & \begin{tabular}{|l|l|} 
\\
\end{tabular} & 0.702 & 0.666 & 0.636 & 0.596 & 0.563 & 0.538 & 0.526 \\
\hline 180 & 1.372 & G5 & 1.20 & 0.092 & 0.503 & 0.500 & 0.548 & 0.573 & 0.583 & 0.641 & 0.677 & 0.706 & 0.760 & 0.805 & 0.86 & 0.93 & 0.962 & .965 & 0.96 & 0.9 & & .872 & 0.828 & 0.775 & 0.738 & 0.692 & 0.654 & 0.628 & 0.590 & 0.552 & 0.527 & 0.515 \\
\hline 181 & 0.498 & G5 & 1.28 & 0.108 & 0.477 & 0.470 & 0.523 & 0.545 & 0.543 & 0.602 & 0.631 & 0.655 & 0.711 & 0.746 & 0.796 & 0.86 & 0.871 & 0.881 & 0.88 & & & .795 & 0.762 & \begin{tabular}{|l|}
0.717 \\
\end{tabular} & 0.682 & 0.646 & 0.602 & 0.588 & \begin{tabular}{|l|l|}
0.551 \\
\end{tabular} & 0.528 & 0.485 & 0.491 \\
\hline
\end{tabular}




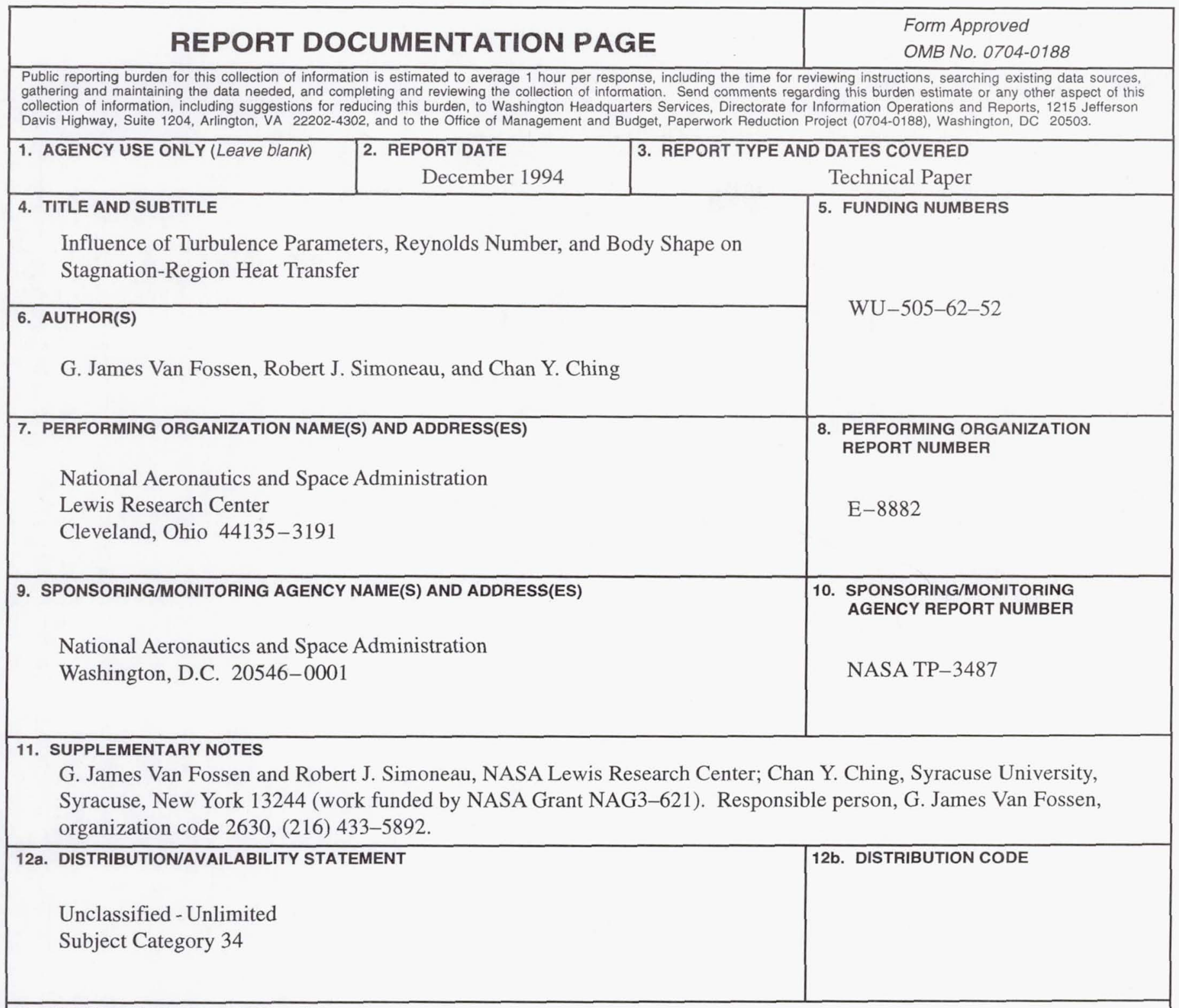

13. ABSTRACT (Maximum 200 words)

The purpose of the present work was threefold: (1) to determine if a free-stream turbulence length scale existed that would cause the greatest augmentation in stagnation-region heat transfer over laminar levels; (2) to investigate the effect of velocity gradient on stagnation-region heat transfer augmentation by free-stream turbulence; and (3) to develop a prediction tool for stagnation heat transfer in the presence of free-stream turbulence. Heat transfer was measured in the stagnation region of four models with elliptical leading edges that had ratios of major to minor axes of 1:1, 1.5:1, 2.25:1, and 3:1. Five turbulence-generating grids were fabricated; four were square mesh, biplane grids made from square bars. The fifth grid was an array of fine parallel wires that were perpendicular to the model spanwise direction. Heat transfer data were taken at Reynolds numbers ranging from 37000 to 228000 . Turbulence intensities were in the range of 1.1 to 15.9 percent while the ratio of integral length scale to leading-edge diameter ranged from 0.05 to 0.30 . Stagnation-point velocity gradient was varied by nearly 50 percent.Stagnation-region heat transfer augmentation was found to increase with decreasing length scale but no optimum length scale was found. Heat transfer augmentation due to turbulence was found to be unaffected by the velocity gradient near the leading edge. A correlation was developed that fit heat transfer data for the square-bar grids to within \pm 4 percent.

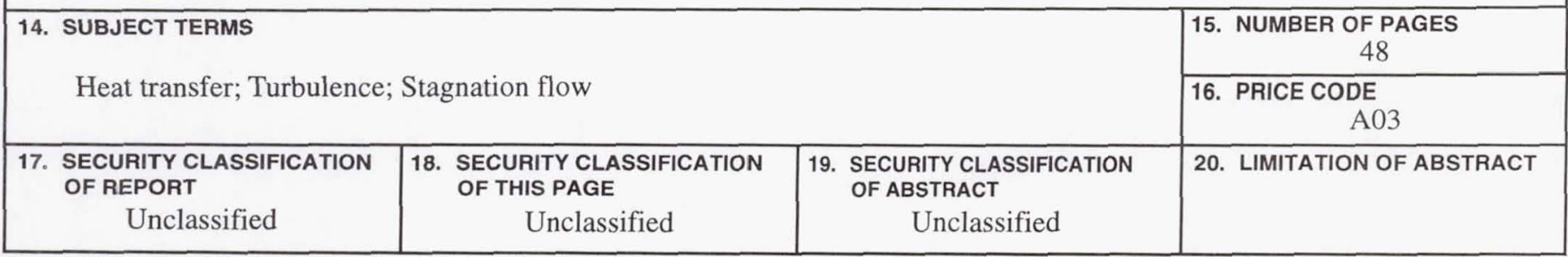

